\title{
A most formidable arsenal: genetic technologies for building a better mouse
}

\author{
James F. Clark, ${ }^{1}$ Colin J. Dinsmore, ${ }^{1}$ and Philippe Soriano \\ Department of Cell, Developmental, and Regenerative Biology, Icahn School of Medicine at Mt. Sinai, New York, New York \\ 10029, USA
}

\begin{abstract}
The mouse is one of the most widely used model organisms for genetic study. The tools available to alter the mouse genome have developed over the preceding decades from forward screens to gene targeting in stem cells to the recent influx of CRISPR approaches. In this review, we first consider the history of mice in genetic study, the development of classic approaches to genome modification, and how such approaches have been used and improved in recent years. We then turn to the recent surge of nuclease-mediated techniques and how they are changing the field of mouse genetics. Finally, we survey common classes of alleles used in mice and discuss how they might be engineered using different methods.
\end{abstract}

The origins of mice as a genetic system

The house mouse, Mus musculus, has been a tool of genetic inquiry for well over a century. A case can be made that the tradition dates back even further to 18 th century Japan and China where local mouse and rat fanciers wrote guidebooks on how to raise these animals, including detailed breeding strategies to obtain particular coat patterns (Tokuda 1935; Kuramoto 2011). The hobby of mouse fancying was exported to England and from there to the United States, where fancier stocks formed the basis of many modern inbred strains (Morse 1978). Nevertheless, the first genetic experiment using mice may have been performed in 1887 by August Weismann, who surgically removed the tails of mice, bred them, and found offspring with tails of normal length (Weismann 1889). This result challenged Lamarckian inheritance and led Weismann to propose the germ theory of inheritance, which stated that hereditary information was transmitted only through germ cells: the sperm and egg. The origin of mice as a model system for genetic analysis, with intrinsic variable and heritable traits worthy of study, dates to 1902 when Lucien Cuénot published the first in a series of papers de-

[Keywords: gene targeting; CRISPR; mice; genetics; transgenesis]

${ }^{1}$ These authors contributed equally to this work.

Corresponding author: philippe.soriano@mssm.edu

Article is online at http://www.genesdev.org/cgi/doi/10.1101/gad.342089. 120. scribing Mendelian inheritance for mouse coat color characteristics (Cuénot 1902). Mendel himself had started down this same road fifty years earlier, only for his bishop to snuff out the nascent breeding program because a monk had no business, frankly, breeding (Paigen 2003).

Following Cuénot's papers (Cuénot 1902), genetic research using the mouse began in earnest, often through the study of spontaneous mouse mutants. One line of research further explored the complicated genetics of pigmentation and the sometimes-surprising coincident phenotypes. The Dominant white spotting allele $W$ (an allele of the receptor tyrosine kinase Kit) was found to affect not only pigmentation but also hematopoiesis and fertility, for instance. Another line focused on the genetic basis of other variable traits such as histocompatibility, sex determination and $\mathrm{X}$-inactivation, and classic studies of tail length and the Tlocus (Silver 1995). Perhaps the most consequential endeavor, however, was the effort to understand the relationship between genetics and cancer, as this led to the establishment of many of today's inbred mouse strains as well as the founding of mouse genetic research centers such as the Jackson Laboratory in 1929, Oak Ridge in 1943, MRC Harwell in 1947, and the National Institute of Genetics in Japan in 1949 (Silver 1995). Alongside research using laboratory inbred strains, study of wild mouse populations led to important insights in immunity, cancer, and adaptation (Phifer-Rixey and Nachman 2015). Modern genomic techniques now couple wild populations' variations and selective pressures with molecular precision (Harr et al. 2016; Barrett et al. 2019). A full accounting of the history of mouse genetic research is beyond the scope of this article, but has been the subject of several excellent books and reviews (Russell 1985; Silver 1995; Paigen 2003; García-García 2020).

Even with these impressive genetic bona fides, the true potential of mouse genetics lies in the ability of the researcher to modify the mouse genome. This ability, along with the fact that mice are mammals with substantial genetic similarity to humans, has made mice a favorite

(C) 2020 Clark et al. This article is distributed exclusively by Cold Spring Harbor Laboratory Press for the first six months after the full-issue publication date (see http://genesdev.cshlp.org/site/misc/terms.xhtml). After six months, it is available under a Creative Commons License (Attribution-NonCommercial 4.0 International), as described at http://creativecommons.org/licenses/by-nc/4.0/. 
system for understanding the genetic underpinnings of mammalian development and human disease (Rosenthal and Brown 2007). Indeed, as of July 28, 2020, there were 64,204 mutant mouse alleles listed in the Mouse Genome Informatics (MGI) database. The tools available to generate these alleles have been steadily expanded from forward genetic screens, to viral and gene trap-mediated approaches, as well as classic homologous recombination-based targeting in mouse embryonic stem cells (mESCs) that served as the basis for the myriad knockout, knock-in, knockdown, conditional, and lineage-tracing mouse models that now exist. More recently, nuclease-mediated technologies such as CRISPR/Cas have led to a second explosion of techniques. These not only promise an easier, more efficient means to traditional genetic ends, but are also opening the door to ways of modifying the genome that were previously impractical or impossible with classical techniques.

\section{Forward genetic screens}

Forward genetic screens involve germline mutagenesis and subsequent breeding of male mice to obtain a collection of novel mutations. Offspring in the first generation (termed G1, the result of crossing a mutagenized mouse with a wild-type female) can be immediately screened for dominant mutations giving rise to a phenotype of interest. For recessive mutations, G1 males can be crossed with a wild-type female and then any G2 females are crossed back to their G1 father to generate homozygous offspring in the third generation (G3). After identifying mutant lines with the desired phenotype, the underlying mutation is identified. This was traditionally achieved by time-consuming genetic mapping but can now be resolved through genome sequencing, greatly accelerating the overall process (Wang et al. 2015; Geister et al. 2018). The advantage of genetic screens is that mutations are generated semi-randomly throughout the genome, so screens are unbiased with respect to the underlying mutation and can reveal unexpected genotype-phenotype connections. One reason for this is that such screens can identify many genes important for a given process that have not yet been investigated or linked to that process. A second is that genetic screens induce not only null alleles, but also hypomorphic, hypermorphic, and neomorphic alleles through point mutations, truncations, insertions, deletions, and chromosomal rearrangements, that can affect coding or regulatory sequences. Of note, chemical mutagenesis and other nontargeted genome modification techniques (e.g., transgene, retrovirus, and transposon insertion events, discussed below) are not completely random but exhibit some bias or unique preference in mutation/insertion site (Takahasi et al. 2007; Li et al. 2013; de Jong et al. 2014). We therefore refer to these events as semi-random throughout the review. Although the prospect can be daunting, with careful planning screens can be performed by individual laboratories (Horner and Caspary 2011) and often reveal exciting, unforeseen biology (Huangfu et al. 2003). Screens have been used to better understand topics ranging from mouse development (Kasarskis et al. 1998; Nolan et al. 2000), to circadian rhythms (Vitaterna et al. 1994), congenital heart disease (Li et al. 2015), and the genetic basis of sleep (Miyoshi et al. 2019), among many others.

The precursor to mouse genetic screens arose from an interest in cancer and the effects of atomic radiation on mammals. These effects were investigated using mice, principally at the Oak Ridge National Laboratory in Oak Ridge, Tennessee, and the MRC Radiobiological Research Unit in Harwell, England. This research generated numerous mutant mouse strains, but because X-rays induce double-stranded breaks (DSBs) in DNA, the approach often caused large deletions and chromosomal rearrangements that affected multiple genes, making interpretation of the mutant phenotypes difficult (Silver 1995). Radiation has been supplanted by chemical mutagenesis with the DNA alkylating agent N-ethyl-N-nitrosourea (ENU), which is more mutagenic than X-rays (Russell et al. 1979) and more likely to result in point mutations (Popp et al. 1983). Because screening large numbers of mice in the G3 generation is so time- and labor-intensive, there are several modified approaches that allow for recovery of recessive mutations in the G2 generation. Specifically, modifier (enhancer or suppressor) and noncomplementation screens are performed by crossing G1 mutants with an existing mutant strain and assaying for a modified phenotype or failure to complement. This usually identifies new genes that genetically interact with the gene of interest or novel alleles of the same gene, respectively. Deletion screens, in which G1 males are crossed to females carrying a deletion of a chromosomal interval, facilitate rapid identification of mutations in this region. Finally, balancer screens, most famous from the world of fly genetics, can also be performed in mice even though the number of existing balancer chromosomes is limited (Zheng et al. 1999/. These involve crossing mutagenized males to mice carrying a balancer chromosome, which has the following features: one or a series of tandem chromosomal inversions that suppress recombination within the region, a dominant visible trait such as coat color, and often a recessive lethal mutation (Zheng et al. 1999; Ye et al. 2016). This combination of factors allows efficient breeding schemes to quickly isolate mutations within the balanced chromosome or region (Kile et al. 2003).

\section{Transgenics, viruses, transposons, and gene trap-mediated transgenesis}

Transgenesis is the process of introducing genetic information from one organism into another. The first mouse carrying exogenous DNA was made in 1974 by injecting simian virus 40 (SV40) DNA into the cavity of an E3.5 mouse blastocyst, although the DNA was incorporated variably throughout the animal (Jaenisch and Mintz 1974). A similar study using infection of morula-stage embryos with Moloney leukemia virus subsequently demonstrated that exogenous provirus could integrate into the germline (Jaenisch 1976). The technique was refined to 
show that injection of DNA into the pronucleus of a onecell embryo resulted in incorporation and expression of DNA from a variety of sources (Brinster et al. 1981; Costantini and Lacy 1981; Gordon and Ruddle 1981; Harbers et al. 1981; Wagner et al. 1981a,b). Transgenesis via pronuclear injection is still popular whenever expression of an exogenous gene is desired (Palmiter and Brinster 1985; Jaenisch 1988; Pu et al. 2019). The technique is reliable, although relatively inefficient and the microinjection process itself has the potential to induce cellular and chromosomal damage (Yamauchi et al. 2007). Nevertheless, pups can quickly be screened by PCR to identify transgenics. Due to its semi-random site of integration, the transgene is subject to the effects of local environment (chromatin state, proximity to enhancers, etc.) such that individual founders can exhibit different expression levels and expression patterns, their expression levels can lessen over time due to methylation-induced silencing, and they often have multiple copies of the transgene integrated in tandem (Wall 2001; Davis et al. 2012). These effects can be partially suppressed through the inclusion of insulator elements on both ends of the inserted sequence /Giraldo et al. 2003), though position effects are still sometimes observed (Farzaneh et al. 2019). Furthermore, transgenes can disrupt endogenous genes by insertional mutagenesis so transgenics should be analyzed for unexpected phenotypes. Transgenics are most safely maintained as heterozygotes because homozygotes can be complicated to genotype and are more likely to display undesired phenotypes (Davis et al. 2012). However, transgenics can be bred to homozygosity to check whether an essential gene was disrupted or whether the transgene has unexpected dosage-dependent toxicity (Wagner et al. 1983; Woychik et al. 1985). Multiple individuals should always be screened for expression patterns or levels and founders selected carefully. The insertion site should be mapped whenever possible. Once laborious, this is now facilitated through various PCR techniques or next-generation sequencing. Alternatively, transgenesis can be targeted without resorting to homologous recombination-based techniques by recombinase-mediated insertion, provided the recognition site has been knocked in to the genome (Schilit et al. 2016).

Several techniques that also rely on the random insertion of genetic material were developed in the intervening decades to enable lineage tracing, gene knockout, and gene and enhancer discovery that we only briefly mention here, as they have largely been superseded by other methods. Infection of preimplantation or postimplantation embryos with retroviruses leads to semi-random integration of the viral genome and occasional disruption of mouse genes, which can then be identified using viral sequences as a landmark (Schnieke et al. 1983; Soriano et al. 1987). Similarly, mESCs can be infected with a retrovirus, the cells injected into blastocyst stage embryos, and the mutant lines recovered by breeding the chimeric offspring (Robertson et al. 1986).

Transposons are genetic elements that insert semi-randomly into the genome upon expression of a transposase enzyme (Beckmann and Largaespada 2020). Terminal inverted repeat sequences located at each end of a transpo- son are bound by the transposase, which mobilizes the element and mediates its insertion at a new locus. Several systems have been used in mice, each with their own efficiencies and insertion biases, but piggyBac and Sleeping Beauty are the most widely used. These systems have been used to drive insertional mutagenesis in both mESCs (Luo et al. 1998) and mice (Collier et al. 2005; Ding et al. 2005; Dupuy et al. 2005). Transposon studies carried out in an embryo or adult mouse are basically a variation of a forward genetic screen. The transposon is typically activated in a subset of cells, mice with a desired phenotype are identified (often a tumor or developmental malformation), and the transposon insertion site is mapped.

Gene trapping has been used widely to generate mutant alleles, rapidly clone them, and assess their expression patterns (Gossler et al. 1989; Friedrich and Soriano 1991; von Melchner et al. 1992; Friedel and Soriano 2010). Typically, a trapping vector is used that contains a splice acceptor attached to a promoterless reporter gene such as lacZ or $\beta g e o$. mESCs are transfected with the vector or infected with a retrovirus transducing a gene trap and selected for expression of the reporter gene, as insertion within an intron of an expressed gene will also result in marker expression. The trapped gene can be cloned using $5^{\prime}$ or $3^{\prime}$ RACE and sequences from the reporter gene (Chen et al. 2004). One caveat of the approach is that alternative splicing can splice around the trap in some gene trap designs if the splice acceptor is not strong enough, resulting in a hypomorphic allele (McClive et al. 1998). A second is that correctly trapped genes will not be identified if the gene is not expressed in mESCs. Nonexpressed genes can be successfully trapped, however, by using polyadenylation trap vectors. These use a separate promoter to drive expression of the resistance marker, which itself contains a splice donor but no poly(A) sequence, relying instead on the 3' UTR of the trapped gene (Zambrowicz et al. 1998; Stanford et al. 2001; Chen et al. 2004). Multiple large-scale trapping efforts have taken place, sometimes targeting specific classes of genes, many using sophisticated vectors that allow further modification or conditional mutagenesis of the trapped locus (Wurst et al. 1995; Zambrowicz et al. 1998; Mitchell et al. 2001; Stanford et al. 2001; Chen et al. 2004; Skarnes et al. 2004; Schnutgen et al. 2005; Singla et al. 2010). A significant number of genes have also been trapped through the targeted insertion of promoterless trap vectors using homologous recombination rather than random insertion (Friedel et al. 2005). Numerous trapped lines are available that can be used to generate mutant mice (Table 1).

\section{Embryonic stem cells and homologous recombination}

Experiments performed in the 1970s demonstrated that tumor-derived embryonal carcinoma cells injected into mouse blastocysts could generate chimeric mice but never successfully colonized the germline (Brinster 1974; Mintz and Illmensee 1975; Papaioannou et al. 1975). In 1981, Evans and Kaufman (1981) and Martin (1981) independently isolated embryo-derived mESCs and 
Table 1. Mouse genetic resources for finding mutant mouse strains, ES lines, genome information, and other helpful sites

\begin{tabular}{|c|c|c|c|c|}
\hline \multicolumn{5}{|l|}{ Mutant mouse resources } \\
\hline Resource & Acronym & Description & References & Website \\
\hline Mouse Genome Informatics & MGI & $\begin{array}{l}\text { Database of mouse alleles, gene } \\
\text { expression, phenotypes, publications, } \\
\text { and recombinases }\end{array}$ & $\begin{array}{l}\text { Law and } \\
\text { Shaw } 2018\end{array}$ & $\begin{array}{l}\text { http://www.informatics.jax } \\
\quad \text {.org }\end{array}$ \\
\hline $\begin{array}{l}\text { International Mouse Strain } \\
\text { Resource }\end{array}$ & IMSR & $\begin{array}{l}\text { Database of mouse strains, stocks, and ES } \\
\text { lines and links to the holding } \\
\text { institution }\end{array}$ & $\begin{array}{l}\text { Eppig et al. } \\
2015\end{array}$ & http://www.findmice.org \\
\hline $\begin{array}{l}\text { Knockout Mouse Project } \\
\text { Repository }\end{array}$ & KOMP & $\begin{array}{l}\text { Database for cells and mice generated } \\
\text { through the KOMP }\end{array}$ & $\begin{array}{l}\text { Austin et al. } \\
2004\end{array}$ & https://www.komp.org \\
\hline $\begin{array}{l}\text { International Mouse } \\
\text { Phenotyping Consortium }\end{array}$ & IMPC & $\begin{array}{l}\text { Standardised phenotyping data for mutant } \\
\text { mice made by the International Mouse } \\
\text { Knockout Consortium. }\end{array}$ & $\begin{array}{l}\text { Dickinson } \\
\text { et al. } 2016\end{array}$ & $\begin{array}{l}\text { https://www } \\
\text {.mousephenotype.org }\end{array}$ \\
\hline Mutagenetix & & $\begin{array}{l}\text { Database of ENU alleles from the Beutler } \\
\text { laboratory and the Australian } \\
\text { Phenomics Network }\end{array}$ & $\begin{array}{l}\text { Wang et al. } \\
2018\end{array}$ & $\begin{array}{l}\text { https://mutagenetix } \\
\text {.utsouthwestern.edu/home } \\
\text {.cfm }\end{array}$ \\
\hline $\begin{array}{l}\text { International Gene Trap } \\
\text { Consortium }\end{array}$ & IGTC & $\begin{array}{l}\text { Database of gene trap lines from member } \\
\text { laboratories and institutions }\end{array}$ & $\begin{array}{l}\text { Nord et al. } \\
2006\end{array}$ & https://igtc.org \\
\hline $\begin{array}{l}\text { National Mouse Metabolic } \\
\text { Phenotyping Centers }\end{array}$ & MMPC & $\begin{array}{l}\text { USA-based centers providing mouse } \\
\text { phenotyping services }\end{array}$ & & https://www.mmpc.org \\
\hline $\begin{array}{l}\text { International Society for } \\
\text { Transgenic Technology }\end{array}$ & ISTT & $\begin{array}{l}\text { Scientific society supporting the rapid } \\
\text { exchange of transgenic technology and } \\
\text { ideas; maintains online resources, } \\
\text { listserv, and organizes a meeting }\end{array}$ & & $\begin{array}{l}\text { https://www } \\
\text {.transtechsociety.org }\end{array}$ \\
\hline
\end{tabular}

\begin{tabular}{|c|c|c|c|c|}
\hline Repository & Acronym & Strains & Location & Website \\
\hline Australian Phenome Bank & APB & 1619 mouse strains & Australia & http://pb.apf.edu.au \\
\hline $\begin{array}{l}\text { Center for Animal Resources } \\
\text { and Deveopment }\end{array}$ & CARD & 1757 mouse strains; $31 \mathrm{mESC}$ lines & Japan & $\begin{array}{l}\text { http://cardb.cc.kumamoto-u } \\
\text {.ac.jp/transgenic }\end{array}$ \\
\hline $\begin{array}{l}\text { Canadian Mouse Mutant } \\
\text { Repository }\end{array}$ & CMMR & 845 mouse strains; $13,654 \mathrm{mESC}$ lines & Canada & http://www.cmmr.ca \\
\hline Charles River Laboratories & CRL & 56 mouse strains & USA & https://www.criver.com \\
\hline $\begin{array}{l}\text { Envigo (formerly Harlan } \\
\text { Sprague Dawley) }\end{array}$ & HSD & 45 mouse strains & USA & https://www.envigo.com \\
\hline $\begin{array}{l}\text { European Mouse Mutant } \\
\text { Archive }\end{array}$ & EMMA & 6920 mouse strains. & Europe & https://www.infrafrontier.eu \\
\hline $\begin{array}{l}\text { European Mouse Mutant } \\
\text { Cell Repository }\end{array}$ & EuMMCR & 16,828 mESC lines. & Europe & http://www.eummcr.org \\
\hline GemPharmatech & GPT & 6910 mouse strains & China & $\begin{array}{l}\text { http://www.gempharmatech } \\
\text {.com/en }\end{array}$ \\
\hline MRC Harwell & HAR & 1491 mouse strains & UK & http://www.har.mrc.ac.uk \\
\hline JAX Mice and Services & JAX & 11,109 mouse strains; 2 mESC lines & USA & $\begin{array}{l}\text { https://www.jax.org/jax- } \\
\text { mice-and-services }\end{array}$ \\
\hline $\begin{array}{l}\text { Korea Mouse Phenotyping } \\
\text { Center }\end{array}$ & KMPC & 157 mouse strains & Korea & http://www.mouseinfo.kr \\
\hline $\begin{array}{l}\text { National Cancer Institute at } \\
\text { Frederick }\end{array}$ & NCIMR & 139 mouse strains & USA & http://mouse.ncifcrf.gov \\
\hline $\begin{array}{l}\text { National Institute of } \\
\text { Genetics }\end{array}$ & NIG & 142 mouse strains & Japan & $\begin{array}{l}\text { http://www.shigen.nig.ac.jp/ } \\
\text { mouse/nig }\end{array}$ \\
\hline Oak Ridge Collection at JAX & ORNL & 908 mouse strains & USA & $\begin{array}{l}\text { https://www.jax.org/ } \\
\text { research-and-faculty/tools/ } \\
\text { oak-ridge-strains }\end{array}$ \\
\hline $\begin{array}{l}\text { RIKEN BioResource } \\
\text { Research Center }\end{array}$ & RBRC & 5357 mouse strains; $1747 \mathrm{mESC}$ lines & Japan & $\begin{array}{l}\text { http://www.brc.riken.jp/lab/ } \\
\text { animal/en }\end{array}$ \\
\hline $\begin{array}{l}\text { National Applied Research } \\
\text { Laboratories }\end{array}$ & $\begin{array}{l}\text { RMRC- } \\
\text { NLAC }\end{array}$ & 351 mouse strains & Taiwan & $\begin{array}{l}\text { http://www.nlac.org.tw/ } \\
\text { RMRC/index_e.aspx }\end{array}$ \\
\hline $\begin{array}{l}\text { Shanghai Model Organisms } \\
\text { Center }\end{array}$ & SMOC & 2898 mouse strains & China & https://www.modelorg.com \\
\hline Taconic Biosciences & TAC & 2725 mouse strains & USA & http://www.taconic.com \\
\hline
\end{tabular}


Clark et al.

Table 1. Continued

\begin{tabular}{lcccc}
\hline Mutant mouse repositories $^{\mathrm{a}}$ & & & & \\
\hline Repository & Acronym & Strains & Location & Website \\
\hline $\begin{array}{l}\text { Texas A\&M Institute for } \\
\text { Genomic Medicine }\end{array}$ & TIGM & 195 mouse strains; 142,543 mESC lines & USA & http://www.tigm.org \\
$\begin{array}{l}\text { University of North Caroina, } \\
\begin{array}{l}\text { Chapel Hill Systems } \\
\text { Genetics Core }\end{array}\end{array}$ & UNC & 75 mouse strains & USA & http://csbio.unc.edu/ \\
CCstatus/index.py
\end{tabular}

Genome information

\begin{tabular}{|c|c|c|c|c|}
\hline Resource & Acronym & Description & References & Website \\
\hline $\begin{array}{l}\text { University of California, } \\
\text { Santa Cruz Genome } \\
\text { Browser }\end{array}$ & UCSC & $\begin{array}{l}\text { Genome browser with integration of } \\
\text { wide-ranging "omics" data sets as } \\
\text { unique tracks, including predicted } \\
\text { CRISPR sites }\end{array}$ & $\begin{array}{l}\text { Lee et al. } \\
\text { 2020a }\end{array}$ & https://genome.ucsc.edu \\
\hline Ensembl & Ensembl & $\begin{array}{l}\text { Genome browser and annotation; } \\
\text { resources for comparative genomics, } \\
\text { regulation, and genome variation }\end{array}$ & $\begin{array}{l}\text { Yates et al. } \\
2020\end{array}$ & $\begin{array}{l}\text { https://www.ensembl.org/ } \\
\text { Mus_musculus }\end{array}$ \\
\hline $\begin{array}{l}\text { National Center for } \\
\text { Biotechnology Information }\end{array}$ & NCBI & $\begin{array}{l}\text { National sequence repository with } \\
\text { extensive bioinformatic tools }\end{array}$ & & $\begin{array}{l}\text { https://www.ncbi.nlm.nih } \\
\text {.gov }\end{array}$ \\
\hline
\end{tabular}

${ }^{a}$ Information retrieved from the International Mouse Strain Resource (IMSR) at http://findmice.org on June 12, 2020, except for Envigo, whose information was retrieved from their website. Several smaller repositories omitted for space can be found at http:// findmice.org

demonstrated that in chimeras these cells could contribute much more extensively to multiple organs. Several years later it was shown that mESCs were able to colonize the germline (Bradley et al. 1984), even when carrying a transgene (Gossler et al. 1986; Robertson et al. 1986). In 1987 , building on work in cancer cells and fibroblasts, homologous recombination (HR) between exogenous and chromosomal DNA was demonstrated in mESCs (Folger et al. 1982; Lin et al. 1984; Smithies et al. 1984, 1985; Thomas et al. 1986; Doetschman et al. 1987; Thomas and Capecchi 1987). By introducing exogenous DNA with a desired genetic alteration between two arms of homology to a region of interest, it became possible to make precise genetic modifications. Because the natural ratio of HR to random insertion is generally low, typically around one to several thousand (Würtele et al. 2003), the first alterations were to genes where correctly targeted cells could be directly selected for, for example, mutation of the gene Hprt, which allowed growth in selective media (Doetschman et al. 1987; Hooper et al. 1987; Kuehn et al. 1987; Thomas and Capecchi 1987). HR was soon extended to nonselectable loci, by screening large numbers of clones by PCR (Joyner et al. 1989; Zimmer and Gruss 1989), and demonstrated in nonexpressed genes (Johnson et al. 1989|. The process was made more efficient with the introduction of positive-negative selection that selects both for cells that integrate donor DNA into the genome and simultaneously against cells that integrate the DNA randomly (Mansour et al. 1988). This constellation of breakthroughs enabled scientists to manipulate the mouse genome with precision and relative ease. Almost any genetic change one could imagine could now be introduced and studied in a living mammal.
In ES cell gene targeting strategies, the targeting constructs are typically defined by two homology arms $\left(5^{\prime}\right.$ and $\left.3^{\prime}\right)$ that are several kilobases in length. These flank a selectable marker such as neoR and any mutations or genetic sequence to be inserted at the intended locus. The positive selection marker can be flanked by loxP or FRT sites to enable its later removal using a site-specific recombinase (SSR) (see "Conditional Mutations" below). This is oftentimes desirable as its presence can interfere with local gene expression (Rijli et al. 1994; Fiering et al. 1995) or can affect gene expression from the locus (Meyers et al. 1998). Outside the homology arms is a negative-selection marker, most commonly herpes simplex virus-1 thymidine kinase (HSV-TK) or diphtheria toxin fragment A (DTA), which selects against random insertion (Mansour et al. 1988; Yagi et al. 1990). Targeting efficiencies for positive-negative HR can range from $<1 \%$ of clones correctly targeted to near $80 \%$ for permissive loci using well-optimized vectors. The ratio of HR to random insertion depends on how the DNA is introduced to cells, electroporation yielding the best ratio for the effort (Vasquez et al. 2001). The efficiency of targeting can be improved by increasing the length of the homology arms (Hasty et al. 1991; Deng and Capecchi 1992). Of particular importance, homology arms constructed from the same strain as the mESC line that will be targeted greatly increase the targeting rate (te Riele et al. 1992). Most early targeting was performed in mESCs derived from the agouti-pigmented 129 mouse strain, as these cells had a high rate of germline transmission (Simpson et al. 1997; Threadgill et al. 1997). Once the targeted mESC clone is verified, the cells can either be injected into the cavity of embryonic day E3.5 blastocyst stage embryos or aggregated with 
E2.5 morula stage embryos (Behringer et al. 2014). Because not all chimeras have mESC contribution to the germline, using agouti 129 mESCs and nonagouti host embryos, chimeras with the highest degree of overall mESC contribution can easily be chosen based on coat color. Alternatively, complete germline transmission can be consistently achieved by injecting mESCs into a mutant mouse strain that cannot form male germ cells, a technique that is offered commercially (Koentgen et al. 2016). If the final mouse needs to be a different strain, then at least 10 generations of time-consuming and costly backcrossing are required to be considered congenic, though this can be accelerated by speed congenics (Markel et al. 1997; Wakeland et al. 1997). Even after backcrossing, genes near the targeted locus are more likely to be derived from the mESC line, introducing a variable that could complicate subtle phenotypes such as behavior (Gerlai 1996). Indeed, the strain for an experiment should be carefully considered as different backgrounds can show variable phenotypes from an otherwise identical underlying mutation (Brewer et al. 2015). By using newer culture conditions there are now mESC lines from other inbred strains that show high degrees of germline competency, such as C57BL/6N-derived JM8 or VGB6 cells used in the Knockout Mouse Project (KOMP) (Poueymirou et al. 2007; Pettitt et al. 2009). Additionally, there are protocols for deriving germline-competent mESCs from many strains (Czechanski et al. 2014) and numerous lines are commercially available. Therefore, when possible, researchers should build their targeting constructs and perform the targeting itself in a mESC line derived from the same strain they use in their mouse colony. Alternative sources of germline-competent pluripotent cells include embryonic germ cells and induced pluripotent stem cells, though these are rarely used for generating novel mouse models (Labosky et al. 1994; Stewart et al. 1994; Okita et al. 2007; Wernig et al. 2007).

Alternative techniques to accelerate targeting or boost its efficiency have also been explored. The possibility of HR directly in zygotes was tested, but resulted in a single case of successful targeting among 500 embryos injected, so the technique was considered infeasible (Brinster et al. 1989). Knockdown of Blm, a known suppressor of HR, improved targeting by around threefold at multiple loci (Luo et al. 2000; Fukuda et al. 2016). Most portentously, inducing a DSB at the edit site, here by using a rare cutting endonuclease, enhanced HR efficiency as much as 5000-fold (Smih et al. 1995; Donoho et al. 1998). However, until recently, generating such a specific DSB was so laborious as to be impractical.

\section{Programmable nucleases}

In 1996, zinc finger nucleases (ZFNs) were introduced, representing a new customizable method for the induction of DSBs at a specific site in the genome (Kim et al. 1996). ZFNs are engineered proteins consisting of multiple ZF motifs and the FokI nuclease domain. The FokI domain induces DSBs in DNA when bound as a dimer, re- quiring two ZFNs to bind in reverse orientation, one on each strand of DNA (Bitinaite et al. 1998; Smith et al. 2000). Typically, each ZF binds a 3-nt recognition sequence; with concatenated domains, a recognition sequence of nine or more nucleotides can be engineered. However, designing ZFNs in a purely modular fashion is difficult, as the recognition sequence of individual fingers may be altered by the adjacent fingers (Carroll 2011).

Transcription activator-like effector nucleases (TALENs) were the next evolution in targetable nucleases (Christian et al. 2010). Like ZFNs, TALENs use the FokI nuclease domain to facilitate the induction of DSBs. However, rather than relying on ZFs, TALE DNA-binding domains are used to dictate sequence specificity. Each TALE domain recognizes a single nucleotide based on the repeat variable di-residue (RVD), a pair of amino acids that dictate nucleotide interaction (Boch et al. 2009; Moscou and Bogdanove 2009); multiple domains can be strung together to produce a nuclease with a unique binding sequence. TALENs provided the potential to target any sequence of nucleotides within a genome.

While both ZFNs and TALENs provided a valuable resource for genetic manipulation and were successfully used in embryos to make mutant mice (Meyer et al. 2010; Sung et al. 2013), new nucleases need to be constructed for each target. Additionally, if the target does not contain inverted binding sites for each copy of the nuclease, two different nucleases would need to be produced to allow for dimerization of FokI. In the process of testing binding efficiency and specificity, numerous protein constructs would need to be cloned and produced for each locus. Over the years, various tools and databases have been developed to offer improved prediction and design of both ZFNs and TALENs (Heigwer et al. 2013; Joung and Sander 2013; Feng et al. 2014; Sakuma and Yamamoto 2016; Zhao et al. 2016). However, because of this complicated workflow, they were quickly overshadowed by the advent of an RNA-guided endonuclease.

\section{CRISPR/Cas9 editing}

The history of CRISPR /clustered regularly interspaced short palindromic repeats) began with the observation of a repeated DNA sequence in E. coli (Ishino et al. 1987). The function of these repeated sequences was subsequently identified in adaptive immunity (Mojica et al. 1995; Jansen et al. 2002; Barrangou et al. 2007). The typical locus of a CRISPR system (Fig. 1A) consists of a spaced repeat region accompanied by a protein-coding region. The repeat region acts as a library of previous infections, with unique spacers between each repeat corresponding to previously encountered invading DNA. Each spacer and repeat represent a CRISPR RNA (crRNA). The adjacent protein-coding region encodes multiple CRISPRassociated (Cas) proteins that are involved in the acquisition, processing, and utilization of crRNAs. Mature crRNAs function to guide the Cas endonuclease to target DNA (Fig. 1B). The cleavage target for a given Cas complex is specified by two elements: a recognition sequence 


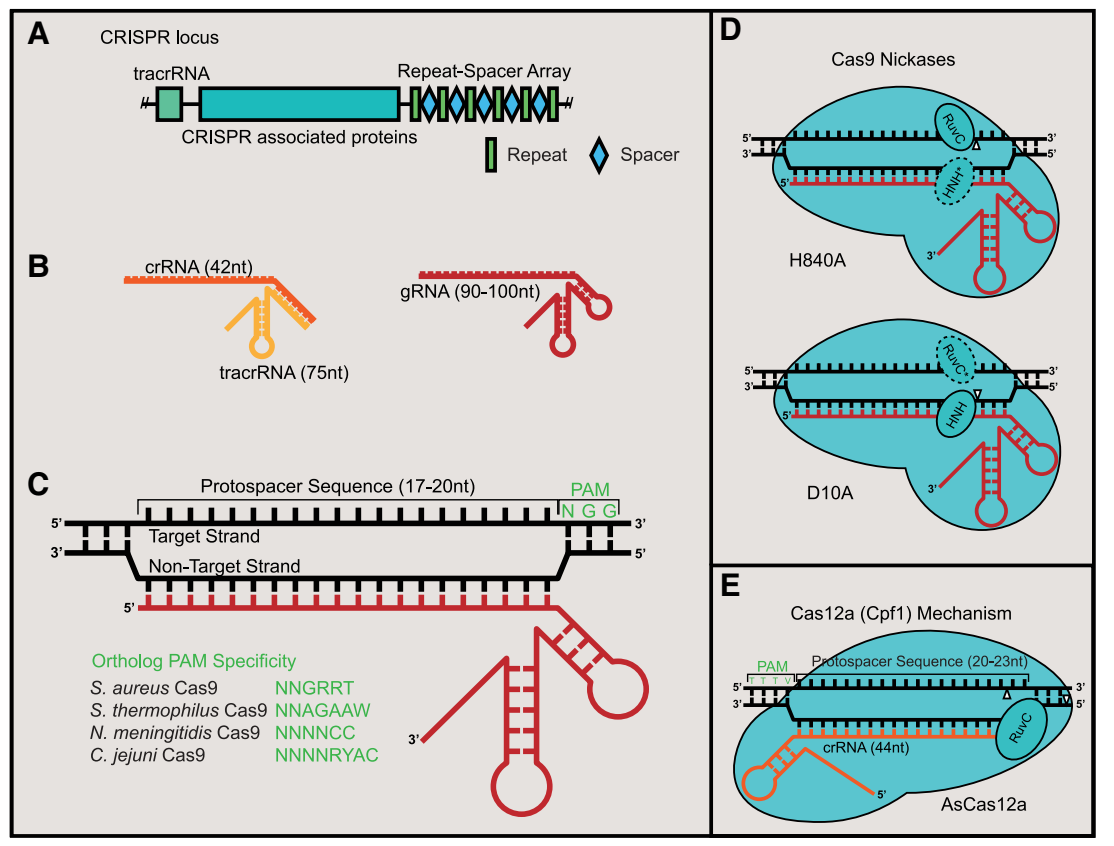

Figure 1. Overview of CRISPR/Cas mechanism. (A) A typical CRISPR/Cas9 locus consists of a repeat-spacer array, transactivating CRISPR RNA (tracrRNA), and a Cas proteincoding region. $(B)$ The repeat-spacer array encodes the CRISPR RNAs (crRNA), which form a heteroduplex with the tracrRNA and guide the Cas9 endonuclease to its target. The crRNA:tracrRNA duplex can be replaced with a single guide RNA (gRNA). (C) Binding of the gRNA is dictated by the protospacer sequence and the protospacer adjacent motif (PAM) site located downstream. The specific $\mathrm{PAM}$ site is unique for the various orthologs of Cas9. (R) A/G; (W) A/T; (Y) C/T (D) Cas9 creates DSBs via its RuvC and HNH nuclease domains. Cas9 nickases can be made via a single amino acid substitution in either of the nuclease domains. (E) Cas12a, another single nuclease Cas system, uses a single crRNA, an increased protospacer region, an upstream PAM site, and a single RuvC domain that induces a 5-nt $5^{\prime}$ overhang. (protospacer) encoded in the crRNA that must occur in the target DNA next to a protospacer adjacent motif (PAM) whose identity is specific to individual Cas complexes (Fig. 1C). Once the Cas complex is bound to a target, endonuclease domains induce DSBs in the DNA (for review, see Marraffini and Sontheimer 2010).

Cas9, the endonuclease of the class 2 type II CRISPR system (Makarova et al. 2020), was the first to be explored for gene editing as it only required a single protein (Jinek et al. 2012; Cong et al. 2013; Mali et al. 2013). Type II systems require an additional nonprotein-coding transactivating CRISPR RNA (tracrRNA) that is necessary for the recruitment and activation of Cas9 (Deltcheva et al. 2011). The crRNA:tracrRNA complex can be replaced with a single guide RNA (sgRNA or gRNA) that contains both sequences and a short linker to maintain proper conformation (Fig. 1B). Harnessing this technology, the first mouse models were created, paving the way for the use of CRISPR/Cas9 in mice (Shen et al. 2013; Wang et al. 2013). The efficiency of CRISPR/Cas editing promised to speed up the creation of in vivo mouse models by bypassing mESCs to directly edit zygotes.

Early experiments used Streptococcus pyogenes Cas9 (SpCas9), which recognizes an NGG PAM site. While theoretically, NGG, or its complement, NCC, should occur once every $8 \mathrm{bp}$ in a random sequence, the specificity of the protospacer and the requirement of the PAM to occur as close to the editing site as possible left targets of interest without efficient gRNAs. Subsequently, groups began using directed evolution to alter the PAM specificity of Cas9. Additionally, SpCas9 orthologs, such as the Staphylococcus aureus SaCas9, proved a valuable resource as they recognize different PAM sequences (Fig. 1C; Kleinstiver et al. 2015a,b). Cas12a, previously known as Cpf1, is an additional class 2 single protein CRISPR/Cas system that recognizes a T-rich PAM sequence (Fig. 1E), supply- ing new editing possibilities for AT-rich regions of the genome (Zetsche et al. 2015). Additionally, Cas12a is a type $\mathrm{V}$ system and does not require the use of a tracrRNA (Makarova et al. 2015). Currently, a plethora of Cas9 and Cas12a variants provide flexibility in PAM and gRNA selection (Table 2; Ma et al. 2019; Chatterjee et al. 2020; Miller et al. 2020; Walton et al. 2020).

Additional mutations have been made in Cas9 to alter the functionality of the enzyme. Mammalian codon optimization was used to improve expression and nuclear localization sequences were added to facilitate proper localization (Cong et al. 2013; Mali et al. 2013). Early alterations also targeted the nuclease domains. Cas9 contains two nuclease domains: RuvC cleaves the targeted strand, while $\mathrm{HNH}$ cleaves the nontargeted strand (Fig. 1D). A D10A substitution inactivates the RuvC domain, while an $\mathrm{H} 840 \mathrm{~A}$ substitution inactivates the $\mathrm{HNH}$ domain (Jinek et al. 2012). Inactivating one domain results in a DNA nickase (Cas9n) while inactivating both results in catalytically dead Cas9 (Cas9d). The modified activity has not only aided the development of multiple genome engineering strategies, as discussed below, but also opened the door for various nonediting roles, such as transcriptional regulation and chromosomal mapping (Wang et al. 2016a; Adli 2018), the discussion of which is beyond the scope of this review.

CRISPR/Cas can be used to create two general types of mutations. The first is the formation of small insertions or deletions (indels) through the repair of DSBs via nonhomologous end joining (NHEJ) (for review, see Pannunzio et al. 2018). Indels typically result in frameshift mutations, which often lead to an early stop codon and subsequent nonsense-mediated decay (NMD) of mRNA transcripts. To facilitate large deletions, two distinct gRNAs are used to induce DSBs that flank the region of interest, effectively deleting the internal sequence (Li et al. 2014; Zheng et al. 2014; Kraft et al. 2015; Zhang et al. 2015). 
Table 2. CRISPR resources: PAM sites or editing windows for Cas variants, base editors, and prime editors, as well as the systems in which each has been tested

\begin{tabular}{|c|c|c|c|c|c|}
\hline $\begin{array}{l}\text { CRISPR/Cas } \\
\text { nucleases }\end{array}$ & PAM & $\begin{array}{l}\text { Human } \\
\text { cells }\end{array}$ & $\begin{array}{l}\text { Mouse } \\
\text { cells }\end{array}$ & Embryos & References \\
\hline
\end{tabular}

\begin{tabular}{|c|c|c|c|c|c|}
\hline \multicolumn{6}{|c|}{ Cas9 (Note: Cas9 PAM sites are downstream from protospacer region) } \\
\hline SpCas9 & NGG & $\mathrm{Y}$ & $\mathrm{Y}$ & $\mathrm{Y}$ & $\begin{array}{l}\text { Jinek et al. 2012; Cong et al. 2013; Mali et al. 2013; } \\
\text { Shen et al. } 2013\end{array}$ \\
\hline SpCas9-VQR & NGAN & $\mathrm{Y}$ & $\mathrm{Y}$ & $\mathrm{Y}$ & Kleinstiver et al. 2015a; Robertson et al. 2018 \\
\hline SpCas9-VRER & NGCG & $\mathrm{Y}$ & $\mathrm{Y}$ & $\mathrm{Y}$ & Kleinstiver et al. 2015a; Robertson et al. 2018 \\
\hline SpCas9-QQR & NAAG & $\mathrm{Y}$ & $\mathrm{N}$ & $\mathrm{N}$ & Anders et al. 2016 \\
\hline xCas9 3.7 & $\begin{array}{l}\text { NG, NNG, GAA, } \\
\text { GAT, CAA }\end{array}$ & $\mathrm{Y}$ & $\mathrm{N}$ & $\mathrm{N}$ & Hu et al. 2018 \\
\hline SpCas9-NG & NG & $\mathrm{Y}$ & $\mathrm{N}$ & $\mathrm{N}$ & Nishimasu et al. 2018 \\
\hline SpCas9-NRRH & NRRH & $\mathrm{Y}$ & $\mathrm{N}$ & $\mathrm{N}$ & Miller et al. 2020 \\
\hline SpG & NGN & $\mathrm{Y}$ & $\mathrm{N}$ & $\mathrm{N}$ & Walton et al. 2020 \\
\hline SpRY & $N R N>N Y N$ & $\mathrm{Y}$ & $\mathrm{N}$ & $\mathrm{N}$ & Walton et al. 2020 \\
\hline SaCas9 & NNGRRT & $\mathrm{Y}$ & $\mathrm{Y}$ & $\mathrm{Y}$ & Ran et al. 2015; Zhang et al. 2016 \\
\hline SaCas9-KKH & NNNRRT & $\mathrm{Y}$ & $\mathrm{Y}$ & $\mathrm{Y}$ & Kleinstiver et al. 2015b; Robertson et al. 2018 \\
\hline St1Cas9 & NNAGAAW & $\mathrm{Y}$ & $\mathrm{Y}$ & $\mathrm{N}$ & Müller et al. 2016; Agudelo et al. 2020 \\
\hline St3Cas9 & NGGNG & $\mathrm{Y}$ & $\mathrm{N}$ & $\mathrm{N}$ & Müller et al. 2016 \\
\hline Nm1Cas9 & NNNNGATT & $\mathrm{Y}$ & $\mathrm{N}$ & $\mathrm{N}$ & Hou et al. 2013 \\
\hline Nm2Cas9 & NNNNCC & $\mathrm{Y}$ & $\mathrm{N}$ & $\mathrm{N}$ & Edraki et al. 2019 \\
\hline FnCas9 & NGG & $\mathrm{Y}$ & $\mathrm{Y}$ & $\mathrm{Y}$ & Hirano et al. 2016 \\
\hline CjCas9 & NNNNRYAC & $\mathrm{Y}$ & $\mathrm{Y}$ & $\mathrm{Y}$ & Kim et al. 2017a; Lee et al. 2020c \\
\hline \multicolumn{6}{|c|}{ Cas12a (Note: Cas12a PAM sites are upstream of protospacer region) } \\
\hline AsCas $12 \mathrm{a}$ & TTTV & $\mathrm{Y}$ & $\mathrm{Y}$ & $\mathrm{Y}$ & Zetsche et al. 2015; Kim et al. 2016; Hur et al. 2016 \\
\hline AsCas12a-RR & TYCV & $\mathrm{Y}$ & $\mathrm{Y}$ & $\mathrm{N}$ & Gao et al. 2017 \\
\hline AsCas12a-RVR & TATV & $\mathrm{Y}$ & $\mathrm{Y}$ & $\mathrm{N}$ & Gao et al. 2017 \\
\hline CeCas12a & TTTN & $\mathrm{Y}$ & $\mathrm{N}$ & $\mathrm{N}$ & Chen et al. 2020 \\
\hline ErCas12a & YTTN & $\mathrm{Y}$ & $\mathrm{Y}$ & $\mathrm{Y}$ & Liu et al. 2020c \\
\hline FnCas $12 \mathrm{a}$ & TTTV & $\mathrm{Y}$ & $\mathrm{N}$ & $\mathrm{N}$ & Zetsche et al. 2015 \\
\hline LbCas12a & TTTV & $\mathrm{Y}$ & $\mathrm{Y}$ & $\mathrm{Y}$ & Zetsche et al. 2015; Kim et al. 2016 \\
\hline LbCas12a-RVRR & TNTN & $\mathrm{Y}$ & $\mathrm{N}$ & $\mathrm{N}$ & Toth et al. 2020 \\
\hline Mb3Cas $12 \mathrm{a}$ & TTV & $\mathrm{Y}$ & $\mathrm{Y}$ & $\mathrm{Y}$ & Wang et al. 2020d \\
\hline Base editors & Window & $\begin{array}{l}\text { Human } \\
\text { cells }\end{array}$ & $\begin{array}{l}\text { Mouse } \\
\text { cells }\end{array}$ & Embryos & References \\
\hline
\end{tabular}

\begin{tabular}{|c|c|c|c|c|c|}
\hline \multicolumn{6}{|l|}{ ABEs } \\
\hline ABE7.10 & N4-N7 & $\mathrm{Y}$ & $\mathrm{Y}$ & $\mathrm{Y}$ & Gaudelli et al. 2017; Liu et al. 2018c \\
\hline ABEmax & N4-N7 & $\mathrm{Y}$ & $\mathrm{Y}$ & $\mathrm{Y}$ & Koblan et al. 2018; Huang et al. 2019a \\
\hline CP-ABEmax & $\mathrm{N} 4-\mathrm{N} 12$ & $\mathrm{Y}$ & $\mathrm{N}$ & $\mathrm{N}$ & Huang et al. $2019 \mathrm{~b}$ \\
\hline ABE8e & N4-N8 & $\mathrm{Y}$ & $\mathrm{N}$ & $\mathrm{N}$ & Richter et al. 2020 \\
\hline SaABE8e & N3-N14 & $\mathrm{Y}$ & $\mathrm{N}$ & $\mathrm{N}$ & Richter et al. 2020 \\
\hline enAsABE8e & N8-N14 & $\mathrm{Y}$ & $\mathrm{N}$ & $\mathrm{N}$ & Richter et al. 2020 \\
\hline \multicolumn{6}{|l|}{ CBEs } \\
\hline $\mathrm{BE} 3$ & N4-N8 & $\mathrm{Y}$ & $\mathrm{Y}$ & $\mathrm{Y}$ & Komor et al. 2016; Sasaguri et al. 2018 \\
\hline YEE-BE3 & N5-N6 & $\mathrm{Y}$ & $\mathrm{N}$ & $\mathrm{N}$ & Kim et al. $2017 b$ \\
\hline YE1-BE3-FNLS & N5-N7 & $\mathrm{N}$ & $\mathrm{Y}$ & $\mathrm{Y}$ & Zuo et al. 2020 \\
\hline Target-AID & N1-N5 & $\mathrm{Y}$ & $\mathrm{Y}$ & $\mathrm{Y}$ & Nishida et al. 2016; Sasaguri et al. 2018 \\
\hline $\mathrm{BE} 4$ & $\mathrm{~N} 4-\mathrm{N} 8$ & $\mathrm{Y}$ & $\mathrm{Y}$ & $\mathrm{Y}$ & Komor et al. 2017 \\
\hline BE4max & N4-N8 & $\mathrm{Y}$ & $\mathrm{Y}$ & $\mathrm{N}$ & Koblan et al. 2018; Yang et al. 2020 \\
\hline St1BE4max & N2-N12 & $\mathrm{Y}$ & $\mathrm{Y}$ & $\mathrm{N}$ & Agudelo et al. 2020 \\
\hline CP-CBEmax & N4-N11 & $\mathrm{Y}$ & $\mathrm{N}$ & $\mathrm{N}$ & Huang et al. $2019 \mathrm{~b}$ \\
\hline hyeA3A-BE4max & N4-N15 & $\mathrm{Y}$ & $\mathrm{Y}$ & $\mathrm{Y}$ & Zhang et al. 2020a \\
\hline BEACON & N7-N12 & $\mathrm{Y}$ & $\mathrm{Y}$ & $\mathrm{Y}$ & Wang et al. $2020 \mathrm{a}$ \\
\hline \multicolumn{6}{|l|}{ Dual BEs } \\
\hline A\&C-BEmax & $\mathrm{N} 2-\mathrm{N} 17$ & $\mathrm{Y}$ & $\mathrm{N}$ & $\mathrm{N}$ & Zhang et al. 2020b \\
\hline SPACE & $\begin{array}{l}\text { A-G: N4-N7 C-T: } \\
\text { N2-N7 }\end{array}$ & $\mathrm{Y}$ & $\mathrm{N}$ & $\mathrm{N}$ & Grunewald et al. 2020 \\
\hline Target-ACEmax & $\begin{array}{l}\text { A-G: N4-N7 C-T: } \\
\text { N1-N5 }\end{array}$ & $\mathrm{Y}$ & $\mathrm{N}$ & $\mathrm{N}$ & Sakata et al. 2020 \\
\hline \multicolumn{6}{|l|}{ Prime editors } \\
\hline PE3 & & $\mathrm{Y}$ & $\mathrm{Y}$ & $\mathrm{Y}$ & Anzalone et al. 2019; Liu et al. 2020b \\
\hline
\end{tabular}


Clark et al.

Table 2. Continued

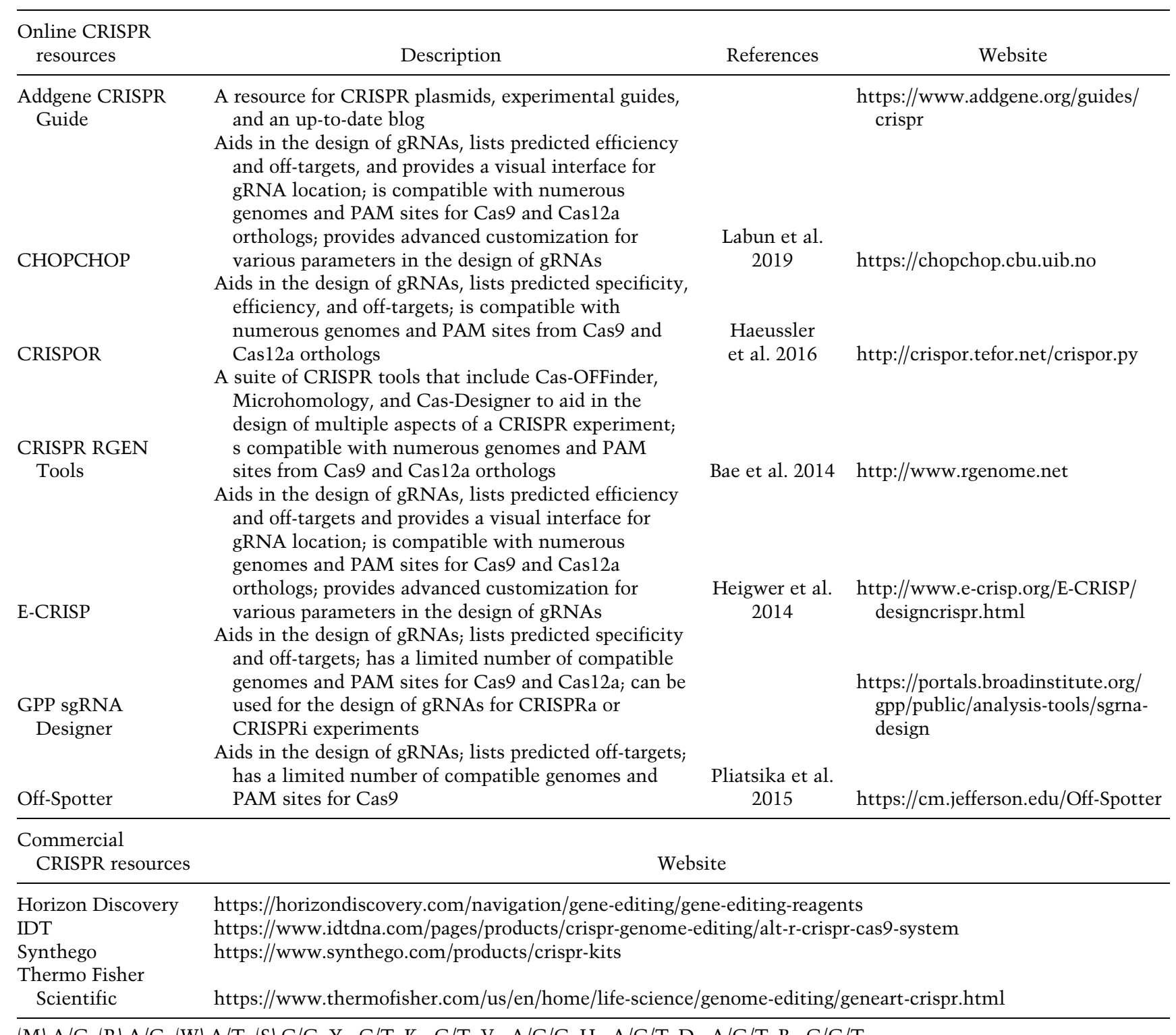

(M) A/C; (R) A/G; (W) A/T; (S) C/G; Y = C/T, K = G/T, V=A/C/G, H=A/C/T, D = A/G/T, B = C/G/T

The second type of mutation is the introduction of specific edits using donor DNA via homology-directed repair (HDR). HDR is much less efficient than NHEJ, leading to a lower success rate. Various groups have worked along multiple lines to improve the efficiency of CRISPR/Casinduced HDR. Early experiments typically used plasmid dsDNA as a donor, similar in design as used for $\mathrm{HR}$, with modest efficiency (Cong et al. 2013; Mali et al. 2013). Single-stranded oligodeoxynucleotide (ssODN) donors were also used alongside Cas9 to introduce short tags and $l_{0 x} P$ sites, albeit with variable efficiencies (Yang et al. 2013; Bishop et al. 2016). With both strategies, NHEJ was still the predominant outcome. These limitations spurred researchers to consider alternative approaches and attempt to quantify the numerous parameters that produce high-efficiency donors. Two promising systems have been developed in recent years, Easi-CRISPR and Tild-CRISPR (Quadros et al. 2017; Miura et al. 2018; Yao et al. 2018). Efficient additions with ssDNA inserts CRISPR (EasiCRISPR) (Quadros et al. 2017) uses long ssDNA (lssDNA) with short homology arms ranging from $\sim 50$ to $100 \mathrm{bp}$ in length flanking the sequence to be inserted. Easi-CRISPR has been used to create floxed alleles and knock-in cassettes up to $\sim 1.5 \mathrm{~kb}$, with efficiency ranging from $8.5 \%$ to $100 \%$ and $25 \%$ to $67 \%$, respectively (Quadros et al. 2017). While the results of this study are promising, using lssDNA limits the length of insertion to $\sim 1-1.5 \mathrm{~kb}$ due to errors in production. Using dsDNA can introduce larger segments of exogenous DNA into the targeted locus. Targeted integration with linearized dsDNA CRISPR (TildCRISPR) (Yao et al. 2018) uses linear dsDNA with 800 bp of homology flanking the desired sequence edit, with 
no other DNA outside the homology arms. One group successfully inserted cassettes ranging from 0.6 to $6 \mathrm{~kb}$ via injection into mouse embryos, with efficiencies ranging from $6.9 \%$ to $54.4 \%$ in pups across six genomic loci (Yao et al. 2018). Alternatively, homology-independent targeted integration (HITI) and related techniques have been used to insert various protein tags onto genes of interest. HITI uses a gRNA target sequence in both the gene of interest and the plasmid containing the insertion. The resulting DSBs are then repaired via NHEJ rather than HDR. Unlike HDR-based Cas9 editing, HITI provides an avenue for editing nonmitotic cells and tissues (Suzuki et al. 2016; Gao et al. 2019; Li et al. 2019).

Another method for improving efficiency has been to actively recruit donor DNA to the targeted locus. One option is to use a modified Cas9 containing a monomeric streptavidin domain and biotinylated donor DNA. The strong affinity of streptavidin-biotin recruits the donor DNA to the site of the DSB. Using this strategy, flanking loxP sites were successfully inserted at a rate of $15 \%-$ $22 \%$, when screened in pups (Ma et al. 2017). A second group inserted larger fluorescent tags, reporting high rates of success, with one locus exhibiting correct tagging in three out of three founder males (Gu et al. 2018). Alternatively, Aird et al. (2018) described the use of Cas9 fused to a porcine circovirus 2 rep (PCV) domain. This PCV domain allows for the covalent linkage of ssDNA to the Cas9 protein, which resulted in increased rates of HDR when attempting to insert fluorescent tags (Aird et al. 2018). However, the investigators only examined the use of this strategy in human cell lines. As such, the translation of this success into mice is unknown, but promising. Overall, recruiting donor DNA to the targeted locus appears to have a significant effect on the success of HDR.

When using CRISPR/Cas there are potential pitfalls to consider. Early emphasis was placed on determining the specificity of Cas9, in an effort to examine the scope of off-target mutations. Wild-type Cas9 can tolerate nucleotide mismatches in the gRNA, especially in the $5^{\prime}$ end. Reducing the length of the protospacer sequence from 20 to $17 \mathrm{nt}$ or $18 \mathrm{nt}$ may impart a positive effect on specificity while maintaining on-target activity by increasing the thermodynamic impact of each nucleotide (Hsu et al. 2013; Kuscu et al. 2014). Directed mutagenesis has produced multiple high-fidelity enzymes that boast on-target activity comparable with wild type with significantly reduced levels of off-target mutations (Kleinstiver et al. 2016; Slaymaker et al. 2016; Chen et al. 2017; Lee et al. 2018). Multiple webtools exist to aid in the design of gRNAs and prediction of off-target binding, incorporating various modified Cas9 enzymes and thermodynamic models of gRNA binding (Table 2). Efficacy of gRNA designs can be validated in vitro via nuclease-based mismatch cleavage assays, such as Surveyor or T7E1 (Vouillot et al. 2015; Sentmanat et al. 2018). Another strategy to reduce off-target mutations is through the use of Cas9n and two gRNAs. One gRNA targeted to each strand of DNA in conjunction with Cas9n will create two staggered nicks in the DNA, creating a DSB. This technique reduces off-target effects by requiring the annealing of two separate gRNAs in close proximity (Ran et al. 2013a). Off-target screening should always be performed to characterize the extent of additional genome modifications in each individual experiment. However, when generating mice, off-target mutations can be removed via outcrossing, unless tightly linked.

The majority of analysis has focused on off-target mutations; however, recent studies have reported various ontarget rearrangements when using CRISPR/Cas9. One study examined the variability in alleles generated using a single cut site, either in an exon or intron, and found evidence of various forms of genomic damage at three different loci. Most alleles resulting from a cut in an exon exhibited indels $<50 \mathrm{bp}$; however, there were instances of deletions up to $6 \mathrm{~kb}$ in length. Various alleles recovered from either exon or intron targeted gRNAs also resulted in large insertions up to $2.5 \mathrm{~kb}$, or displayed evidence of translocation or inversion (Kosicki et al. 2018). A second group performed analysis on 109 different loci using Cas9n with pairs of gRNAs to reduce off-target effects. Southern blot analysis revealed possible genomic damage at $40 \%$ of all loci examined, accounting for roughly $8 \%$ of all clones (Rezza et al. 2019). Of note, both studies were performed in mESCs; when creating in vivo models, extensive DNA damage may partially account for the low recovery of CRISPR/Cas9 engineered live pups. However, both studies emphasize the need for proper screening of mutations at both off-target and on-target loci, as the full extent of genomic damage may not be readily apparent via short-range PCR and sequencing.

\section{Base editors}

In 2016, the Liu laboratory (Komor et al. 2016) published a paper describing a Cas9 fusion protein that could alter a nucleotide without a DSB, referred to as a base editor (BE) (Fig. 2A). The first BEs consisted of Cas9n fused to a cytidine deaminase domain (APOBEC1) and a uracil DNA glycosylase inhibitor (UGI). APOBEC1 converts cytidine to uracil without requiring a break in the dsDNA backbone. The UGI represses base excision of the uracil while the Cas9n nicks the nonedited strand, resulting in more favorable repair of the nicked strand and thus effecting a C-to-T transition mutation (Fig. 2B). The following year, the same group published a new variant, Cas9n fused to an adenine deaminase domain (TadA) able to convert adenine into inosine, which would effectively be repaired as guanine (Gaudelli et al. 2017). Multiple groups have worked on improving the efficiency and specificity of both cytidine base editors (CBEs) and adenine base editors (ABEs) (Komor et al. 2017; Koblan et al. 2018). BEs function as a genetic pickaxe, able to alter a single nucleotide with relative precision and accuracy, and offer a wide variety of uses: correcting or mimicking disease-causing SNPs, altering enzyme function via precise amino acid changes, inducing an early stop codon, altering a binding motif, or even inducing or altering alternative splicing behavior, as was recently reported using a CBE system (Yuan et al. 2018). 


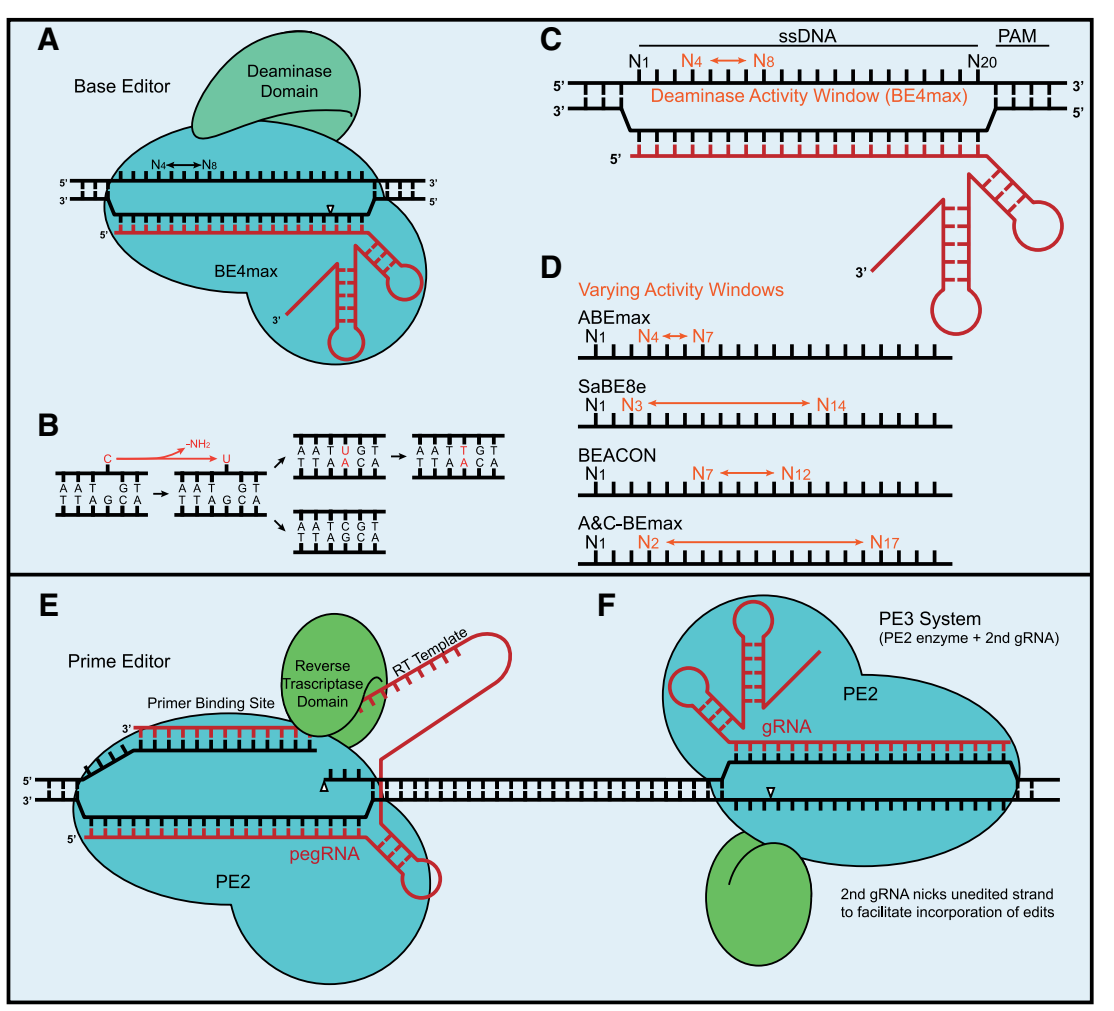

Figure 2. CRISPR/Cas base editors and prime editor. (A) Base editor systems can induce nucleotide changes without the need for DSBs in the target DNA. Cas9n (D10A) is used to nick the unedited strand to facilitate incorporation of the deaminated nucleotide. $(B)$ Base editors use a deaminase domain to convert $\mathrm{C}$ to $\mathrm{T}$ (or $\mathrm{A}$ to $\mathrm{G}$ ). (C) The conversions can occur within the ssDNA deaminase activity window upstream of the PAM site. $(D)$ The width of the activity window is dictated by the base editor system. (E) The prime editor system uses a Mo-MLV RT domain to reverse-transcribe small insertions and deletions into the target DNA. A specialized pegRNA contains a protospacer, scaffold sequence, an RT template, and a primer binding sequence. Cas9n (H840A) nicks the targeted strand of DNA to allow the RT domain to reverse transcribe the template into the DNA strand. $(F)$ The PE3 system uses an additional gRNA to induce a nick in the unedited strand at a nearby locus to facilitate incorporation of the edited DNA.
The deaminase enzymes catalyze ssDNA. When the BE binds to its target, the gRNA forms a heteroduplex with the complementary DNA strand, leaving the noncomplementary strand exposed as ssDNA (Fig. 2C). The targetable nucleotides therefore fall within the protospacer sequence $\left(\mathrm{N}_{1} \ldots \mathrm{N}_{20}\right)$ prior to the PAM site $\left(\mathrm{N}_{21} \mathrm{~N}_{22} \mathrm{~N}_{23}\right)$. Particular BEs have varying targeting windows (Fig. 2D); for instance, the recent CBEmax is optimal at nucleotides $\mathrm{N}_{4}$ through $\mathrm{N}_{8}$, while ABEmax is optimal at $\mathrm{N}_{4}$ through $\mathrm{N}_{7}$ (Koblan et al. 2018). Altering the Cas9 enzyme also affects the targeting window; saBE3 has an expanded window of editing between $\mathrm{N}_{2}$ and $\mathrm{N}_{15}$ (Kim et al. 2017b). Additionally, the use of novel circularly permutated variants of spCas9 can adjust the targeting window (Oakes et al. 2019). This allows for an increase in the editing window of CBEmax (CP-CBEmax) and ABEmax (CP-ABEmax) to $\mathrm{N}_{4}$ through $\mathrm{N}_{11}$ and $\mathrm{N}_{4}$ through $\mathrm{N}_{12}$, respectively (Huang et al. 2019b). Careful selection of a BE system can produce an efficient window for the desired mutation.

While base editing certainly has advantages over traditional CRISPR/Cas systems, it is not without its caveats. Currently, only four of 12 possible base edits are achievable (C to T, G to A, A to $G$, and $T$ to $C$ ), thus allowing for only 66 amino acid substitutions out of a possible 420. Selecting an optimal gRNA is more restricted when using base editing. First, as discussed above, the target nucleotide must fall within the window of editing dictated by the BE. Second, the deaminases are not selective and will potentially edit all targets within the window. Early in vitro data suggest that the enzyme works sequentially, moving from upstream nucleotides to downstream ones (Komor et al. 2016). This can be either a detriment or a strength, depending on the desired edit. Additionally, base editing can result in off-target mutations similarly to traditional CRISPR/Cas systems. Care must be taken to screen predicted off-target sites based on gRNA mismatches and the respective editing windows for potential mutations. However, the rate of indel formation is lower than traditional Cas9 via the use of Cas9n.

Many disease-causing alleles can be traced to deleterious point mutations and the ability to produce and study mammalian models of those mutations is quite valuable. Base editing is seen as a powerful toolbox to create disease models accurately and efficiently. Multiple BEs have been successfully used to create mouse models (Liu et al. 2018c; Yeh et al. 2020; Wang et al. 2020c). However, reports have begun to shed light on the promiscuity of CBE systems in mouse embryos. A recent study used whole genome sequencing to examine the frequency of off-target mutations. The investigators injected sibling embryos at the one-cell stage with either $\mathrm{ABE}$ or $\mathrm{CBE}$, both using the same gRNA, and compared de novo SNPs and indels with noninjected sibling embryos. A twofold increase in novel SNPs was observed using CBE, while ABE had levels comparable with those of controls. Surprisingly, only $2 \%$ of the SNPs correlated with predicted off-target sites, indicating that screening off-targets based on the gRNA sequence is not sufficient to adequately determine the degree of unintended mutations. The number of indels was comparable between the three groups, indicating that the cytosine deaminase is the likely culprit and not the Cas9n (Lee et al. 2020b). Further optimization and analysis of CBE systems is necessary depending on the experiment. 


\section{Prime editor}

To overcome the editing limitations of BEs, the Liu group (Anzalone et al. 2019) introduced a system, termed a prime editor (PE) (Fig. 2E). PEs consist of Cas9n fused to a MoMLV reverse transcriptase (RT) domain alongside a multifunction prime editing gRNA (pegRNA). The pegRNA consists of a protospacer, a modified scaffold, and an extended 3' sequence containing a template and complementary binding sequence, known as the primer binding sequence (PBS). Cas9n nicks the PAM-adjacent DNA strand, the free DNA strand hybridizes with the PBS of the pegRNA, the RT domain reverse transcribes the template into the DNA strand, and finally the DNA is repaired. In PE3, a second gRNA nicks the nonedited strand to favor repair using the newly edited DNA (Fig. 2F).

Like BEs, PE benefits from the ability to avoid DSBs. Indel formation is much lower than that of normal Cas9 $\mathrm{HDR}$, and is comparable with BE. The second strength of prime editing lies in its specificity. To properly introduce the desired mutation, the target DNA must contain both a compatible protospacer region and complementarity to the PBS. This stringency results in significantly lower off-target mutations, with the investigators reporting $<1 \%$ at predicted sites. The pegRNA also imparts PE's main restriction: The length of the template has an upper limit. The PE system is suited to small-scale edits, with successful insertions up to $44 \mathrm{bp}$ and deletions up to 80 bp (Anzalone et al. 2019).

PE was recently used in mice, by injecting mRNA encoding the PE3 system into one-cell embryos (Liu et al. 2020b). One locus yielded correct editing in 10\%-27\% of live pups; however, no successful editing was observed at a second locus. Additionally, indel frequency was low $(<0.3 \%)$, while targeted deep sequencing and whole-genome sequencing found no off-target editing. The major problem noted by the investigators was the fidelity of the edit in embryos, as unintended conversions at the targeted base were observed. The investigators concluded that prime editing shows promise as a highly specific mechanism for gene editing in mice, however the accuracy of the editing may need improvement alongside substantial screening of pegRNAs (Liu et al. 2020b).

\section{In vivo delivery of CRISPR/Cas systems}

Successful editing requires careful consideration on the delivery of CRISPR/Cas machinery. The Cas enzyme and gRNA are delivered in one of three forms: plasmid DNA, RNA, or in complex as ribonucleoproteins (RNPs). A single plasmid containing Cas and gRNA sequences can be used (Cong et al. 2013; Mali et al. 2013), but may result in several potential drawbacks. The delay in editing is on the order of several hours, as the enzyme needs to be transcribed and translated. The window of editing can also be quite long, as the plasmid persists, resulting in prolonged expression and greater off-target risk. Additionally, the plasmid may randomly integrate into the genome. Delivering the components as RNA is less risky as it reduces the potential of prolonged expression or genomic integration and editing proceeds sooner once the mRNA is translated. A drawback is that the gRNA is exposed to native RNA degradation machinery, which could reduce efficiency. Chemically modified gRNAs can be acquired commercially to improve stability. The method considered to support the highest efficiency, while reducing off-target effects, is the delivery of Cas nuclease and gRNA as an RNP complex (Sung et al. 2014; Liang et al. 2015; Zuris et al. 2015; Gertsenstein and Nutter 2018). The complexes consist of a single Cas9 nuclease and a single gRNA molecule and are precomplexed in vitro before delivery, typically using 1:1.1 molar ratio of Cas9:gRNA (Gertsenstein and Nutter 2018). Editing begins upon nuclear localization, the gRNA is protected from degradation by the Cas nuclease, and the limited supply of RNP reduces the window of editing, resulting in fewer off-target mutations. However, while many Cas variants are commercially available as protein, the majority of engineered Cas9 and Cas12a enzymes are only available as plasmids, adding the necessary steps of protein production, purification, and activity verification.

Once the CRISPR/Cas payload is determined, the system must be efficiently delivered. The means of delivery will differ depending on the goal of the experiment; however, two main strategies are commonly used when attempting to create an in vivo model. The first is electroporation, an efficient method of transferring DNA into a large quantity of cells. Similar to gene targeting, mESCs can be electroporated to deliver the CRISPR/Cas reagents. Individual colonies of mESCs can be screened for proper editing before being injected into blastocysts. Alternatively, electroporation can be used to transfer CRISPR/Cas reagents directly into zygotes. The zygote electroporation of nuclease (ZEN) technique can deliver Cas9 RNP and ssDNA via a high-throughput workflow, yielding knock-in rates of correct mutations in over $40 \%$ of living pups (Qin et al. 2015; Wang et al. 2016b). A similar protocol, CRISPR RNP electroporation of zygotes (CRISPR-EZ), also uses RNP and ssDNA, reporting successful HDR in $42 \%$ of live pups (Chen et al. 2016). Alternatively, the improved genome-editing via oviductal nucleic acids delivery (i-GONAD) technique uses direct electroporation of the oviduct in pregnant females to induce CRISPR/Cas editing without ex vivo manipulation of zygotes (Takahashi et al. 2015; Ohtsuka et al. 2018; Kobayashi et al. 2020; Sato et al. 2020). These protocols highlight the strength of electroporation: high-throughput processing of embryos without requiring as much technical expertise as direct injection. Of note, both ZEN and CRISPR-EZ use ssDNA; larger mutations requiring a dsDNA donor may not be feasible.

The second delivery strategy is direct physical injection into embryos (Shen et al. 2013; Wang et al. 2013; Yang et al. 2013; Gertsenstein and Nutter 2018). Injection requires technical expertise but can achieve some of the highest rates of successful CRISPR/Cas9 editing. CRISPR/Cas reagents can be injected either into the cytosol or the nucleus. Pronuclear injection can yield the highest efficiency as the reagents are physically delivered directly to the site of editing. This efficiency is 
potentiated when used in conjunction with RNPs as editing can begin within minutes. Cytosolic injection can still achieve high rates of successful HDR without the need for Nomarski optics. However, the most opportune time for injection, yielding the greatest efficiencies, is debated.

Timing of delivery is indeed important, as homologous recombination occurs predominantly in the late $S$ and G2 phases. Chemical synchronization of the cell cycle was examined in HEK293T cells and indicated that increased HDR efficiency could be achieved via synchronization up to roughly $33 \%$ when nucleofecting RNP at the G2 stage (Lin et al. 2014). While chemical synchronization can be used for cell culture, these techniques cannot be used in embryos, although embryos may be more synchronized if produced by in vitro fertilization. Microinjection during the two-cell stage could increase efficiency, as the G2 phase is prolonged $(\sim 12 \mathrm{~h})$ and coincides with zygotic genome activation, providing a more open chromatin configuration. Editing efficiency up to $35 \%$ was observed for insertion of a fluorescent tag when injecting at the two-cell stage compared with $6.5 \%$ in zygotes $(\mathrm{Gu}$ et al. 2018). Conversely, a recent paper compared pronuclear injection at various time points during both the one-cell and two-cell zygote stages and reported the most successful knock-in efficiencies at pronuclear stages 3 and 4 of the one-cell embryo, corresponding to $S$ phase when the paternal and maternal DNA are replicating, prior to the fusion of the pronuclei. Additionally, injecting into a single pronucleus can only result in a heterozygote, while injecting into both pronuclei can result in a homozygote (Abe et al. 2020). This can be particularly useful when attempting to create alleles that may be nonfunctional in essential genes, as homozygous zygotes would not survive development.

Alternatively, lipid- and viral-mediated transfection have both been used for CRISPR/Cas editing. Lipid-mediated transfection is predominantly used in cell culture (Ran et al. 2013b), and can effectively transport DNA, RNA, or RNP across the cell membrane (Zuris et al. 2015). Once optimized, transfection is an efficient method for introducing CRISPR/Cas editing in cell culture and can be used to assess the efficacy of gRNAs prior to embryo editing. Conversely, viral-mediated transfection is mainly used for editing in somatic tissues (Yeh et al. 2020; Zhang et al. 2020c), although it has been used to edit embryos for certain applications (Mizuno et al. 2018; Romeo et al. 2020). Adeno-associated viruses (AAVs) are commonly used to deliver DNA encoding the Cas nuclease and gRNA; however, smaller Cas9 homologs are better suited due to space limitation within the viral envelope (Wang et al. 2020a).

\section{HR, CRISPR, and generating specific alleles}

Traditional homologous recombination and newer CRISPR-centric techniques are both capable of generating most common modified mouse alleles, so the questions naturally arise: Which is better and should this be done in mESCs or zygotes? We refrain from providing an out- right recommendation here, as the desired allele, available laboratory expertise and reagents, and nature of available transgenic facilities will yield many different answers. However, we first evaluate tradeoffs between the approaches, before briefly reviewing common classes of transgenic mouse alleles and relevant points for making them by HR or CRISPR.

A recent study (Rezza et al. 2019) compared traditional HR and CRISPR/Cas9 in mESCs across 128 loci in the mouse genome. The investigators defined two measures to assess targeting: discovery index, describing the ability to produce mutant clones, and validation index, describing the number of correct mutant clones. They found that at every locus tested, CRISPR/Cas had a significantly higher discovery index, albeit a lower validation index compared with traditional HR. HR yielded correct bands in $99.5 \%$ of clones, while CRISPR/Cas yielded $92.4 \%$. However, the investigators note that CRISPR/Cas showed higher efficiency when inserting sequences $>8 \mathrm{~kb}$.

When using traditional gene targeting, each mESC clone contains a single recombination event on one of two homologous chromosomes that is validated prior to blastocyst injection. On the other hand, CRISPR/Cas has the potential to create two distinct mutant alleles, one on each homologous chromosome, in a single cell or zygote. This is an especially relevant concern for knockout alleles, as each NHEJ event will be uniquely repaired. Additionally, CRISPR/Cas reagents injected into a zygote can continue to edit for as long as they persist, resulting in more than two different mutant alleles if editing occurs after the one-cell stage (Yen et al. 2014).

However, despite the comforting known quantity aspect of traditional HR, CRISPR has two enormous advantages over its tried and true forebear. First, the ability to perform in embryo editing allows researchers to bypass mESCs altogether, yielding significant time and cost savings (Fig. 3). Second, the increase in editing efficiency means repair sequences do not need to contain a positive selection marker and genome edits can be made to produce a "clean" allele without leaving any exogenous sequence behind (Fig. 4). One caveat is that the relatively lower efficiency of obtaining large insertions by CRISPR may still limit one or both of these advantages for the time being.

\section{Null alleles}

One of the most common goals in mouse genetics is to interrogate gene function by generating a complete loss-offunction, or null allele. Indeed, the KOMP was established to generate a null mutant for every mouse gene (Austin et al. 2004). Null alleles can be generated by removal of one or several exons, or creation of short indel mutations that cause a frameshift in the resulting transcript leading to NMD. Such efforts are typically focused at the $5^{\prime}$ end of genes to increase the chances of NMD and reduce the chance of making a mutation that results in a truncated protein that retains some function. Prospective null alleles should be verified by RNA and/or protein expression analysis to confirm there is no residual gene product and the allele is therefore a true null. An alternative approach 


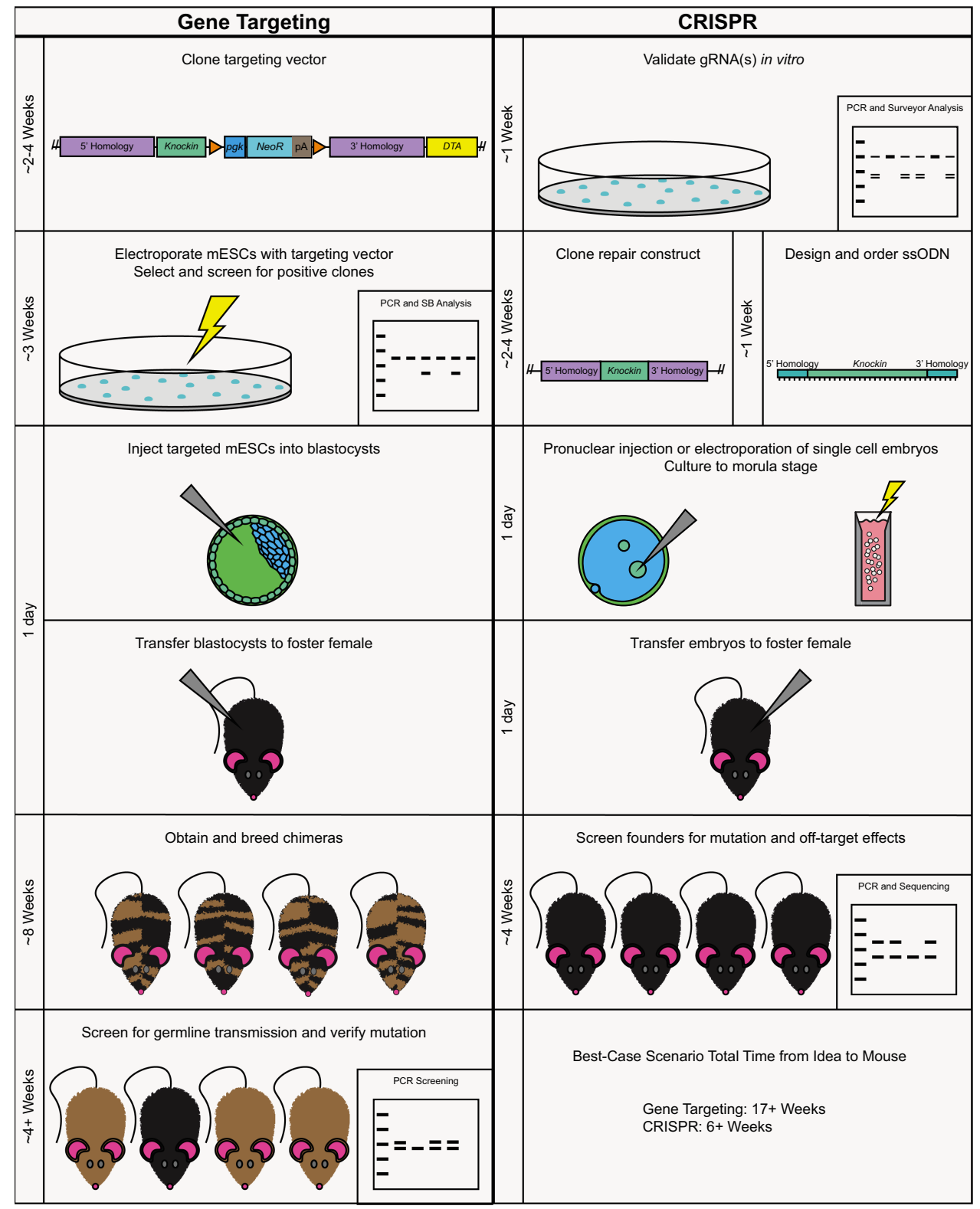

Figure 3. Typical workflow. The typical workflow required for the creation of a mouse model varies between gene targeting or CRISPR. For gene targeting, mESC clones should be screened via PCR and Southern blot to verify correct integration prior to injection into blastocysts. Chimeras are chosen based on coat color contribution and bred. Their pups are then screened via PCR /and coat color if crossing to a different strain) for germline transmission of the intended mutation. For CRISPR, gRNA cutting efficiency should be verified via PCR and Surveyor (or T7E1) assays. After introducing the CRISPR reagents to embryos, founder pups should be screened for both the correct mutation and any off-target effects. CRISPR has the potential to significantly reduce the time needed to create a mouse model.

is to delete all (or most) exons of a gene and thereby prevent any expression whatsoever. While this method assuredly creates a null allele, the lost DNA may include regulatory regions that affect other genes or encode microRNAs. A recent report described a mechanism of genetic compensation, whereby degraded mRNA transcripts lead to the up-regulation of related genes, blunting the impact of the mutation (El-Brolosy et al. 2019). Conversely, alleles that transcribe no mRNA at all do not exhibit this phenomenon and have comparatively stronger phenotypes. The extent of this effect across existing mouse strains is not currently known, but will be worth accounting for when designing future knockout mice, particularly if the gene has closely related paralogs. According to MGI, 14,981 genes have mutant mouse alleles and a further 6937 genes are mutated in mESC lines, so assessing existing models is an important first step in any new mouse genetic research project. However, depending on the nature of the allele and the genetic background of the strain it was generated in, researchers may still prefer generating their own knockout, even if one already exists. 


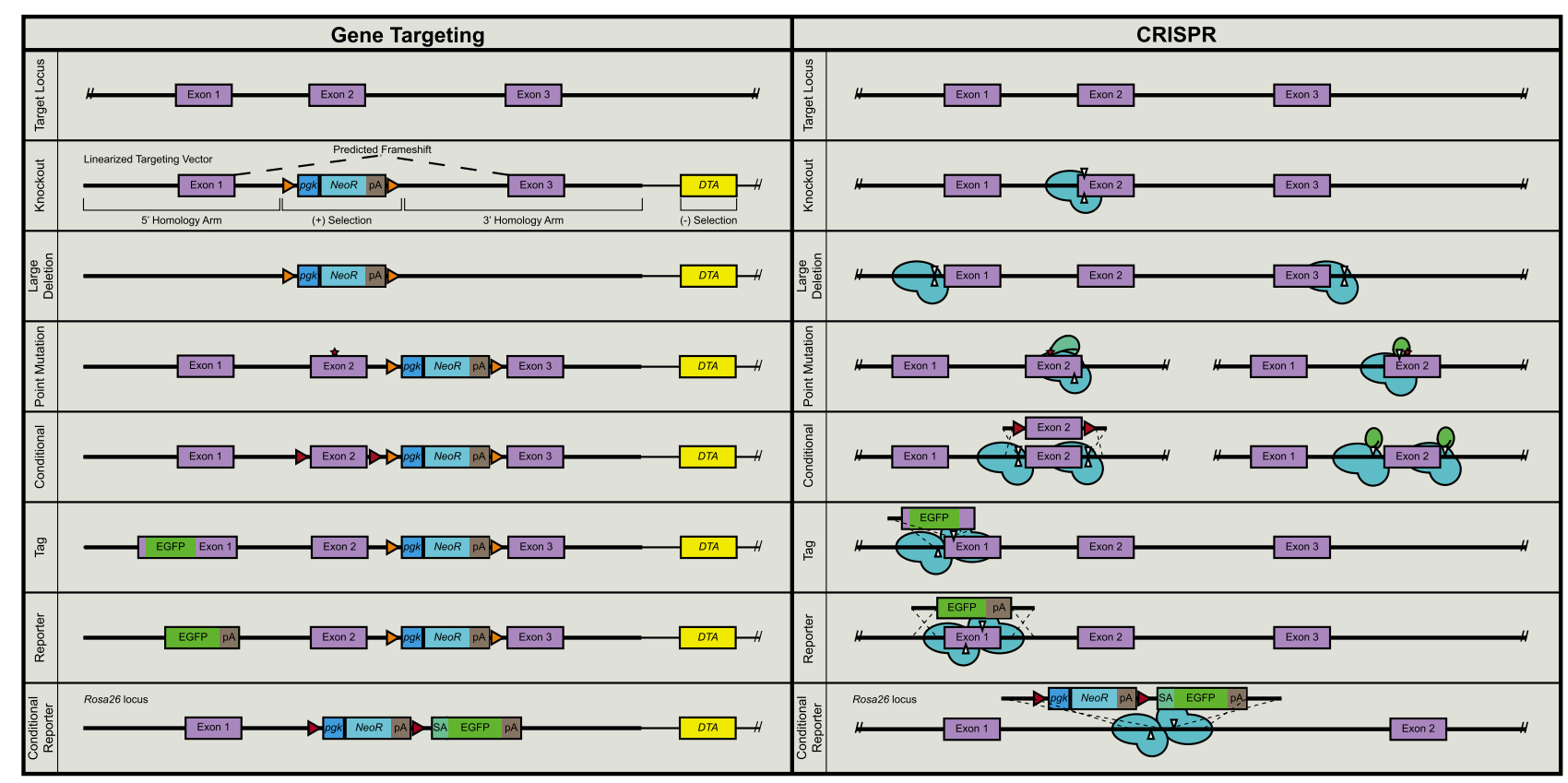

Figure 4. Designing alleles via gene targeting or CRISPR/Cas. Various genetic alterations can be constructed using either gene targeting or CRISPR. Gene targeting constructs typically consist of sequence containing the intended edit and a positive selection marker flanked by homology arms to facilitate integration. A negative selection marker is located outside of the homology arms to select against random insertion. For CRISPR, repair constructs are mainly used for conditional, tag, and reporter alleles and do not require the use of selection markers. Base or prime editing systems can be used for smaller point mutations. The conditional reporter is depicted here at the commonly targeted ROSA26 locus using a splice acceptor (SA) to drive the reporter off the endogenous promoter. Alternatively, an exogenous promoter such as CAG can be used. Orange triangles represent FRT sites, red triangles are loxP sites, red stars are point mutations, single white triangles are nicks, and double white triangles are DSBs.

For traditional HR gene targeting to induce a frameshift through exon deletion, a repair construct would be used to replace the targeted exon with a selection cassette flanked by SSR sites (Fig. 4). When using CRISPR/Cas, two strategies to induce a frameshift are available. The first involves using a single gRNA to induce a DSB within an exon (or two gRNAs with Cas9n), with the goal of making an indel that causes an early stop codon. The sequence of the exon should be examined for potential stops induced by frameshifts downstream from the DSB, as short genes especially may be unlikely to generate an NMD-causing mutation. The alternative method is to use gRNAs that flank an exon, ideally resulting in the deletion of the exon. When using Cas9n, this approach would require four different gRNAs, which may impose limitations on the ability to design efficient gRNAs while reducing off-target effects, potentially negating the benefit of using Cas9n.

To delete an entire gene, HR repair constructs can be built with homology arms using sequence from either side of a gene and a resistance cassette in between where the gene would otherwise be. Regions up to $40 \mathrm{~kb}$ were consistently deleted via HR by Regeneron using a process termed VelociGene, as part of the KOMP, so this approach is accessible by HR for many genes (Valenzuela et al. 2003; Bradley et al. 2012). Larger regions can be deleted by knocking in widely spaced lox $P$ sites (see below) and expressing Cre recombinase, but this approach requires multiple rounds of targeting (Ramirez-Solis et al. 1995).
CRISPR/Cas targeting at two distant sites and deletion of the intervening sequence has been demonstrated in mouse embryos at the kilobase and megabase scales (Kato et al. 2017; Dumeau et al. 2019). The repaired allele can be made somewhat more predictable using a short donor that bridges the intended deletion. CRISPR/Cas provides an overall simple approach to creating a knockout allele; however, the alleles recovered in each individual will vary, requiring screening, sequencing, and functional analysis to verify that the modification results in a null. Another consideration is whether the targeted gene is essential, as CRISPR/Cas may edit both copies of the gene, resulting in inviable mice. To overcome this, it may be beneficial to inject only one pronucleus during the single cell stage, injecting one cell at the two-cell stage, or carefully titrating the RNP dose. Conversely, using traditional gene targeting would guarantee that each founder had an identical heterozygous mutation.

\section{Point mutations}

It is also possible to engineer precise edits to the mouse genome using HR or CRISPR-based strategies (Fig. 4). In traditional gene targeting, the targeting vector contains the intended mutation in close proximity to the selection cassette, which is flanked by SSR sites for later removal with a recombinase such as Cre. For CRISPR/Cas targeting, the reagents are supplied along with a short donor sequence, 
usually a ssODN, harboring the mutation, and if necessary, additional silent mutations in the PAM or recognition sequence to prevent postrepair recutting. If compatible, a base or prime editor system can be used to change the nucleotide without introducing a DSB or repair construct, and would ideally reduce indel formation compared with traditional CRISPR/Cas9. This type of allele is one where CRISPR may have a decided advantage as short ssDNA donors can be produced commercially in just days or weeks. Furthermore, even after removal of the resistance cassette using an SSR such as Cre (see "Conditional Mutations" below), some residual exogenous sequence will remain and even these short sequences can interfere with gene expression (Meier et al. 2010). The ability to introduce targeted point mutations is a powerful complement to the semi-random point mutations obtained in ENU mutagenesis screens, as they allow a researcher to leverage biochemical, structural, and genomic knowledge in an organismal context under the control of endogenous regulatory elements. Point mutations impart a degree of experimental subtlety to reveal biology that may be missed with a simple knockout. Indeed, point mutations have been used to tremendous effect, enabling the introduction and correction of disease mutations (Zeiher et al. 1995; Long et al. 2014), mutation of regulatory binding sites (Arango et al. 1999; Soukup et al. 2019), phospho-mimetic and phospho-dead mutations (Heuchel et al. 1999; Aubin et al. 2004), kinase and other enzymatic-activating or inactivating mutations /Olson and Soriano 2009; Yamagata et al. 2009), and allelic series that systematically test individual binding or regulatory sites on a single protein (Klinghoffer et al. 2002; Tallquist et al. 2003; Brewer et al. 2015).

\section{Knock-ins and tagging}

The coding sequence of genes can be similarly extended or replaced using traditional gene targeting or CRISPR-based methods, the only difference being the nature of the targeting vector or donor sequence. This approach can be used to add a tag or fluorescent protein to a gene, generating a fusion protein that can enable biochemical, localization, expression, imaging, and sorting experiments. These are typically added at the $5^{\prime}$ or $3^{\prime}$ end of a gene along with a short flexible linker to alleviate any steric hindrances; however, with careful planning and detailed knowledge of a gene's protein structure such tags can also be added internally. Another use is to replace a gene with a paralog or functionally related gene (Hanks et al. 1995; Wang et al. 1996), an ortholog from another species (Hanks et al. 1998; Geng et al. 1999), perform domain swapping between genes (Klinghoffer et al. 2001), or insert a human disease allele (Wheeler et al. 1999; Leissring et al. 2000). This is sometimes possible by knocking in one or a few replacement exons, but becomes unwieldy if the entire gene must be replaced and especially so if the endogenous regulation is to be maintained. In these cases, knock-in of a complete or partial cDNA along with a splice acceptor creates a hybrid transcript that expresses the desired protein product. However, this can affect gene expression by bypassing any splicing-mediated regulation (Hoch and Soriano 2006). Therefore, a control cDNA should always be knocked in in a separate mouse strain to control for this effect (Klinghoffer et al. 2001). Knock-in-knockout strategies replace a gene or the first exon with an alternative gene, such as a reporter, which allows simultaneous study of gene expression and loss-of-function analysis (Le Mouellic et al. 1990; Mansour et al. 1990). Finally, genes can be knocked in to a locus and expressed as a separate protein from a single transcript, thus leaving the original gene product relatively unaffected. This can be achieved by inserting a sequence at the $3^{\prime}$ end of a gene in-frame, with a self-cleaving peptide sequence (e.g., P2A) in between, or with a virally derived internal ribosome entry sequence (IRES) that allows independent translation of the two genes from a dicistronic transcript (Mountford et al. 1994; Kim et al. 2011).

When using traditional gene targeting to create a knockin or tagged allele, the repair construct should contain the modification or tag of choice (fluorescent protein, epitope, etc.) aligned within the same reading frame as the targeted protein, along with a selection cassette flanked by SSR sites (Fig. 4). When using CRISPR/Cas, the size of the knock-in dictates the method used. For smaller tags, the prime editing system can be used to insert up to $\sim 45 \mathrm{bp}$ without inducing a DSB. The prime editor holds promise as an accurate and efficient method to insert small tags. However, if the insert is larger, a lssDNA $(\sim 1-$ to $1.5-\mathrm{kb})$ or dsDNA (>1.5-kb) repair template can be used alongside traditional CRISPR/Cas9. Large, complex knock-ins may benefit from CRISPR/Cas editing in mESCs to facilitate screening rather than direct injection into zygotes.

\section{Conditional mutations}

A common goal of researchers is to achieve spatiotemporal control over gene expression. One approach is to place genes under the control of drugs that can be administered to mice. The tetracycline-controlled trans-activator protein (tTA) and related reverse tTA (rtTA) system can be used in mice to repress or activate genes, respectively, in response to the drug doxycycline (Furth et al. 1994; Kistner et al. 1996). The gene of interest is put under control of a tetracycline responsive element and crossed to a mouse expressing tTA/rtTA, sometimes under control of a tissue-specific promoter. This system enables reversible activation or repression of a gene in a time- and dosedependent manner. Several updates have been made to the original system to enhance its usefulness in mice, making the system both less leaky and more sensitive to doxycycline for greater dynamic range and accessibility in hard-to-drug tissue; for instance, the central nervous system, where crossing the blood-brain barrier is limiting for many small molecules (Dow et al. 2014; Das et al. 2016). Another approach for conditional control of gene expression uses the yeast-derived GAL4-UAS system, where GAL4 activator is expressed by a tissue-specific promoter and drives expression of a gene controlled by GAL4-responsive UAS elements (Ornitz et al. 1991). However, this system did not achieve the same popularity in the 
mouse as it did in the fly and there were several reports of GAL4-induced toxicity (Habets et al. 2003; Govindarajan et al. 2005).

More commonly, spatiotemporal control is achieved through the use of SSRs (Branda and Dymecki 2004). These enzymes mediate recombination between short recognition sequences that can be inserted into specific genetic loci via HR. Recognition sequences have an intrinsic directionality such that the recombinase will loop out and delete the sequence between two recognition sequences oriented in parallel. Antiparallel recognition sites can be used to create inversions and this approach has been used to generate balancer chromosomes, discussed above (Ramirez-Solis et al. 1995).

Conditional knockouts are made by flanking a critical exon or exons of a gene with recognition sites (Fig. 4). Expression of the recombinase deletes the flanked region either creating a truncated protein, or more typically, introducing a frameshift that causes NMD and thus a null allele. Naturally, this approach can also be used to flank entire genes or genomic regions, as well as regulatory sequences, with the caveat that efficiency of recombination generally decreases with increasing distance between recognition sequences (Coppoolse et al. 2005; Liu et al. 2013). Genes can also be conditionally activated by placing a STOP signal, such as tandem polyA motifs or a resistance marker, between the promoter and the coding sequence of the gene to be expressed. Removal of the intervening STOP by the SSR enables expression of the gene. This strategy can be used to overexpress (or express mutant forms of) genes to study their function (Chan et al. 2004), mark cells with expression of LacZ or EGFP for lineage tracing or cell sorting (Soriano 1999; Abe and Fujimori 2013), exert optogenetic control over signaling (Deisseroth 2011), express signaling sensors such as calcium indicators (Chen et al. 2013), or to kill cells by expression of DTA (Voehringer et al. 2008).

Expression of the SSR (or tTA/rtTA) is achieved by creating a separate mouse line and then crossing the two. The SSR line is often made as a transgene that inserts semirandomly into the genome, but whose expression is driven by a promoter and regulatory sequences that restrict expression to a tissue or cell type of interest. As for all transgenes, multiple founders should be screened for proper expression, especially to assure there is no misexpression in the male or female germline (Luo et al. 2020). Alternatively, SSRs can be knocked in to the locus of a gene with the desired expression pattern. This can purposely knock out the endogenous gene in the process or the SSR can be knocked in at the $3^{\prime}$ end creating a fusion transcript that codes for a self-cleaving peptide or IRES as discussed above (Michael et al. 1999; Lange et al. 2012). An alternative approach is to knock the SSR into a gene of interest not in the mouse genome, but in a bacterial artificial chromosome (BAC) that is then inserted into the mouse genome as a transgene, thereby retaining the desired regulatory activity without affecting the endogenous gene (Parkitna et al. 2009). Finally, exogenous genes can be targeted to so-called "safe harbor" loci, genomic sites where exogenous DNA can be intro- duced and stably expressed without being influenced by (or influencing) nearby genetic elements or disrupting a developmentally important gene, thus avoiding undesirable positional effects. The most popular safe harbor in the mouse is the ROSA26 locus, which disrupts a nonprotein-coding gene of unknown function, though several other safe harbors have been identified (Friedrich and Soriano 1991; Bronson et al. 1996; Zambrowicz et al. 1997; Beard et al. 2006; Hippenmeyer et al. 2010; Liu et al. $2018 b$ ). Identification of safe harbor sites will be important for gene therapy approaches and the mouse is currently the best organismal model for this effort (Papapetrou and Schambach 2016). In most cases, the above strategies can also be used to drive expression of any gene of interest, not only SSRs.

Temporal control can be further refined using the ERT/ERT2 system where the SSR is fused to a mutant estrogen receptor that retains it in the cytoplasm until the administration of tamoxifen (Feil et al. 1996; Indra et al. 1999). The degree of SSR-ERT activity can be tuned by the tamoxifen dose, number of doses, and route of administration (Park et al. 2008). High doses of tamoxifen can induce abortions in pregnant mice, an effect that can be offset by coadministration of progesterone (Nakamura et al. 2006). Nevertheless, dosing should be carefully controlled, particularly for embryonic recombination. Similar to tamoxifen-inducible systems, a fusion can be made between an SSR and a mutant progesterone receptor that is activated by administration of the synthetic steroid RU486, though this system is less widely used (Kellendonk et al. 1996). Alternatively, the SSR can be expressed by a promoter that is only active under certain conditions, such as an inflammatory stimulus, which is how the first conditional Cre allele was made (Kuhn et al. 1995). More recently, photoactivatable SSRs have been used successfully in mice (Schindler et al. 2015).

There is now a toolbox of multiple SSRs available for conditional genetics, but by far the most widely used is the Cre-lox system (Tsien et al. 1996). Cre recombinase is a bacteriophage-derived SSR that mediates recombination between 34-bp-long loxP sites. There are now over 3000 Cre recombinase-expressing mouse strains or mESC lines listed at MGI driven by hundreds of unique drivers, attesting to its usefulness. Extending Cre's capabilities, mutant loxP sites that do not recombine with the WT sequence or are inactivated after undergoing recombination can be used to generate gene expression switches (FLEx switches) or mediate efficient insertion of floxed DNA into a previously targeted genomic loxP site, respectively (Fukushige and Sauer 1992; Araki et al. 1997; Schnutgen et al. 2003). These have also been used to generate a lineage reporter that can mark two lineages, depending on the level of Cre activity (Klinger et al. 2010). Complementing Cre, the Flp-FRT (Dymecki 1996; Buchholz et al. 1998; Raymond and Soriano 2007), Dre-Rox (Anastassiadis et al. 2009), Vika-Vox (Karimova et al. 2018), Nigri-Nox (Liu et al. 2018a), and $\phi$ C31 SSR systems (Buchholz et al. 1998; Raymond and Soriano 2007) have all been validated or optimized for use in mice. These 
systems can be used in combination to mark multiple lineages or in intersectional genetic schemes to create sophisticated logic gates governing conditional gene expression (Awatramani et al. 2003; He et al. 2017; Soriano 2018; Liu et al. 2020a; Poulin et al. 2020). An alternative intersectional genetic strategy could use a split-Cre, where two fragments of the gene are expressed by different promoters and the protein is only reconstituted where expression overlaps (Hirrlinger et al. 2009).

To generate a conditional allele, a pair of SSR sites need to be inserted flanking an exon or gene for removal upon expression of the SSR. When using traditional HR gene targeting, a repair construct should contain the WT exon flanked by SSRs along with a selection cassette flanked by distinct SSR sites (e.g., loxP sites flanking the exon and FRT sites flanking the selection cassette). If using CRISPR/Cas to create a conditional allele, multiple methods may be considered. Early reports suggested that using two gRNAs alongside two ssODNs could be used to insert flanking SSR sites (Yang et al. 2013); however, correct insertion of both SSR sites on the same allele happens at a low frequency (Gurumurthy et al. 2019). A single lssDNA containing both SSR sites and the flanked exon can be used to ensure that both SSR sites are inserted in cis. Alternatively, a single SSR site can be inserted and once that mouse strain is screened and verified, a second SSR site can be inserted through a second round of CRISPR/ Cas editing. Although currently untested, the prime editor system may be able to insert flanking SSR sites through the codelivery of two pegRNAs. While this method suffers the same pitfalls as using unmodified Cas9, the decreased prevalence of indels may increase the overall efficiency. CRISPR/Cas has the potential to significantly reduce the time necessary for obtaining a conditional allele, however published efficiencies of simultaneously modifying two regions on the same allele are still quite low and will require future optimization.

\section{Lineage tracing and clonal analysis}

To study cell fate and mark distinct lineages, conditional expression of reporter alleles is now commonplace (Legué and Joyner 2010). There are an enormous number of mouse reporter lines that conditionally express an enzyme (e.g., lacZ) or fluorescent protein following expression of Cre or another SSR. This irrevocably marks all cells and their progeny and is often used to validate Cre lines, perform lineage analysis, and mark conditional mutant cells when used in conjunction with a conditional mutant allele. However, different reporters and mutant alleles can have varying rates of recombination, depending on both the distance between SSR recognition sequences and other less well-understood effects likely involving the local chromatin environment (Zheng et al. 2000; Vooijs et al. 2001), so such mice should be carefully analyzed to understand the degree of overlap between the marked (e.g., fluorescent) and mutant populations. This is especially important for tamoxifen-inducible systems where the window of recombination is limited or the goal is to mark very few cells for clonal analysis, as the limited number of events may highlight differences in efficiency that are otherwise overcome by a constitutively active Cre line. For particularly timing-sensitive experiments, it is worth noting that tamoxifen exhibits an $\sim 12$-hr delay to be converted to the active metabolite 4-hydroxytamoxifen (4-OHT) and delivered to embryonic tissue, after which it can remain active for hours or even days, depending on the dose, Cre line, and particular recombination (Nakamura et al. 2006). More rapid recombination can be induced by administering 4-OHT directly. Several systems that link reporter expression with loss of a mutant allele, assuring overlap between the two populations. Mosaic analysis with double markers (MADM) relies on Cremediated interchromosomal mitotic recombination to generate homozygous mutant and wild-type daughter cells from a heterozygous parent cell, while simultaneously marking mutant cells with a fluorescent protein (Zong et al. 2005). An alternate strategy, mosaic mutant analysis with spatial and temporal control of recombination (MASTR), uses FLP-ER to control expression of CreEGFP, which simultaneously marks cells and mediates recombination of any existing floxed conditional allele (Lao et al. 2012). Two recent tools for clonal analysis are worth pointing out. The first is the Brainbow and Confetti class of reporters, which uses pairs of variant and mutually incompatible lox sites to randomly express one or a combination of fluorescent proteins upon Cre expression, ideally using an inducible Cre, allowing multiple adjacent clones to be tracked (Livet et al. 2007; Snippert et al. 2010; Cai et al. 2013; Baggiolini et al. 2015). Second, CRISPRbased lineage tracing uses a CRISPR-induced mutation rather than expression of a marker to track cells. As cells divide during embryogenesis, mutations accumulate so that the lineage relationship and fate of these cells can be reconstructed using single-cell sequencing (Kalhor et al. 2018; Chan et al. 2019; Bowling et al. 2020; Wagner and Klein 2020).

When constructing reporter alleles, traditional gene targeting repair constructs typically contain a ubiquitous promoter driving the expression of a selection cassette flanked by SSR sites (Fig. 4). Further downstream is the reporter itself. When using CRISPR/Cas, due to the size of the reporter, a dsDNA or lssDNA donor will most likely be required. Using two gRNAs in conjunction with Cas9n would ideally yield fewer off-target mutations.

\section{Existing resources}

The fastest way to make any kind of mouse is if someone else has already made it for you. The best places to begin searching are at the International Mouse Strain Resource, which compiles strain information from multiple repositories, and the Mouse Genome Informatics database, which also contains a list of most of the existing alleles for a given gene, as well as phenotype and expression data, and a list of publications using each allele. These websites and additional resources, including mutagenesis consortia and mutant mouse repositories, are listed in Table 1. 


\section{The future of mouse genetics}

Charles Dickens opened A Tale of Two Cities by declaring, "It was the best of times, it was the worst of times." Although admittedly not as consequential as human travails during the French Revolution, the same sentiment could apply to mice during the current CRISPR revolution. In many ways, there has been no better time to make a mouse. Forty years of genetic lessons and tool building have now been supercharged so that new and more sophisticated genetic models can be made with less effort, cost, and time than ever before. However, CRISPR has also opened the door to making these same genetic edits, once the exclusive domain of mice, flies, worms, yeast, and bacteria, in any system that can express exogenous DNA or be injected with CRISPR RNP complexes. In particular, the stunning complexity seen in human ESC-derived organoids and gastruloids will certainly appeal to researchers interested in studying human disease, as this grants them a source of tissue, made of human cells, without the need to maintain a mouse colony (for review, see Simunovic and Brivanlou 2017). Traditional model organisms with certain superior embryological properties such as fish, frog, and chick can now be strong genetic systems, as well, not to mention the increasing number of nontraditional organisms that now vie for genetic attention (Reardon 2019). However, between the need to study development and disease in a living mammal, the existing unrivaled genetic toolkit, and its many advantageous characteristics for laboratory use, it is hard to see the mouse going away anytime soon (Lloyd et al. 2016). Rather than a passing of the torch, the age of CRISPR will be more like a sharing of the genetic spotlight. It is going to be quite a show.

\section{Glossary}

4-OHT: 4-hydroxytamoxifen

AAV: adeno-associated virus

ABE: adenine base editor

BAC: bacterial artificial chromosome

BE: base editor

Cas: CRISPR-associated protein

Cas9d: catalytically dead Cas9

Cas9n: Cas9 nickase

CBE: cytidine base editor

CRISPR: clustered regularly interspaced short palindromic repeats

CRISPR-EZ: CRISPR RNP electroporation of zygotes

crRNA: CRISPR RNA

DSB: double-stranded breaks

DTA: diptheria toxin fragment A

Easi-CRISPR: efficient additions with ssDNA inserts-CRISPR

ENU: N-ethyl-N-nitrosourea

G1: generation 1

G2: generation 2 or second growth phase

G3: generation 3

gRNA: guide RNA

HDR: homology-directed repair

HITI: homology-independent targeted integration

HR: homologous recombination

HSV-TK: herpes simplex virus-1 thymidine kinase
i-GONAD: improved genome editing via oviductal nucleic acids delivery

IRES: internal ribosome entry sequence

KOMP: knockout mouse project

lssDNA: long single-stranded DNA

MADM: mosaic analysis with double markers

MASTR: mosaic mutant analysis with spacial and temporal control of recombination

mESCs: murine embryonic stem cells

MGI: mouse genome informatics

NHEJ: nonhomologous end joining

NMD: nonsense-mediated decay

ODN: oligodeoxynucleotide

PAM: protospacer-adjacent motif

PBS: primer-binding sequence

PCR: polymerase chain reaction

PCV: porcine circovirus 2 rep

PE: prime editor

pegRNA: prime-editing gRNA

RNP: ribonucleoprotein

RT: reverse transcriptase

SNP: single nucleotide polymorphism

SSR: site-specific recombinase

SV40: simian virus 40

TALEN: transcription activator-like effector nuclease

Tild-CRISPR: targeted integration with linearized dsDNACRISPR

tracrRNA: transactivating CRISPR RNA

tTA: tetracycline-controlled trans-activator protein

UAS: upstream activation sequence

UGI: uracil DNA glycosylase inhibitor

UTR: untranslated region

ZEN: zygote electroporation of nuclease

ZFN: zinc finger nuclease

\section{Acknowledgments}

We thank Yas Furuta, Alex Joyner, Kevin Kelley, Chris Raymond, and our laboratory colleagues for critical comments on the manuscript. We apologize to the many colleagues whose work we could not cite, due to space limitations. J.F.C. and C.J.D. are supported by F32 DE029387 and DE026678, respectively, from the National Institute of Dental and Craniofacial Research (NIDCR). Work in the authors' laboratory is supported by grants DE022363 and DE022778 from the NIDCR to P.S.

\section{References}

Abe T, Fujimori T. 2013. Reporter mouse lines for fluorescence imaging. Dev Growth Differ 55: 390-405. doi:10.1111/dgd .12062

Abe T, Inoue KI, Furuta Y, Kiyonari H. 2020. Pronuclear microinjection during S-phase increases the efficiency of CRISPRCas9-assisted knockin of large DNA donors in mouse zygotes. Cell Rep 31: 107653. doi:10.1016/j.celrep.2020.107653

Adli M. 2018. The CRISPR tool kit for genome editing and beyond. Nat Commun 9: 1911. doi:10.1038/s41467-018-04252-2

Agudelo D, Carter S, Velimirovic M, Duringer A, Rivest JF, Levesque S, Loehr J, Mouchiroud M, Cyr D, Waters PJ, et al. 2020. Versatile and robust genome editing with Streptococcus thermophilus CRISPR1-Cas9. Genome Res 30: 107-117. doi:10.1101/gr.255414.119

Aird EJ, Lovendahl KN, St Martin A, Harris RS, Gordon WR. 2018. Increasing Cas9-mediated homology-directed repair 
efficiency through covalent tethering of DNA repair template. Commun Biol 1: 54. doi:10.1038/s42003-018-0054-2

Anastassiadis K, Fu J, Patsch C, Hu S, Weidlich S, Duerschke K, Buchholz F, Edenhofer F, Stewart AF. 2009. Dre recombinase, like Cre, is a highly efficient site-specific recombinase in E. coli, mammalian cells and mice. Dis Model Mech 2: 508515. doi:10.1242/dmm.003087

Anders C, Bargsten K, Jinek M. 2016. Structural plasticity of PAM recognition by engineered variants of the RNA-guided endonuclease Cas9. Mol Cell 61: 895-902. doi:10.1016/j.molcel .2016 .02 .020

Anzalone AV, Randolph PB, Davis JR, Sousa AA, Koblan LW, Levy JM, Chen PJ, Wilson C, Newby GA, Raguram A, et al. 2019. Search-and-replace genome editing without doublestrand breaks or donor DNA. Nature 576: 149-157. doi:10 .1038/s41586-019-1711-4

Araki K, Araki M, Yamamura K. 1997. Targeted integration of DNA using mutant lox sites in embryonic stem cells. Nucleic Acids Res 25: 868-872. doi:10.1093/nar/25.4.868

Arango NA, Lovell-Badge R, Behringer RR. 1999. Targeted mutagenesis of the endogenous mouse Mis gene promoter: in vivo definition of genetic pathways of vertebrate sexual development. Cell 99: 409-419. doi:10.1016/S0092-8674(00)81527-5

Aubin J, Davy A, Soriano P. 2004. In vivo convergence of BMP and MAPK signaling pathways: impact of differential Smad1 phosphorylation on development and homeostasis. Genes Dev 18: 1482-1494. doi:10.1101/gad.1202604

Austin CP, Battey JF, Bradley A, Bucan M, Capecchi M, Collins FS, Dove WF, Duyk G, Dymecki S, Eppig JT, et al. 2004. The knockout mouse project. Nat Genet 36: 921-924. doi:10 $.1038 / \mathrm{ng} 0904-921$

Awatramani R, Soriano P, Rodriguez C, Mai JJ, Dymecki SM. 2003. Cryptic boundaries in roof plate and choroid plexus identified by intersectional gene activation. Nat Genet 35: 70-75. doi:10.1038/ng1228

Bae S, Park J, Kim JS. 2014. Cas-OFFinder: a fast and versatile algorithm that searches for potential off-target sites of Cas9 RNA-guided endonucleases. Bioinformatics 30: 1473-1475. doi:10.1093/bioinformatics/btu048

Baggiolini A, Varum S, Mateos JM, Bettosini D, John N, Bonalli M, Ziegler U, Dimou L, Clevers H, Furrer R, et al. 2015. Premigratory and migratory neural crest cells are multipotent in vivo. Cell Stem Cell 16: 314-322. doi:10.1016/j.stem.2015 .02 .017

Barrangou R, Fremaux C, Deveau H, Richards M, Boyaval P, Moineau S, Romero DA, Horvath P. 2007. CRISPR provides acquired resistance against viruses in prokaryotes. Science 315: 1709-1712. doi:10.1126/science. 1138140

Barrett RDH, Laurent S, Mallarino R, Pfeifer SP, Xu CCY, Foll M, Wakamatsu K, Duke-Cohan JS, Jensen JD, Hoekstra HE. 2019. Linking a mutation to survival in wild mice. Science 363: 499504. doi:10.1126/science.aav3824

Beard C, Hochedlinger K, Plath K, Wutz A, Jaenisch R. 2006. Efficient method to generate single-copy transgenic mice by sitespecific integration in embryonic stem cells. Genesis 44: 23-28. doi:10.1002/gene. 20180

Beckmann PJ, Largaespada DA. 2020. Transposon insertion mutagenesis in mice for modeling human cancers: critical insights gained and new opportunities. Int J Mol Sci 21: 1172. doi:10.3390/ijms21031172

Behringer RR, Gertsenstein M, Nagy KV, Nagy A. 2014. Manipulating the mouse embryo: a laboratory manual, 2nd edn. Cold Spring Harbor Press, Cold Spring Harbor, New York.

Bishop KA, Harrington A, Kouranova E, Weinstein EJ, Rosen CJ, Cui X, Liaw L. 2016. CRISPR/Cas9-mediated insertion of
loxP sites in the mouse Dock7 gene provides an effective alternative to use of targeted embryonic stem cells. G3 (Bethesda) 6: 2051-2061. doi:10.1534/g3.116.030601

Bitinaite J, Wah DA, Aggarwal AK, Schildkraut I. 1998. FokI dimerization is required for DNA cleavage. Proc Natl Acad Sci 95: 10570-10575. doi:10.1073/pnas.95.18.10570

Boch J, Scholze H, Schornack S, Landgraf A, Hahn S, Kay S, Lahaye T, Nickstadt A, Bonas U. 2009. Breaking the code of DNA binding specificity of TAL-type III effectors. Science 326: 1509-1512. doi:10.1126/science.1178811

Bowling S, Sritharan D, Osorio FG, Nguyen M, Cheung P, Rodriguez-Fraticelli A, Patel S, Yuan WC, Fujiwara Y, Li BE, et al. 2020. An engineered CRISPR-Cas9 mouse line for simultaneous readout of lineage histories and gene expression profiles in single cells. Cell 181: 1410-1422.e27. doi:10.1016/j.cell.2020 .04 .048

Bradley A, Evans M, Kaufman MH, Robertson E. 1984. Formation of germ-line chimaeras from embryo-derived teratocarcinoma cell lines. Nature 309: 255-256. doi:10.1038/309255a0

Bradley A, Anastassiadis K, Ayadi A, Battey JF, Bell C, Birling MC, Bottomley J, Brown SD, Burger A, Bult CJ, et al. 2012. The mammalian gene function resource: the international knockout mouse consortium. Mamm Genome 23: 580-586. doi:10 .1007/s00335-012-9422-2

Branda CS, Dymecki SM. 2004. Talking about a revolution: the impact of site-specific recombinases on genetic analyses in mice. Dev Cell 6: 7-28. doi:10.1016/S1534-5807(03)00399-X

Brewer JR, Molotkov A, Mazot P, Hoch RV, Soriano P. 2015. Fgfr1 regulates development through the combinatorial use of signaling proteins. Genes Dev 29: 1863-1874. doi:10.1101/gad .264994 .115

Brinster RL. 1974. The effect of cells transferred into the mouse blastocyst on subsequent development. I Exp Med 140: 1049-1056. doi:10.1084/jem.140.4.1049

Brinster RL, Chen HY, Trumbauer M, Senear AW, Warren R, Palmiter RD. 1981. Somatic expression of herpes thymidine kinase in mice following injection of a fusion gene into eggs. Cell 27: 223-231. doi:10.1016/0092-8674/81)90376-7

Brinster RL, Braun RE, Lo D, Avarbock MR, Oram F, Palmiter RD. 1989. Targeted correction of a major histocompatibility class II Ea gene by DNA microinjected into mouse eggs. Proc Natl Acad Sci 86: 7087-7091. doi:10.1073/pnas.86.18.7087

Bronson SK, Plaehn EG, Kluckman KD, Hagaman JR, Maeda N, Smithies O. 1996. Single-copy transgenic mice with chosensite integration. Proc Natl Acad Sci 93: 9067-9072. doi:10 $.1073 /$ pnas.93.17.9067

Buchholz F, Angrand PO, Stewart AF. 1998. Improved properties of FLP recombinase evolved by cycling mutagenesis. Nat Biotechnol 16: 657-662. doi:10.1038/nbt0798-657

Cai D, Cohen KB, Luo T, Lichtman JW, Sanes JR. 2013. Improved tools for the Brainbow toolbox. Nat Methods 10: 540-547. doi:10.1038/nmeth.2450

Carroll D. 2011. Genome engineering with zinc-finger nucleases. Genetics 188: 773-782. doi:10.1534/genetics.111.131433

Chan IT, Kutok JL, Williams IR, Cohen S, Kelly L, Shigematsu H, Johnson L, Akashi K, Tuveson DA, Jacks T, et al. 2004. Conditional expression of oncogenic K-ras from its endogenous promoter induces a myeloproliferative disease. J Clin Invest 113: 528-538. doi:10.1172/JCI20476

Chan MM, Smith ZD, Grosswendt S, Kretzmer H, Norman TM, Adamson B, Jost M, Quinn JJ, Yang D, Jones MG, et al. 2019. Molecular recording of mammalian embryogenesis. Nature 570: 77-82. doi:10.1038/s41586-019-1184-5

Chatterjee P, Lee J, Nip L, Koseki SRT, Tysinger E, Sontheimer EJ, Jacobson JM, Jakimo N. 2020. A Cas9 with PAM recognition 
for adenine dinucleotides. Nat Commun 11: 2474. doi:10 .1038/s41467-020-16117-8

Chen WV, Delrow J, Corrin PD, Frazier JP, Soriano P. 2004. Identification and validation of PDGF transcriptional targets by microarray-coupled gene-trap mutagenesis. Nat Genet 36: 304-312. doi:10.1038/ng1306

Chen TW, Wardill TJ, Sun Y, Pulver SR, Renninger SL, Baohan A, Schreiter ER, Kerr RA, Orger MB, Jayaraman V, et al. 2013. Ultrasensitive fluorescent proteins for imaging neuronal activity. Nature 499: 295-300. doi:10.1038/nature12354

Chen S, Lee B, Lee AY, Modzelewski AJ, He L. 2016. Highly efficient mouse genome editing by CRISPR ribonucleoprotein electroporation of zygotes. I Biol Chem 291: 14457-14467. doi: $10.1074 /$ ibc.M116.733154

Chen JS, Dagdas YS, Kleinstiver BP, Welch MM, Sousa AA, Harrington LB, Sternberg SH, Joung JK, Yildiz A, Doudna JA. 2017. Enhanced proofreading governs CRISPR-Cas9 targeting accuracy. Nature 550: 407-410. doi:10.1038/nature24268

Chen P, Zhou J, Wan Y, Liu H, Li Y, Liu Z, Wang H, Lei J, Zhao K, Zhang Y, et al. 2020. A Cas12a ortholog with stringent PAM recognition followed by low off-target editing rates for genome editing. Genome Biol 21: 78. doi:10.1186/s13059-020-01989-2

Christian M, Cermak T, Doyle EL, Schmidt C, Zhang F, Hummel A, Bogdanove AJ, Voytas DF. 2010. Targeting DNA doublestrand breaks with TAL effector nucleases. Genetics 186: 757-761. doi:10.1534/genetics.110.120717

Collier LS, Carlson CM, Ravimohan S, Dupuy AJ, Largaespada DA. 2005. Cancer gene discovery in solid tumours using transposon-based somatic mutagenesis in the mouse. Nature 436: 272-276. doi:10.1038/nature03681

Cong L, Ran FA, Cox D, Lin S, Barretto R, Habib N, Hsu PD, Wu $\mathrm{X}$, Jiang W, Marraffini LA, et al. 2013. Multiplex genome engineering using CRISPR/Cas systems. Science 339: 819-823. doi:10.1126/science.1231143

Coppoolse ER, de Vroomen MJ, van Gennip F, Hersmus BJ, van Haaren MJ. 2005. Size does matter: cre-mediated somatic deletion efficiency depends on the distance between the target lox-sites. Plant Mol Biol 58: 687-698. doi:10.1007/s11103005-7705-7

Costantini F, Lacy E. 1981. Introduction of a rabbit $\beta$-globin gene into the mouse germ line. Nature 294: 92-94. doi:10.1038/ 294092a0

Cuénot L. 1902. La loi de Mendel et l'hérédité de la pigmentation chez les souris. Arch Zool Exp Gen 10: xxvii-xxx.

Czechanski A, Byers C, Greenstein I, Schrode N, Donahue LR, Hadjantonakis AK, Reinholdt LG. 2014. Derivation and characterization of mouse embryonic stem cells from permissive and nonpermissive strains. Nat Protoc 9: 559-574. doi:10 $.1038 /$ nprot.2014.030

Das AT, Tenenbaum L, Berkhout B. 2016. Tet-on systems for doxycycline-inducible gene expression. Curr Gene Ther 16: 156167. doi:10.2174/1566523216666160524144041

Davis J, Maillet M, Miano JM, Molkentin JD. 2012. Lost in transgenesis: a user's guide for genetically manipulating the mouse in cardiac research. Circ Res 111: 761-777. doi:10.1161/CIR CRESAHA.111.262717

Deisseroth K. 2011. Optogenetics. Nat Methods 8: 26-29. doi:10 .1038/nmeth.f.324

de Jong J, Akhtar W, Badhai J, Rust AG, Rad R, Hilkens J, Berns A, van Lohuizen M, Wessels LF, de Ridder J. 2014. Chromatin landscapes of retroviral and transposon integration profiles. PLoS Genet 10: e1004250. doi:10.1371/journal.pgen .1004250

Deltcheva E, Chylinski K, Sharma CM, Gonzales K, Chao Y, Pirzada ZA, Eckert MR, Vogel J, Charpentier E. 2011. CRISPR
RNA maturation by trans-encoded small RNA and host factor RNase III. Nature 471: 602-607. doi:10.1038/nature09886

Deng C, Capecchi MR. 1992. Reexamination of gene targeting frequency as a function of the extent of homology between the targeting vector and the target locus. Mol Cell Biol 12: 3365-3371. doi:10.1128/MCB.12.8.3365

Dickinson ME, Flenniken AM, Ji X, Teboul L, Wong MD, White JK, Meehan TF, Weninger WJ, Westerberg H, Adissu $\mathrm{H}$, et al. 2016. High-throughput discovery of novel developmental phenotypes. Nature 537: 508-514. doi:10.1038/ nature 19356

Ding S, Wu X, Li G, Han M, Zhuang Y, Xu T. 2005. Efficient transposition of the piggyBac $(\mathrm{PB})$ transposon in mammalian cells and mice. Cell 122: 473-483. doi:10.1016/j.cell.2005.07 .013

Doetschman T, Gregg RG, Maeda N, Hooper ML, Melton DW, Thompson S, Smithies O. 1987. Targeted correction of a mutant HPRT gene in mouse embryonic stem cells. Nature 330: 576-578. doi:10.1038/330576a0

Donoho G, Jasin M, Berg P. 1998. Analysis of gene targeting and intrachromosomal homologous recombination stimulated by genomic double-strand breaks in mouse embryonic stem cells. Mol Cell Biol 18: 4070-4078. doi:10.1128/MCB.18.7 .4070

Dow LE, Nasr Z, Saborowski M, Ebbesen SH, Manchado E, Tasdemir N, Lee T, Pelletier J, Lowe SW. 2014. Conditional reverse tet-transactivator mouse strains for the efficient induction of TRE-regulated transgenes in mice. PLoS One 9: e95236. doi:10.1371/journal.pone.0095236

Dumeau CE, Monfort A, Kissling L, Swarts DC, Jinek M, Wutz A. 2019. Introducing gene deletions by mouse zygote electroporation of Cas12a/Cpf1. Transgenic Res 28: 525-535.

Dupuy AJ, Akagi K, Largaespada DA, Copeland NG, Jenkins NA. 2005. Mammalian mutagenesis using a highly mobile somatic sleeping beauty transposon system. Nature 436: 221-226. doi:10.1038/nature03691

Dymecki SM. 1996. Flp recombinase promotes site-specific DNA recombination in embryonic stem cells and transgenic mice. Proc Natl Acad Sci 93: 6191-6196. doi:10.1073/pnas.93.12 .6191

Edraki A, Mir A, Ibraheim R, Gainetdinov I, Yoon Y, Song CQ, Cao Y, Gallant J, Xue W, Rivera-Perez JA, et al. 2019. A compact, high-accuracy Cas9 with a dinucleotide PAM for in vivo genome editing. Mol Cell 73: 714-726.e4. doi:10.1016/j .molcel.2018.12.003

El-Brolosy MA, Kontarakis Z, Rossi A, Kuenne C, Gunther S, Fukuda N, Kikhi K, Boezio GLM, Takacs CM, Lai SL, et al. 2019. Genetic compensation triggered by mutant mRNA degradation. Nature 568: 193-197. doi:10.1038/s41586-0191064-z

Eppig JT, Motenko H, Richardson JE, Richards-Smith B, Smith CL. 2015. The international mouse strain resource (IMSR): cataloging worldwide mouse and ES cell line resources. Mamm Genome 26: 448-455. doi:10.1007/s00335-015-9600-0

Evans MJ, Kaufman MH. 1981. Establishment in culture of pluripotential cells from mouse embryos. Nature 292: 154-156. doi: $10.1038 / 292154 \mathrm{a} 0$

Farzaneh F, Mirzapoor Z, Jahangirian E, Heidari F, Hashemi E, Rahim-Tayefeh A, Fatemi N, Jamshidizad A, Dashtizad M, Shamsara M. 2019. The chicken hypersensitive site-4 insulator cannot fully shield the murine phosphoglycerate kinase-1 promoter from integration site effects in transgenic mice. 3 Biotech 9: 255. doi:10.1007/s13205-019-1786-5

Feil R, Brocard J, Mascrez B, LeMeur M, Metzger D, Chambon P. 1996. Ligand-activated site-specific recombination in mice. 
Proc Natl Acad Sci 93: 10887-10890. doi:10.1073/pnas.93.20 .10887

Feng Y, Zhang S, Huang X. 2014. A robust TALENs system for highly efficient mammalian genome editing. Sci Rep 4: 3632. doi:10.1038/srep03632

Fiering S, Epner E, Robinson K, Zhuang Y, Telling A, Hu M, Martin DI, Enver T, Ley TJ, Groudine M. 1995. Targeted deletion of $5^{\prime} \mathrm{HS} 2$ of the murine $\beta$-globin LCR reveals that it is not essential for proper regulation of the $\beta$-globin locus. Genes Dev 9: 2203-2213. doi:10.1101/gad.9.18.2203

Folger KR, Wong EA, Wahl G, Capecchi MR. 1982. Patterns of integration of DNA microinjected into cultured mammalian cells: evidence for homologous recombination between injected plasmid DNA molecules. Mol Cell Biol 2: 1372-1387. doi:10.1128/MCB.2.11.1372

Friedel RH, Soriano P. 2010. Gene trap mutagenesis in the mouse. Methods Enzymol 477: 243-269. doi:10.1016/S0076-6879(10) 77013-0

Friedel RH, Plump A, Lu X, Spilker K, Jolicoeur C, Wong K, Venkatesh TR, Yaron A, Hynes M, Chen B, et al. 2005. Gene targeting using a promoterless gene trap vector ('targeted trapping') is an efficient method to mutate a large fraction of genes. Proc Natl Acad Sci 102: 13188-13193. doi:10.1073/ pnas.0505474102

Friedrich G, Soriano P. 1991. Promoter traps in embryonic stem cells: a genetic screen to identify and mutate developmental genes in mice. Genes Dev 5: 1513-1523. doi:10.1101/gad.5.9 .1513

Fukuda M, Inoue M, Muramatsu D, Miyachi H, Shinkai Y. 2016. Knockout mouse production assisted by Blm knockdown. I Reprod Dev 62: 121-125. doi:10.1262/jrd.2015-122

Fukushige S, Sauer B. 1992. Genomic targeting with a positive-selection lox integration vector allows highly reproducible gene expression in mammalian cells. Proc Natl Acad Sci 89: 79057909. doi:10.1073/pnas.89.17.7905

Furth PA, St Onge L, Boger H, Gruss P, Gossen M, Kistner A, Bujard H, Hennighausen L. 1994. Temporal control of gene expression in transgenic mice by a tetracycline-responsive promoter. Proc Natl Acad Sci 91: 9302-9306. doi:10.1073/pnas .91 .20 .9302

Gao L, Cox DBT, Yan WX, Manteiga JC, Schneider MW, Yamano T, Nishimasu H, Nureki O, Crosetto N, Zhang F. 2017. Engineered Cpf1 variants with altered PAM specificities. Nat Biotechnol 35: 789-792. doi:10.1038/nbt.3900

Gao Y, Hisey E, Bradshaw TWA, Erata E, Brown WE, Courtland JL, Uezu A, Xiang Y, Diao Y, Soderling SH. 2019. Plug-andplay protein modification using homology-independent universal genome engineering. Neuron 103: 583-597.e8. doi:10 .1016/j.neuron.2019.05.047

García-García MJ. 2020. A history of mouse genetics: from fancy mice to mutations in every gene. Adv Exp Med Biol 1236: 138. doi:10.1007/978-981-15-2389-2_1

Gaudelli NM, Komor AC, Rees HA, Packer MS, Badran AH, Bryson DI, Liu DR. 2017. Programmable base editing of A $\bullet$ to $\mathrm{G} \bullet \mathrm{C}$ in genomic DNA without DNA cleavage. Nature 551: 464-471. doi:10.1038/nature24644

Geister KA, Timms AE, Beier DR. 2018. Optimizing genomic methods for mapping and identification of candidate variants in ENU mutagenesis screens using inbred mice. G3 (Bethesda) 8: 401-409. doi:10.1534/g3.117.300292

Geng Y, Whoriskey W, Park MY, Bronson RT, Medema RH, Li T, Weinberg RA, Sicinski P. 1999. Rescue of cyclin D1 deficiency by knockin cyclin E. Cell 97: 767-777. doi:10.1016/S00928674(00)80788-6
Gerlai R. 1996. Gene-targeting studies of mammalian behavior: is it the mutation or the background genotype? Trends Neurosci 19: 177-181. doi:10.1016/S0166-2236/96/20020-7

Gertsenstein M, Nutter LMJ. 2018. Engineering point mutant and epitope-tagged alleles in mice using Cas9 RNA-guided nuclease. Curr Protoc Mouse Biol 8: 28-53. doi:10.1002/cpmo.40

Giraldo P, Rival-Gervier S, Houdebine LM, Montoliu L. 2003. The potential benefits of insulators on heterologous constructs in transgenic animals. Transgenic Res 12: 751-755. doi:10.1023/B:TRAG.0000005089.30408.25

Gordon JW, Ruddle FH. 1981. Integration and stable germ line transmission of genes injected into mouse pronuclei. Science 214: 1244-1246. doi:10.1126/science.6272397

Gossler A, Doetschman T, Korn R, Serfling E, Kemler R. 1986. Transgenesis by means of blastocyst-derived embryonic stem cell lines. Proc Natl Acad Sci 83: 9065-9069. doi:10 $.1073 /$ pnas.83.23.9065

Gossler A, Joyner AL, Rossant J, Skarnes WC. 1989. Mouse embryonic stem cells and reporter constructs to detect developmentally regulated genes. Science 244: 463-465. doi:10 $.1126 /$ science.2497519

Govindarajan V, Harrison WR, Xiao N, Liang D, Overbeek PA. 2005. Intracorneal positioning of the lens in Pax6-GAL4/ VP16 transgenic mice. Mol Vis 11: 876-886.

Grunewald J, Zhou R, Lareau CA, Garcia SP, Iyer S, Miller BR, Langner LM, Hsu JY, Aryee MJ, Joung JK. 2020. A dual-deaminase CRISPR base editor enables concurrent adenine and cytosine editing. Nat Biotechnol 38: 861-864. doi:10.1038/ s41587-020-0535-y

Gu B, Posfai E, Rossant J. 2018. Efficient generation of targeted large insertions by microinjection into two-cell-stage mouse embryos. Nat Biotechnol 36: 632-637. doi:10.1038/ nbt. 4166

Gurumurthy CB, O'Brien AR, Quadros RM, Adams J Jr, Alcaide P, Ayabe S, Ballard J, Batra SK, Beauchamp MC, Becker KA, et al. 2019. Reproducibility of CRISPR-Cas9 methods for generation of conditional mouse alleles: a multi-center evaluation. Genome Biol 20: 171. doi:10.1186/s13059-0191776-2

Habets PE, Clout DE, Lekanne Deprez RH, van Roon MA, Moorman AF, Christoffels VM. 2003. Cardiac expression of Gal4 causes cardiomyopathy in a dose-dependent manner. I Muscle Res Cell Motil 24: 205-209. doi:10.1023/A :1026055612227

Haeussler M, Schönig K, Eckert H, Eschstruth A, Mianne J, Renaud JB, Schneider-Maunoury S, Shkumatava A, Teboul L, Kent J, et al. 2016. Evaluation of off-target and on-target scoring algorithms and integration into the guide RNA selection tool CRISPOR. Genome Biol 17: 148. doi:10.1186/ s13059-016-1012-2

Hanks M, Wurst W, Anson-Cartwright L, Auerbach AB, Joyner AL. 1995. Rescue of the En-1 mutant phenotype by replacement of En-1 with En-2. Science 269: 679-682. doi:10.1126/sci ence.7624797

Hanks MC, Loomis CA, Harris E, Tong CX, Anson-Cartwright L, Auerbach A, Joyner A. 1998. Drosophila engrailed can substitute for mouse Engrailed1 function in mid-hindbrain, but not limb development. Development 125: 4521-4530.

Harbers K, Jähner D, Jaenisch R. 1981. Microinjection of cloned retroviral genomes into mouse zygotes: integration and expression in the animal. Nature 293: 540-542. doi:10.1038/ 293540a0

Harr B, Karakoc E, Neme R, Teschke M, Pfeifle C, Pezer Z, Babiker H, Linnenbrink M, Montero I, Scavetta R, et al. 2016. Genomic resources for wild populations of the house 
mouse, Mus musculus and its close relative Mus spretus. Sci Data 3: 160075 . doi:10.1038/sdata.2016.75

Hasty P, Rivera-Pérez J, Bradley A. 1991. The length of homology required for gene targeting in embryonic stem cells. Mol Cell Biol 11: 5586-5591. doi:10.1128/MCB.11.11.5586

He L, Li Y, Li Y, Pu W, Huang X, Tian X, Wang Y, Zhang H, Liu Q, Zhang L, et al. 2017. Enhancing the precision of genetic lineage tracing using dual recombinases. Nat Med 23: 14881498. doi: $10.1038 / \mathrm{nm} .4437$

Heigwer F, Kerr G, Walther N, Glaeser K, Pelz O, Breinig M, Boutros M. 2013. E-TALEN: a Web tool to design TALENs for genome engineering. Nucleic Acids Res 41: e190. doi:10.1093/ nar/gkt789

Heigwer F, Kerr G, Boutros M. 2014. E-CRISP: fast CRISPR target site identification. Nat Methods 11: 122-123. doi:10.1038/ nmeth. 2812

Heuchel R, Berg A, Tallquist M, Ahlen K, Reed RK, Rubin K, Claesson-Welsh L, Heldin CH, Soriano P. 1999. Platelet-derived growth factor $\beta$ receptor regulates interstitial fluid homeostasis through phosphatidylinositol-3' kinase signaling. Proc Natl Acad Sci 96: 11410-11415. doi:10.1073/pnas.96.20 .11410

Hippenmeyer S, Youn YH, Moon HM, Miyamichi K, Zong H, Wynshaw-Boris A, Luo L. 2010. Genetic mosaic dissection of Lis1 and Ndell in neuronal migration. Neuron 68: 695709. doi:10.1016/j.neuron.2010.09.027

Hirano H, Gootenberg JS, Horii T, Abudayyeh OO, Kimura M, Hsu PD, Nakane T, Ishitani R, Hatada I, Zhang F, et al. 2016. Structure and engineering of francisella novicida Cas9. Cell 164: 950-961. doi:10.1016/j.cell.2016.01.039

Hirrlinger J, Scheller A, Hirrlinger PG, Kellert B, Tang W, Wehr MC, Goebbels S, Reichenbach A, Sprengel R, Rossner MJ, et al. 2009. Split-cre complementation indicates coincident activity of different genes in vivo. PLoS One 4: e4286. doi:10 .1371 /journal.pone.0004286

Hoch RV, Soriano P. 2006. Context-specific requirements for Fgfr1 signaling through Frs2 and Frs3 during mouse development. Development 133: 663-673. doi:10.1242/dev.02242

Hooper M, Hardy K, Handyside A, Hunter S, Monk M. 1987. HPRT-deficient (Lesch-Nyhan) mouse embryos derived from germline colonization by cultured cells. Nature 326: 292295. doi:10.1038/326292a0

Horner VL, Caspary T. 2011. Creating a 'hopeful monster': mouse forward genetic screens. Methods Mol Biol 770: 313-336. doi:10.1007/978-1-61779-210-6_12

Hou Z, Zhang Y, Propson NE, Howden SE, Chu LF, Sontheimer EJ, Thomson JA. 2013. Efficient genome engineering in human pluripotent stem cells using Cas9 from Neisseria meningitidis. Proc Natl Acad Sci 110: 15644-15649. doi:10.1073/ pnas. 1313587110

Hsu PD, Scott DA, Weinstein JA, Ran FA, Konermann S, Agarwala V, Li Y, Fine EJ, Wu X, Shalem O, et al. 2013. DNA targeting specificity of RNA-guided Cas9 nucleases. Nat Biotechnol 31: 827-832. doi:10.1038/nbt.2647

$\mathrm{Hu}$ JH, Miller SM, Geurts MH, Tang W, Chen L, Sun N, Zeina CM, Gao X, Rees HA, Lin Z, et al. 2018. Evolved Cas9 variants with broad PAM compatibility and high DNA specificity. $\mathrm{Na}$ ture 556: 57-63. doi:10.1038/nature26155

Huang S, Liao Z, Li X, Liu Z, Li G, Li J, Lu Z, Zhang Y, Li X, Ma X, et al. 2019a. Developing ABEmax-NG with precise targeting and expanded editing scope to model pathogenic splice site mutations in vivo. iScience 15: 640-648. doi:10.1016/j.isci .2019 .05 .008

Huang TP, Zhao KT, Miller SM, Gaudelli NM, Oakes BL, Fellmann C, Savage DF, Liu DR. 2019b. Circularly permuted and PAM-modified Cas9 variants broaden the targeting scope of base editors. Nat Biotechnol 37: 626-631. doi:10.1038/ s41587-019-0134-y

Huangfu D, Liu A, Rakeman AS, Murcia NS, Niswander L, Anderson KV. 2003. Hedgehog signalling in the mouse requires intraflagellar transport proteins. Nature 426: 83-87. doi:10 $.1038 /$ nature02061

Hur JK, Kim K, Been KW, Baek G, Ye S, Hur JW, Ryu SM, Lee YS, Kim JS. 2016. Targeted mutagenesis in mice by electroporation of Cpf1 ribonucleoproteins. Nat Biotechnol 34: 807808. doi:10.1038/nbt.3596

Indra $\mathrm{AK}$, Warot $\mathrm{X}$, Brocard J, Bornert JM, Xiao JH, Chambon $\mathrm{P}$, Metzger D. 1999. Temporally-controlled site-specific mutagenesis in the basal layer of the epidermis: comparison of the recombinase activity of the tamoxifen-inducible CreERT and Cre-ER/2 recombinases. Nucleic Acids Res 27: 4324-4327. doi:10.1093/nar/27.22.4324

Ishino Y, Shinagawa H, Makino K, Amemura M, Nakata A. 1987. Nucleotide sequence of the iap gene, responsible for alkaline phosphatase isozyme conversion in Escherichia coli, and identification of the gene product. I Bacteriol 169: 54295433. doi:10.1128/JB.169.12.5429-5433.1987

Jaenisch R. 1976. Germ line integration and Mendelian transmission of the exogenous Moloney leukemia virus. Proc Natl Acad Sci 73: 1260-1264. doi:10.1073/pnas.73.4.1260

Jaenisch R. 1988. Transgenic animals. Science 240: 1468-1474. doi:10.1126/science.3287623

Jaenisch R, Mintz B. 1974. Simian virus 40 DNA sequences in DNA of healthy adult mice derived from preimplantation blastocysts injected with viral DNA. Proc Natl Acad Sci 71: 1250-1254. doi:10.1073/pnas.71.4.1250

Jansen R, Embden JD, Gaastra W, Schouls LM. 2002. Identification of genes that are associated with DNA repeats in prokaryotes. Mol Microbiol 43: 1565-1575. doi:10.1046/j.1365-2958 .2002.02839.x

Jinek M, Chylinski K, Fonfara I, Hauer M, Doudna JA, Charpentier E. 2012. A programmable dual-RNA-guided DNA endonuclease in adaptive bacterial immunity. Science 337: 816-821. doi:10.1126/science.1225829

Johnson RS, Sheng M, Greenberg ME, Kolodner RD, Papaioannou VE, Spiegelman BM. 1989. Targeting of nonexpressed genes in embryonic stem cells via homologous recombination. Science 245: 1234-1236. doi:10.1126/science.2506639

Joung JK, Sander JD. 2013. TALENs: a widely applicable technology for targeted genome editing. Nat Rev Mol Cell Biol 14: 49-55. doi:10.1038/nrm3486

Joyner AL, Skarnes WC, Rossant J. 1989. Production of a mutation in mouse En-2 gene by homologous recombination in embryonic stem cells. Nature 338: 153-156. doi:10.1038/ 338153a0

Kalhor R, Kalhor K, Mejia L, Leeper K, Graveline A, Mali P, Church GM. 2018. Developmental barcoding of whole mouse via homing CRISPR. Science 361: eaat9804. doi:10.1126/sci ence.aat9804

Karimova M, Baker O, Camgoz A, Naumann R, Buchholz F, Anastassiadis K. 2018. A single reporter mouse line for Vika, Flp, Dre, and Cre-recombination. Sci Rep 8: 14453. doi:10 $.1038 / \mathrm{s} 41598-018-32802-7$

Kasarskis A, Manova K, Anderson KV. 1998. A phenotype-based screen for embryonic lethal mutations in the mouse. Proc Natl Acad Sci 95: 7485-7490. doi:10.1073/pnas.95.13.7485

Kato T, Hara S, Goto Y, Ogawa Y, Okayasu H, Kubota S, Tamano M, Terao M, Takada S. 2017. Creation of mutant mice with megabase-sized deletions containing custom-designed 
breakpoints by means of the CRISPR/Cas9 system. Sci Rep 7: 59. doi:10.1038/s41598-017-00140-9

Kellendonk C, Tronche F, Monaghan AP, Angrand PO, Stewart F, Schutz G. 1996. Regulation of Cre recombinase activity by the synthetic steroid RU 486. Nucleic Acids Res 24: 1404-1411. doi:10.1093/nar/24.8.1404

Kile BT, Hentges KE, Clark AT, Nakamura H, Salinger AP, Liu B, Box N, Stockton DW, Johnson RL, Behringer RR, et al. 2003. Functional genetic analysis of mouse chromosome 11. Nature 425: 81-86. doi:10.1038/nature01865

Kim YG, Cha J, Chandrasegaran S. 1996. Hybrid restriction enzymes: zinc finger fusions to Fok I cleavage domain. Proc Natl Acad Sci 93: 1156-1160. doi:10.1073/pnas.93.3.1156

Kim JH, Lee SR, Li LH, Park HJ, Park JH, Lee KY, Kim MK, Shin BA, Choi SY. 2011. High cleavage efficiency of a 2A peptide derived from porcine teschovirus-1 in human cell lines, zebrafish and mice. PLoS One 6: e18556. doi:10.1371/journal.pone .0018556

Kim Y, Cheong SA, Lee JG, Lee SW, Lee MS, Baek IJ, Sung YH. 2016. Generation of knockout mice by Cpf1-mediated gene targeting. Nat Biotechnol 34: 808-810. doi:10.1038/nbt.3614

Kim E, Koo T, Park SW, Kim D, Kim K, Cho HY, Song DW, Lee KJ, Jung MH, Kim S, et al. 2017a. In vivo genome editing with a small Cas9 orthologue derived from Campylobacter jejuni. Nat Commun 8: 14500. doi:10.1038/ncomms14500

Kim YB, Komor AC, Levy JM, Packer MS, Zhao KT, Liu DR. $2017 \mathrm{~b}$. Increasing the genome-targeting scope and precision of base editing with engineered Cas9-cytidine deaminase fusions. Nat Biotechnol 35: 371-376. doi:10.1038/nbt.3803

Kistner A, Gossen M, Zimmermann F, Jerecic J, Ullmer C, Lubbert H, Bujard H. 1996. Doxycycline-mediated quantitative and tissue-specific control of gene expression in transgenic mice. Proc Nat1 Acad Sci 93: 10933-10938. doi:10.1073/pnas .93.20.10933

Kleinstiver BP, Prew MS, Tsai SQ, Nguyen NT, Topkar VV, Zheng Z, Joung JK. 2015a. Broadening the targeting range of Staphylococcus aureus CRISPR-Cas9 by modifying PAM recognition. Nat Biotechnol 33: 1293-1298. doi:10.1038/nbt .3404

Kleinstiver BP, Prew MS, Tsai SQ, Topkar VV, Nguyen NT, Zheng Z, Gonzales AP, Li Z, Peterson RT, Yeh JR, et al. 2015b. Engineered CRISPR-Cas9 nucleases with altered PAM specificities. Nature 523: 481-485. doi:10.1038/ nature 14592

Kleinstiver BP, Pattanayak V, Prew MS, Tsai SQ, Nguyen NT, Zheng Z, Joung JK. 2016. High-fidelity CRISPR-Cas9 nucleases with no detectable genome-wide off-target effects. Nature 529: 490-495. doi:10.1038/nature 16526

Klinger M, Chmura SA, Killeen N. 2010. Reporter alleles that inform on differences in Cre recombinase expression. I Immunol 184: 6170-6176. doi:10.4049/jimmunol.1000089

Klinghoffer RA, Mueting-Nelsen PF, Faerman A, Shani M, Soriano P. 2001. The two PDGF receptors maintain conserved signaling in vivo despite divergent embryological functions. Mol Cell 7: 343-354. doi:10.1016/S1097-2765(01)00182-4

Klinghoffer RA, Hamilton TG, Hoch R, Soriano P. 2002. An allelic series at the PDGFaR locus indicates unequal contributions of distinct signaling pathways during development. Dev Cell 2: 103-113. doi:10.1016/S1534-5807(01)00103-4

Kobayashi Y, Aoshima T, Ito R, Shinmura R, Ohtsuka M, Akasaka E, Sato M, Takabayashi S. 2020. Modification of i-GONAD suitable for production of genome-edited C57BL/6 inbred mouse strain. Cells 9: 957. doi:10.3390/ cells9040957
Koblan LW, Doman JL, Wilson C, Levy JM, Tay T, Newby GA, Maianti JP, Raguram A, Liu DR. 2018. Improving cytidine and adenine base editors by expression optimization and ancestral reconstruction. Nat Biotechnol 36: 843-846. doi:10 $.1038 /$ nbt.4172

Koentgen F, Lin J, Katidou M, Chang I, Khan M, Watts J, Mombaerts P. 2016. Exclusive transmission of the embryonic stem cell-derived genome through the mouse germline. Genesis 54: 326-333. doi:10.1002/dvg.22938

Komor AC, Kim YB, Packer MS, Zuris JA, Liu DR. 2016. Programmable editing of a target base in genomic DNA without double-stranded DNA cleavage. Nature 533: 420-424. doi:10 .1038 /nature 17946

Komor AC, Zhao KT, Packer MS, Gaudelli NM, Waterbury AL, Koblan LW, Kim YB, Badran AH, Liu DR. 2017. Improved base excision repair inhibition and bacteriophage $\mathrm{Mu}$ Gam protein yields C:G-to-T:A base editors with higher efficiency and product purity. Sci $A d v$ 3: eaao4774. doi:10.1126/sciadv .aao4774

Kosicki M, Tomberg K, Bradley A. 2018. Repair of double-strand breaks induced by CRISPR-Cas9 leads to large deletions and complex rearrangements. Nat Biotechnol 36: 765-771. doi: $10.1038 /$ nbt.4192

Kraft K, Geuer S, Will AJ, Chan WL, Paliou C, Borschiwer M, Harabula I, Wittler L, Franke M, Ibrahim DM, et al. 2015. Deletions, inversions, duplications: engineering of structural variants using CRISPR/Cas in mice. Cell Rep 10: 833-839. doi:10.1016/j.celrep.2015.01.016

Kuehn MR, Bradley A, Robertson EJ, Evans MJ. 1987. A potential animal model for Lesch-Nyhan syndrome through introduction of HPRT mutations into mice. Nature 326: 295-298. doi:10.1038/326295a0

Kuhn R, Schwenk F, Aguet M, Rajewsky K. 1995. Inducible gene targeting in mice. Science 269: 1427-1429. doi:10.1126/sci ence.7660125

Kuramoto T. 2011. Yoso-tama-no-kakehashi; the first Japanese guidebook on raising rats. Exp Anim 60: 1-6. doi:10.1538/expa nim.60.1

Kuscu C, Arslan S, Singh R, Thorpe J, Adli M. 2014. Genomewide analysis reveals characteristics of off-target sites bound by the Cas9 endonuclease. Nat Biotechnol 32: 677-683. doi:10.1038/nbt.2916

Labosky PA, Barlow DP, Hogan BL. 1994. Mouse embryonic germ (EG) cell lines: transmission through the germline and differences in the methylation imprint of insulin-like growth factor 2 receptor (Igf2r) gene compared with embryonic stem (ES) cell lines. Development 120: 3197-3204.

Labun K, Montague TG, Krause M, Torres Cleuren YN, Tjeldnes H, Valen E. 2019. CHOPCHOP v3: expanding the CRISPR web toolbox beyond genome editing. Nucleic Acids Res 47: W171-W174. doi:10.1093/nar/gkz365

Lange A, Gegg M, Burtscher I, Bengel D, Kremmer E, Lickert H. 2012. FltpT2AiCre: a new knock-in mouse line for conditional gene targeting in distinct mono- and multiciliated tissues. Differentiation 83: S105-S113. doi:10.1016/j.diff.2011.11.003

Lao Z, Raju GP, Bai CB, Joyner AL. 2012. MASTR: a technique for mosaic mutant analysis with spatial and temporal control of recombination using conditional floxed alleles in mice. Cell Rep 2: 386-396. doi:10.1016/j.celrep.2012.07.004

Law M, Shaw DR. 2018. Mouse genome informatics (MGI) is the international resource for information on the laboratory mouse. Methods Mol Biol 1757: 141-161. doi:10.1007/978-14939-7737-6_7

Le Mouellic H, Lallemand Y, Brulet P. 1990. Targeted replacement of the homeobox gene Hox-3.1 by the Escherichia coli 
lacZ in mouse chimeric embryos. Proc Natl Acad Sci 87: 4712-4716. doi:10.1073/pnas.87.12.4712

Lee JK, Jeong E, Lee J, Jung M, Shin E, Kim YH, Lee K, Jung I, Kim D, Kim S, et al. 2018. Directed evolution of CRISPR-Cas9 to increase its specificity. Nat Commun 9: 3048. doi:10.1038/ s41467-018-05477-x

Lee CM, Barber GP, Casper J, Clawson H, Diekhans M, Gonzalez JN, Hinrichs AS, Lee BT, Nassar LR, Powell CC, et al. 2020a. UCSC Genome Browser enters 20th year. Nucleic Acids Res 48: D756-D761. doi:10.1093/nar/gkz1012

Lee HK, Smith HE, Liu C, Willi M, Hennighausen L. 2020b. Cytosine base editor 4 but not adenine base editor generates off-target mutations in mouse embryos. Commun Biol 3: 19. doi:10.1038/s42003-019-0745-3

Lee JY, Jang YJ, Bae JH, Lee YH, Bae HS, Kim S, Park SG, Koo OJ, Yeom SC. 2020c. Efficient and specific generation of knockout mice using Campylobacter jejuni CRISPR/Cas9 system. Biochem Biophys Rep 22: 100752.

Legué E, Joyner AL. 2010. Genetic fate mapping using site-specific recombinases. Methods Enzymol 477: 153-181. doi:10 .1016/S0076-6879(10)77010-5

Leissring MA, Akbari Y, Fanger CM, Cahalan MD, Mattson MP, LaFerla FM. 2000. Capacitative calcium entry deficits and elevated luminal calcium content in mutant presenilin-1 knockin mice. J Cell Biol 149: 793-798. doi:10.1083/jcb.149 .4 .793

Li MA, Pettitt SJ, Eckert S, Ning Z, Rice S, Cadinanos J, Yusa K, Conte N, Bradley A. 2013. The piggyBac transposon displays local and distant reintegration preferences and can cause mutations at noncanonical integration sites. Mol Cell Biol 33: 1317-1330. doi:10.1128/MCB.00670-12

Li K, Wang G, Andersen T, Zhou P, Pu WT. 2014. Optimization of genome engineering approaches with the CRISPR/Cas9 system. PLoS One 9: e105779. doi:10.1371/journal.pone.0105779

Li Y, Klena NT, Gabriel GC, Liu X, Kim AJ, Lemke K, Chen Y, Chatterjee B, Devine W, Damerla RR, et al. 2015. Global genetic analysis in mice unveils central role for cilia in congenital heart disease. Nature 521: 520-524. doi:10.1038/ nature 14269

Li P, Zhang L, Li Z, Xu C, Du X, Wu S. 2019. Cas12a mediates efficient and precise endogenous gene tagging via MITI: microhomology-dependent targeted integrations. Cell Mol Life Sci doi:10.1007/s00018-019-03396-8

Liang X, Potter J, Kumar S, Zou Y, Quintanilla R, Sridharan M, Carte J, Chen W, Roark N, Ranganathan S, et al. 2015. Rapid and highly efficient mammalian cell engineering via Cas9 protein transfection. I Biotechnol 208: 44-53. doi:10.1016/j .jbiotec.2015.04.024

Lin FL, Sperle K, Sternberg N. 1984. Homologous recombination in mouse L cells. Cold Spring Harb Symp Quant Biol 49: 139149. doi:10.1101/SQB.1984.049.01.017

Lin S, Staahl BT, Alla RK, Doudna JA. 2014. Enhanced homologydirected human genome engineering by controlled timing of CRISPR/Cas9 delivery. Elife 3: e04766. doi:10.7554/eLife .04766

Liu J, Willet SG, Bankaitis ED, Xu Y, Wright CV, Gu G. 2013. Non-parallel recombination limits Cre-LoxP-based reporters as precise indicators of conditional genetic manipulation. Genesis 51: 436-442. doi:10.1002/dvg.22384

Liu K, Yu W, Tang M, Tang J, Liu X, Liu Q, Li Y, He L, Zhang L, Evans SM, et al. 2018a. A dual genetic tracing system identifies diverse and dynamic origins of cardiac valve mesenchyme. Development 145: dev167775. doi:10.1242/dev .167775
Liu T, Hu Y, Guo S, Tan L, Zhan Y, Yang L, Liu W, Wang N, Li Y, Zhang Y, et al. 2018b. Identification and characterization of MYH9 locus for high efficient gene knock-in and stable expression in mouse embryonic stem cells. PLoS One 13: e0192641. doi:10.1371/journal.pone.0192641

Liu Z, Lu Z, Yang G, Huang S, Li G, Feng S, Liu Y, Li J, Yu W, Zhang $Y$, et al. 2018c. Efficient generation of mouse models of human diseases via ABE- and BE-mediated base editing. Nat Commun 9: 2338. doi:10.1038/s41467-018-04768-7

Liu K, Jin H, Zhou B. 2020a. Genetic lineage tracing with multiple DNA recombinases: a user's guide for conducting more precise cell fate mapping studies. J Biol Chem 295: 6413-6424. doi:10.1074/jbc.REV120.011631

Liu Y, Li X, He S, Huang S, Li C, Chen Y, Liu Z, Huang X, Wang X. $2020 \mathrm{~b}$. Efficient generation of mouse models with the prime editing system. Cell Discov 6: 27. doi:10.1038/s41421-0200165-z

Liu Z, Schiel JA, Maksimova E, Strezoska Z, Zhao G, Anderson EM, Wu Y, Warren J, Bartels A, van Brabant Smith A, et al. 2020c. ErCas12a CRISPR-MAD7 for model generation in human cells, mice, and rats. CRISPR J 3: 97-108. doi:10.1089/ crispr.2019.0068

Livet J, Weissman TA, Kang H, Draft RW, Lu J, Bennis RA, Sanes JR, Lichtman JW. 2007. Transgenic strategies for combinatorial expression of fluorescent proteins in the nervous system. Nature 450: 56-62. doi:10.1038/nature06293

Lloyd KC, Robinson PN, MacRae CA. 2016. Animal-based studies will be essential for precision medicine. Sci Transl Med 8: $352 \mathrm{ed} 312$.

Long C, McAnally JR, Shelton JM, Mireault AA, Bassel-Duby R, Olson EN. 2014. Prevention of muscular dystrophy in mice by CRISPR/Cas9-mediated editing of germline DNA. Science 345: 1184-1188. doi:10.1126/science. 1254445

Luo G, Ivics Z, Izsvak Z, Bradley A. 1998. Chromosomal transposition of a Tc1/mariner-like element in mouse embryonic stem cells. Proc Natl Acad Sci 95: 10769-10773. doi:10 $.1073 /$ pnas.95.18.10769

Luo G, Santoro IM, McDaniel LD, Nishijima I, Mills M, Youssoufian H, Vogel H, Schultz RA, Bradley A. 2000. Cancer predisposition caused by elevated mitotic recombination in Bloom mice. Nat Genet 26: 424-429. doi:10.1038/82548

Luo L, Ambrozkiewicz MC, Benseler F, Chen C, Dumontier E, Falkner S, Furlanis E, Gomez AM, Hoshina N, Huang WH, et al. 2020. Optimizing nervous system-specific gene targeting with cre driver lines: prevalence of germline recombination and influencing factors. Neuron 106: 37-65.e5. doi:10.1016/j .neuron.2020.01.008

Ma M, Zhuang F, Hu X, Wang B, Wen XZ, Ji JF, Xi JJ. 2017. Efficient generation of mice carrying homozygous double-floxp alleles using the Cas9-Avidin/Biotin-donor DNA system. Cell Res 27: 578-581. doi:10.1038/cr.2017.29

Ma D, Xu Z, Zhang Z, Chen X, Zeng X, Zhang Y, Deng T, Ren M, Sun Z, Jiang R, et al. 2019. Engineer chimeric Cas9 to expand PAM recognition based on evolutionary information. Nat Commun 10: 560. doi:10.1038/s41467-019-08395-8

Makarova KS, Wolf YI, Alkhnbashi OS, Costa F, Shah SA, Saunders SJ, Barrangou R, Brouns SI, Charpentier E, Haft DH, et al. 2015. An updated evolutionary classification of CRISPR-Cas systems. Nat Rev Microbiol 13: 722-736. doi:10.1038/nrmicro3569

Makarova KS, Wolf YI, Iranzo J, Shmakov SA, Alkhnbashi OS, Brouns SIJ, Charpentier E, Cheng D, Haft DH, Horvath P, et al. 2020. Evolutionary classification of CRISPR-Cas systems: a burst of class 2 and derived variants. Nat Rev Microbiol 18: 67-83. doi:10.1038/s41579-019-0299-x 
Mali P, Yang L, Esvelt KM, Aach J, Guell M, DiCarlo JE, Norville JE, Church GM. 2013. RNA-guided human genome engineering via Cas9. Science 339: 823-826. doi:10.1126/science .1232033

Mansour SL, Thomas KR, Capecchi MR. 1988. Disruption of the proto-oncogene int-2 in mouse embryo-derived stem cells: a general strategy for targeting mutations to non-selectable genes. Nature 336: 348-352. doi:10.1038/336348a0

Mansour SL, Thomas KR, Deng CX, Capecchi MR. 1990. Introduction of a lacZ reporter gene into the mouse int-2 locus by homologous recombination. Proc Natl Acad Sci 87: 7688-7692. doi:10.1073/pnas.87.19.7688

Markel P, Shu P, Ebeling C, Carlson GA, Nagle DL, Smutko JS, Moore KJ. 1997. Theoretical and empirical issues for marker-assisted breeding of congenic mouse strains. Nat Genet 17: 280-284. doi:10.1038/ng1197-280

Marraffini LA, Sontheimer EJ. 2010. CRISPR interference: RNAdirected adaptive immunity in bacteria and archaea. Nat ReV Genet 11: 181-190. doi:10.1038/nrg2749

Martin GR. 1981. Isolation of a pluripotent cell line from early mouse embryos cultured in medium conditioned by teratocarcinoma stem cells. Proc Natl Acad Sci 78: 7634-7638. doi:10 $.1073 /$ pnas.78.12.7634

McClive P, Pall G, Newton K, Lee M, Mullins J, Forrester L. 1998. Gene trap integrations expressed in the developing heart: insertion site affects splicing of the PT1-ATG vector. Dev Dyn 212: 267-276. doi:10.1002/(SICI)1097-0177/199806/212 $: 2<267::$ AID-AJA11 $>3.0 . C O ; 2-1$

Meier ID, Bernreuther C, Tilling T, Neidhardt J, Wong YW, Schulze C, Streichert T, Schachner M. 2010. Short DNA sequences inserted for gene targeting can accidentally interfere with off-target gene expression. FASEB J 24: 1714-1724. doi:10 .1096/fj.09-140749

Meyer M, de Angelis MH, Wurst W, Kuhn R. 2010. Gene targeting by homologous recombination in mouse zygotes mediated by zinc-finger nucleases. Proc Natl Acad Sci 107: 15022-15026. doi:10.1073/pnas.1009424107

Meyers EN, Lewandoski M, Martin GR. 1998. An Fgf8 mutant allelic series generated by Cre- and Flp-mediated recombination. Nat Genet 18: 136-141. doi:10.1038/ng0298-136

Michael SK, Brennan J, Robertson EJ. 1999. Efficient gene-specific expression of cre recombinase in the mouse embryo by targeted insertion of a novel IRES-Cre cassette into endogenous loci. Mech Dev 85: 35-47. doi:10.1016/S0925-4773(99|00052-0

Miller SM, Wang T, Randolph PB, Arbab M, Shen MW, Huang TP, Matuszek Z, Newby GA, Rees HA, Liu DR. 2020. Continuous evolution of SpCas9 variants compatible with non-G PAMs. Nat Biotechnol 38: 471-481. doi:10.1038/s41587-020-0412-8

Mintz B, Illmensee K. 1975. Normal genetically mosaic mice produced from malignant teratocarcinoma cells. Proc Natl Acad Sci 72: 3585-3589. doi:10.1073/pnas.72.9.3585

Mitchell KJ, Pinson KI, Kelly OG, Brennan J, Zupicich J, Scherz P, Leighton PA, Goodrich LV, Lu X, Avery BJ, et al. 2001. Functional analysis of secreted and transmembrane proteins critical to mouse development. Nat Genet 28: 241-249. doi:10 $.1038 / 90074$

Miura H, Quadros RM, Gurumurthy CB, Ohtsuka M. 2018. EasiCRISPR for creating knock-in and conditional knockout mouse models using long ssDNA donors. Nat Protoc 13: 195-215. doi:10.1038/nprot.2017.153

Miyoshi C, Kim SI, Ezaki T, Ikkyu A, Hotta-Hirashima N, Kanno S, Kakizaki M, Yamada M, Wakana S, Yanagisawa M, et al. 2019. Methodology and theoretical basis of forward genetic screening for sleep/wakefulness in mice. Proc Natl Acad Sci 116: 16062-16067. doi:10.1073/pnas. 1906774116
Mizuno N, Mizutani E, Sato H, Kasai M, Ogawa A, Suchy F, Yamaguchi T, Nakauchi H. 2018. Intra-embryo gene cassette knockin by CRISPR/Cas9-mediated genome editing with adeno-associated viral vector. iScience 9: 286-297. doi:10 $.1016 /$ j.isci.2018.10.030

Mojica FJ, Ferrer C, Juez G, Rodríguez-Valera F. 1995. Long stretches of short tandem repeats are present in the largest replicons of the Archaea Haloferax mediterranei and Haloferax volcanii and could be involved in replicon partitioning. Mol Microbiol 17: 85-93. doi:10.1111/j.1365-2958.1995.mmi_17 010085.x

Morse HC III. 1978. Origins of inbred mice. National Institute of Allergy and Infectious Diseases, Bethesda, MD.

Moscou MJ, Bogdanove AJ. 2009. A simple cipher governs DNA recognition by TAL effectors. Science 326: 1501. doi:10 $.1126 /$ science. 1178817

Mountford P, Zevnik B, Duwel A, Nichols J, Li M, Dani C, Robertson M, Chambers I, Smith A. 1994. Dicistronic targeting constructs: reporters and modifiers of mammalian gene expression. Proc Natl Acad Sci 91: 4303-4307. doi:10.1073/ pnas.91.10.4303

Müller M, Lee CM, Gasiunas G, Davis TH, Cradick TJ, Siksnys V, Bao G, Cathomen T, Mussolino C. 2016. Streptococcus thermophilus CRISPR-Cas9 systems enable specific editing of the human genome. Mol Ther 24: 636-644. doi:10.1038/mt .2015 .218

Nakamura E, Nguyen MT, Mackem S. 2006. Kinetics of tamoxifen-regulated Cre activity in mice using a cartilage-specific CreERT to assay temporal activity windows along the proximodistal limb skeleton. Dev Dyn 235: 2603-2612. doi:10 $.1002 /$ dvdy.20892

Nishida K, Arazoe T, Yachie N, Banno S, Kakimoto M, Tabata M, Mochizuki M, Miyabe A, Araki M, Hara KY, et al. 2016. Targeted nucleotide editing using hybrid prokaryotic and vertebrate adaptive immune systems. Science 353: aaf8729. doi:10.1126/science.aaf8729

Nishimasu H, Shi X, Ishiguro S, Gao L, Hirano S, Okazaki S, Noda T, Abudayyeh OO, Gootenberg JS, Mori H, et al. 2018. Engineered CRISPR-Cas9 nuclease with expanded targeting space. Science 361: 1259-1262. doi:10.1126/science.aas9129

Nolan PM, Peters J, Strivens M, Rogers D, Hagan J, Spurr N, Gray IC, Vizor L, Brooker D, Whitehill E, et al. 2000. A systematic, genome-wide, phenotype-driven mutagenesis programme for gene function studies in the mouse. Nat Genet 25: 440-443. doi: $10.1038 / 78140$

Nord AS, Chang PJ, Conklin BR, Cox AV, Harper CA, Hicks GG, Huang CC, Johns SJ, Kawamoto M, Liu S, et al. 2006. The International Gene Trap Consortium website: a portal to all publicly available gene trap cell lines in mouse. Nucleic Acids Res 34: D642-D648. doi:10.1093/nar/gkj097

Oakes BL, Fellmann C, Rishi H, Taylor KL, Ren SM, Nadler DC, Yokoo R, Arkin AP, Doudna JA, Savage DF. 2019. CRISPRCas9 circular permutants as programmable scaffolds for genome modification. Cell 176: 254-267.e16. doi:10.1016/j.cell .2018 .11 .052

Ohtsuka M, Sato M, Miura H, Takabayashi S, Matsuyama M, Koyano T, Arifin N, Nakamura S, Wada K, Gurumurthy CB. 2018. i-GONAD: a robust method for in situ germline genome engineering using CRISPR nucleases. Genome Biol 19: 25. doi:10.1186/s13059-018-1400-x

Okita K, Ichisaka T, Yamanaka S. 2007. Generation of germlinecompetent induced pluripotent stem cells. Nature 448: 313 317. doi:10.1038/nature05934 
Olson LE, Soriano P. 2009. Increased PDGFR $\alpha$ activation disrupts connective tissue development and drives systemic fibrosis. Dev Cell 16: 303-313. doi:10.1016/j.devcel.2008.12.003

Ornitz DM, Moreadith RW, Leder P. 1991. Binary system for regulating transgene expression in mice: targeting int- 2 gene expression with yeast GAL4/UAS control elements. Proc Natl Acad Sci 88: 698-702. doi:10.1073/pnas.88.3.698

Paigen K. 2003. One hundred years of mouse genetics: an intellectual history. I. The classical period (1902-1980). Genetics 163: $1-7$.

Palmiter RD, Brinster RL. 1985. Transgenic mice. Cell 41: 343345. doi:10.1016/S0092-8674(85)80004-0

Pannunzio NR, Watanabe G, Lieber MR. 2018. Nonhomologous DNA end-joining for repair of DNA double-strand breaks. I Biol Chem 293: 10512-10523. doi:10.1074/jbc.TM117.000374

Papaioannou VE, McBurney MW, Gardner RL, Evans MJ. 1975. Fate of teratocarcinoma cells injected into early mouse embryos. Nature 258: 70-73. doi:10.1038/258070a0

Papapetrou EP, Schambach A. 2016. Gene insertion into genomic safe harbors for human gene therapy. Mol Ther 24: 678-684. doi:10.1038/mt.2016.38

Park EJ, Sun X, Nichol P, Saijoh Y, Martin JF, Moon AM. 2008. System for tamoxifen-inducible expression of cre-recombinase from the Foxa2 locus in mice. Dev Dyn 237: 447-453. doi:10.1002/dvdy.21415

Parkitna JR, Engblom D, Schutz G. 2009. Generation of Cre recombinase-expressing transgenic mice using bacterial artificial chromosomes. Methods Mol Biol 530: 325-342. doi:10 .1007/978-1-59745-471-1_17

Pettitt SJ, Liang Q, Rairdan XY, Moran JL, Prosser HM, Beier DR, Lloyd KC, Bradley A, Skarnes WC. 2009. Agouti C57BL/6N embryonic stem cells for mouse genetic resources. Nat Methods 6: 493-495. doi:10.1038/nmeth.1342

Phifer-Rixey M, Nachman MW. 2015. Insights into mammalian biology from the wild house mouse Mus musculus. Elife 4: e05959. doi:10.7554/eLife.05959

Pliatsika V, Rigoutsos I. 2015. 'Off-Spotter': very fast and exhaustive enumeration of genomic lookalikes for designing CRISPR/Cas guide RNAs. Biol Direct 10: 4. doi:10.1186/ s13062-015-0035-z

Popp RA, Bailiff EG, Skow LC, Johnson FM, Lewis SE. 1983. Analysis of a mouse a-globin gene mutation induced by ethylnitrosourea. Genetics 105: 157-167.

Poueymirou WT, Auerbach W, Frendewey D, Hickey JF, Escaravage JM, Esau L, Doré AT, Stevens S, Adams NC, Dominguez MG, et al. 2007. F0 generation mice fully derived from genetargeted embryonic stem cells allowing immediate phenotypic analyses. Nat Biotechnol 25: 91-99. doi:10.1038/nbt1263

Poulin JF, Luppi MP, Hofer C, Caronia G, Hsu PK, Chan CS, Awatramani R. 2020. PRISM: a progenitor-restricted intersectional fate mapping approach redefines forebrain lineages. DeV Cell 53: 740-753.e3. doi:10.1016/j.devcel.2020.05.019

$\mathrm{Pu}$ XA, Young AP, Kubisch HM. 2019. Production of transgenic mice by pronuclear microinjection. Methods Mol Biol 1874: 17-41. doi:10.1007/978-1-4939-8831-0_2

Qin W, Dion SL, Kutny PM, Zhang Y, Cheng AW, Jillette NL, Malhotra A, Geurts AM, Chen YG, Wang H. 2015. Efficient CRISPR/Cas9-mediated genome editing in mice by zygote electroporation of nuclease. Genetics 200: 423-430. doi:10 .1534 /genetics.115.176594

Quadros RM, Miura H, Harms DW, Akatsuka H, Sato T, Aida T, Redder R, Richardson GP, Inagaki Y, Sakai D, et al. 2017. EasiCRISPR: a robust method for one-step generation of mice carrying conditional and insertion alleles using long ssDNA do- nors and CRISPR ribonucleoproteins. Genome Biol 18: 92. doi:10.1186/s13059-017-1220-4

Ramirez-Solis R, Liu P, Bradley A. 1995. Chromosome engineering in mice. Nature 378: 720-724. doi:10.1038/378720a0

Ran FA, Hsu PD, Lin CY, Gootenberg JS, Konermann S, Trevino AE, Scott DA, Inoue A, Matoba S, Zhang Y, et al. 2013a. Double nicking by RNA-guided CRISPR Cas9 for enhanced genome editing specificity. Cell 154: 1380-1389. doi:10.1016/j .cell.2013.08.021

Ran FA, Hsu PD, Wright J, Agarwala V, Scott DA, Zhang F. 2013b. Genome engineering using the CRISPR-Cas9 system. Nat Protoc 8: 2281-2308. doi:10.1038/nprot.2013.143

Ran FA, Cong L, Yan WX, Scott DA, Gootenberg JS, Kriz AJ, Zetsche B, Shalem O, Wu X, Makarova KS, et al. 2015. In vivo genome editing using Staphylococcus aureus Cas9. Nature 520: 186-191. doi:10.1038/nature14299

Raymond CS, Soriano P. 2007. High-efficiency FLP and ФC31 site-specific recombination in mammalian cells. PLoS One 2: e162. doi:10.1371/journal.pone.0000162

Reardon S. 2019. CRISPR gene-editing creates wave of exotic model organisms. Nature 568: 441-442. doi:10.1038/d41586019-01300-9

Rezza A, Jacquet C, Le Pillouer A, Lafarguette F, Ruptier C, Billandon M, Isnard Petit P, Trouttet S, Thiam K, Fraichard A, et al. 2019. Unexpected genomic rearrangements at targeted loci associated with CRISPR/Cas9-mediated knock-in. Sci Rep 9: 3486. doi:10.1038/s41598-019-40181-w

Richter MF, Zhao KT, Eton E, Lapinaite A, Newby GA, Thuronyi BW, Wilson C, Koblan LW, Zeng J, Bauer DE, et al. 2020. Phage-assisted evolution of an adenine base editor with improved Cas domain compatibility and activity. Nat Biotechnol 38: 883-891. doi:10.1038/s41587-020-0453-z

Rijli FM, Dollé P, Fraulob V, LeMeur M, Chambon P. 1994. Insertion of a targeting construct in a Hoxd-10 allele can influence the control of Hoxd-9 expression. Dev Dyn 201: 366-377. doi:10.1002/aja.1002010408

Robertson E, Bradley A, Kuehn M, Evans M. 1986. Germ-line transmission of genes introduced into cultured pluripotential cells by retroviral vector. Nature 323: 445-448. doi:10.1038/ $323445 \mathrm{a} 0$

Robertson L, Pederick D, Piltz S, White M, Nieto A, Ahladas M, Adikusuma F, Thomas PQ. 2018. Expanding the RNA-guided endonuclease toolkit for mouse genome editing. CRISPR J 1: 431-439. doi:10.1089/crispr.2018.0050

Romeo C, Chen SH, Goulding E, Van Gorder L, Schwartz M, Walker M, Scott G, Scappini E, Ray M, Martin NP. 2020. AAV diffuses across zona pellucida for effortless gene delivery to fertilized eggs. Biochem Biophys Res Commun 526: 85-90. doi:10.1016/j.bbrc.2020.03.026

Rosenthal N, Brown S. 2007. The mouse ascending: perspectives for human-disease models. Nat Cell Biol 9: 993-999. doi:10 $.1038 / \mathrm{ncb} 437$

Russell ES. 1985. A history of mouse genetics. Annu Rev Genet 19: 1-29. doi:10.1146/annurev.ge.19.120185.000245

Russell WL, Kelly EM, Hunsicker PR, Bangham JW, Maddux SC, Phipps EL. 1979. Specific-locus test shows ethylnitrosourea to be the most potent mutagen in the mouse. Proc Natl Acad Sci 76: 5818-5819. doi:10.1073/pnas.76.11.5818

Sakata RC, Ishiguro S, Mori H, Tanaka M, Tatsuno K, Ueda H, Yamamoto S, Seki M, Masuyama N, Nishida K, et al. 2020. Base editors for simultaneous introduction of C-to-T and A-to-G mutations. Nat Biotechnol 38: 865-869. doi:10.1038/s41587020-0509-0 
Sakuma T, Yamamoto T. 2016. Engineering customized TALENs using the platinum gate TALEN kit. Methods Mol Biol 1338: 61-70. doi:10.1007/978-1-4939-2932-0_6

Sasaguri H, Nagata K, Sekiguchi M, Fujioka R, Matsuba Y, Hashimoto S, Sato K, Kurup D, Yokota T, Saido TC. 2018. Introduction of pathogenic mutations into the mouse Psen 1 gene by base editor and target-AID. Nat Commun 9: 2892. doi:10 .1038/s41467-018-05262-w

Sato M, Miyagasako R, Takabayashi S, Ohtsuka M, Hatada I, Horii T. 2020. Sequential i-GONAD: an improved in vivo technique for CRISPR/Cas9-based genetic manipulations in mice. Cells 9: 546. doi:10.3390/cells9030546

Schilit SLP, Ohtsuka M, Quadros RM, Gurumurthy CB. 2016. Pronuclear injection-based targeted transgenesis. Curr Protoc Hum Genet 91: 15.10.11-15.10.28.

Schindler SE, McCall JG, Yan P, Hyrc KL, Li M, Tucker CL, Lee JM, Bruchas MR, Diamond MI. 2015. Photo-activatable Cre recombinase regulates gene expression in vivo. Sci Rep 5: 13627. doi:10.1038/srep 13627

Schnieke A, Harbers K, Jaenisch R. 1983. Embryonic lethal mutation in mice induced by retrovirus insertion into the al(I) collagen gene. Nature 304: 315-320. doi:10.1038/304315a0

Schnutgen F, Doerflinger N, Calléja C, Wendling O, Chambon P, Ghyselinck NB. 2003. A directional strategy for monitoring Cre-mediated recombination at the cellular level in the mouse. Nat Biotechnol 21: 562-565. doi:10.1038/nbt811

Schnutgen F, De-Zolt S, Van Sloun P, Hollatz M, Floss T, Hansen J, Altschmied J, Seisenberger C, Ghyselinck NB, Ruiz P, et al. 2005. Genomewide production of multipurpose alleles for the functional analysis of the mouse genome. Proc Natl Acad Sci 102: 7221-7226. doi:10.1073/pnas.0502273102

Sentmanat MF, Peters ST, Florian CP, Connelly JP, Pruett-Miller SM. 2018. A survey of validation strategies for CRISPR-Cas9 editing. Sci Rep 8: 888. doi:10.1038/s41598-018-19441-8

Shen B, Zhang J, Wu H, Wang J, Ma K, Li Z, Zhang X, Zhang P, Huang X. 2013. Generation of gene-modified mice via Cas9/ RNA-mediated gene targeting. Cell Res 23: 720-723. doi:10 $.1038 / \mathrm{cr} .2013 .46$

Silver LM. 1995. Mouse genetics: concepts and applications. Oxford University Press, New York.

Simpson EM, Linder CC, Sargent EE, Davisson MT, Mobraaten LE, Sharp JJ. 1997. Genetic variation among 129 substrains and its importance for targeted mutagenesis in mice. Nat Genet 16: 19-27. doi:10.1038/ng0597-19

Simunovic M, Brivanlou AH. 2017. Embryoids, organoids and gastruloids: new approaches to understanding embryogenesis. Development 144: 976-985. doi:10.1242/dev.143529

Singla V, Hunkapiller J, Santos N, Seol AD, Norman AR, Wakenight P, Skarnes WC, Reiter JF. 2010. Floxin, a resource for genetically engineering mouse ESCs. Nat Methods 7: 50-52. doi:10.1038/nmeth.1406

Skarnes WC, von Melchner H, Wurst W, Hicks G, Nord AS, Cox T, Young SG, Ruiz P, Soriano P, Tessier-Lavigne M, et al. 2004. A public gene trap resource for mouse functional genomics. Nat Genet 36: 543-544. doi:10.1038/ng0604-543

Slaymaker IM, Gao L, Zetsche B, Scott DA, Yan WX, Zhang F. 2016. Rationally engineered Cas9 nucleases with improved specificity. Science 351: 84-88. doi:10.1126/science.aad5227

Smih F, Rouet P, Romanienko PJ, Jasin M. 1995. Double-strand breaks at the target locus stimulate gene targeting in embryonic stem cells. Nucleic Acids Res 23: 5012-5019. doi:10 $.1093 /$ nar/23.24.5012

Smith J, Bibikova M, Whitby FG, Reddy AR, Chandrasegaran S, Carroll D. 2000. Requirements for double-strand cleavage by chimeric restriction enzymes with zinc finger DNA-recogni- tion domains. Nucleic Acids Res 28: 3361-3369. doi:10 $.1093 / \mathrm{nar} / 28.17 .3361$

Smithies O, Koralewski MA, Song KY, Kucherlapati RS. 1984. Homologous recombination with DNA introduced into mammalian cells. Cold Spring Harb Symp Quant Biol 49: 161-170. doi:10.1101/SQB.1984.049.01.019

Smithies O, Gregg RG, Boggs SS, Koralewski MA, Kucherlapati RS. 1985. Insertion of DNA sequences into the human chromosomal $\beta$-globin locus by homologous recombination. $\mathrm{Na}$ ture 317: 230-234. doi:10.1038/317230a0

Snippert HJ, van der Flier LG, Sato T, van Es JH, van den Born M, Kroon-Veenboer C, Barker N, Klein AM, van Rheenen J, Simons BD, et al. 2010. Intestinal crypt homeostasis results from neutral competition between symmetrically dividing Lgr5 stem cells. Cell 143: 134-144. doi:10.1016/j.cell.2010 .09 .016

Soriano P. 1999. Generalized lacZ expression with the ROSA26 Cre reporter strain. Nat Genet 21: 70-71. doi:10.1038/5007

Soriano P. 2018. Intersectional gene inactivation: there is more to conditional mutagenesis than Cre. Sci China Life Sci 61: 1115-1117. doi:10.1007/s11427-018-9291-2

Soriano P, Gridley T, Jaenisch R. 1987. Retroviruses and insertional mutagenesis in mice: proviral integration at the Mov 34 locus leads to early embryonic death. Genes Dev 1: 366 375. doi:10.1101/gad.1.4.366

Soukup AA, Zheng Y, Mehta C, Wu J, Liu P, Cao M, Hofmann I, Zhou Y, Zhang J, Johnson KD, et al. 2019. Single-nucleotide human disease mutation inactivates a blood-regenerative GATA2 enhancer. I Clin Invest 129: 1180-1192. doi:10 $.1172 /$ JCI122694

Stanford WL, Cohn JB, Cordes SP. 2001. Gene-trap mutagenesis: past, present and beyond. Nat Rev Genet 2: 756-768. doi:10 $.1038 / 35093548$

Stewart CL, Gadi I, Bhatt H. 1994. Stem cells from primordial germ cells can reenter the germ line. Dev Biol 161: 626-628. doi:10.1006/dbio.1994.1058

Sung YH, Baek IJ, Kim DH, Jeon J, Lee J, Lee K, Jeong D, Kim JS, Lee HW. 2013. Knockout mice created by TALEN-mediated gene targeting. Nat Biotechnol 31: 23-24. doi:10.1038/nbt .2477

Sung YH, Kim JM, Kim HT, Lee J, Jeon J, Jin Y, Choi JH, Ban YH, Ha SJ, Kim CH, et al. 2014. Highly efficient gene knockout in mice and zebrafish with RNA-guided endonucleases. Genome Res 24: 125-131. doi:10.1101/gr.163394.113

Suzuki K, Tsunekawa Y, Hernandez-Benitez R, Wu J, Zhu J, Kim EJ, Hatanaka F, Yamamoto M, Araoka T, Li Z, et al. 2016. In vivo genome editing via CRISPR/Cas9 mediated homologyindependent targeted integration. Nature 540: 144-149. doi:10.1038/nature20565

Takahashi G, Gurumurthy CB, Wada K, Miura H, Sato M, Ohtsuka M. 2015. GONAD: genome-editing via oviductal nucleic acids delivery system: a novel microinjection independent genome engineering method in mice. Sci Rep 5: 11406. doi:10 $.1038 /$ srep 11406

Takahasi KR, Sakuraba Y, Gondo Y. 2007. Mutational pattern and frequency of induced nucleotide changes in mouse ENU mutagenesis. BMC Mol Biol 8: 52. doi:10.1186/1471-2199-8-52

Tallquist MD, French WJ, Soriano P. 2003. Additive effects of PDGF receptor $\beta$ signaling pathways in vascular smooth muscle cell development. PLOS Biol 1: E52. doi:10.1371/journal .pbio.0000052

te Riele H, Maandag ER, Berns A. 1992. Highly efficient gene targeting in embryonic stem cells through homologous recombination with isogenic DNA constructs. Proc Natl Acad Sci 89: 5128-5132. doi:10.1073/pnas.89.11.5128 
Thomas KR, Capecchi MR. 1987. Site-directed mutagenesis by gene targeting in mouse embryo-derived stem cells. Cell 51: 503-512. doi:10.1016/0092-8674/87)90646-5

Thomas KR, Folger KR, Capecchi MR. 1986. High frequency targeting of genes to specific sites in the mammalian genome. Cell 44: 419-428. doi:10.1016/0092-8674(86)90463-0

Threadgill DW, Yee D, Matin A, Nadeau JH, Magnuson T. 1997. Genealogy of the 129 inbred strains: $129 / \mathrm{SvJ}$ is a contaminated inbred strain. Mamm Genome 8: 390-393. doi:10.1007/ s003359900453

Tokuda M. 1935. An eighteenth century japanese guide-book on mouse-breeding. J Hered 26: 481-484. doi:10.1093/oxfordjour nals.jhered.a104011

Toth E, Varga E, Kulcsár PI, Kocsis-Jutka V, Krausz SL, Nyeste A, Welker Z, Huszar K, Ligeti Z, Talas A, et al. 2020. Improved LbCas12a variants with altered PAM specificities further broaden the genome targeting range of Cas12a nucleases. Nucleic Acids Res 48: 3722-3733. doi:10.1093/nar/ gkaa110

Tsien JZ, Chen DF, Gerber D, Tom C, Mercer EH, Anderson DJ, Mayford M, Kandel ER, Tonegawa S. 1996. Subregion- and cell type-restricted gene knockout in mouse brain. Cell 87: 13171326. doi:10.1016/S0092-8674/00|81826-7

Valenzuela DM, Murphy AJ, Frendewey D, Gale NW, Economides AN, Auerbach W, Poueymirou WT, Adams NC, Rojas J, Yasenchak J, et al. 2003. High-throughput engineering of the mouse genome coupled with high-resolution expression analysis. Nat Biotechnol 21: 652-659. doi:10.1038/nbt822

Vasquez KM, Marburger K, Intody Z, Wilson JH. 2001. Manipulating the mammalian genome by homologous recombination. Proc Natl Acad Sci 98: 8403-8410. doi:10.1073/pnas .111009698

Vitaterna MH, King DP, Chang AM, Kornhauser JM, Lowrey PL, McDonald JD, Dove WF, Pinto LH, Turek FW, Takahashi JS. 1994. Mutagenesis and mapping of a mouse gene, clock, essential for circadian behavior. Science 264: 719-725. doi:10 $.1126 /$ science. 8171325

Voehringer D, Liang HE, Locksley RM. 2008. Homeostasis and effector function of lymphopenia-induced 'memory-like' $\mathrm{T}$ cells in constitutively T cell-depleted mice. I Immunol 180: 47424753. doi:10.4049/jimmunol.180.7.4742

von Melchner H, DeGregori JV, Rayburn H, Reddy S, Friedel C, Ruley HE. 1992. Selective disruption of genes expressed in totipotent embryonal stem cells. Genes Dev 6: 919-927. doi:10 $.1101 /$ gad.6.6.919

Vooijs M, Jonkers J, Berns A. 2001. A highly efficient ligand-regulated Cre recombinase mouse line shows that LoxP recombination is position dependent. EMBO Rep 2: 292-297. doi:10 .1093/embo-reports/kve064

Vouillot L, Thélie A, Pollet N. 2015. Comparison of T7E1 and surveyor mismatch cleavage assays to detect mutations triggered by engineered nucleases. G3 (Bethesda) 5: 407-415. doi:10 $.1534 / \mathrm{g} 3.114 .015834$

Wagner DE, Klein AM. 2020. Lineage tracing meets single-cell omics: opportunities and challenges. Nat Rev Genet 21: 410-427. doi:10.1038/s41576-020-0223-2

Wagner EF, Stewart TA, Mintz B. 1981a. The human $\beta$-globin gene and a functional viral thymidine kinase gene in developing mice. Proc Natl Acad Sci 78: 5016-5020. doi:10.1073/pnas 78.8.5016

Wagner TE, Hoppe PC, Jollick JD, Scholl DR, Hodinka RL, Gault JB. 1981b. Microinjection of a rabbit $\beta$-globin gene into zygotes and its subsequent expression in adult mice and their offspring. Proc Natl Acad Sci 78: 6376-6380. doi:10.1073/pnas .78 .10 .6376
Wagner EF, Covarrubias L, Stewart TA, Mintz B. 1983. Prenatal lethalities in mice homozygous for human growth hormone gene sequences integrated in the germ line. Cell 35: 647655. doi:10.1016/0092-8674|83|90097-1

Wakeland E, Morel L, Achey K, Yui M, Longmate J. 1997. Speed congenics: a classic technique in the fast lane (relatively speaking). Immunol Today 18: 472-477. doi:10.1016/S01675699(97)01126-2

Wall RJ. 2001. Pronuclear microinjection. Cloning Stem Cells 3: 209-220. doi:10.1089/15362300152725936

Walton RT, Christie KA, Whittaker MN, Kleinstiver BP. 2020. Unconstrained genome targeting with near-PAMless engineered CRISPR-Cas9 variants. Science 368: 290-296. doi:10 $.1126 /$ science.aba8853

Wang Y, Schnegelsberg PN, Dausman J, Jaenisch R. 1996. Functional redundancy of the muscle-specific transcription factors Myf5 and myogenin. Nature 379: 823-825. doi:10.1038/ 379823a0

Wang H, Yang H, Shivalila CS, Dawlaty MM, Cheng AW, Zhang F, Jaenisch R. 2013. One-step generation of mice carrying mutations in multiple genes by CRISPR/Cas-mediated genome engineering. Cell 153: 910-918. doi:10.1016/j.cell.2013.04 .025

Wang T, Zhan X, Bu CH, Lyon S, Pratt D, Hildebrand S, Choi JH, Zhang Z, Zeng M, Wang KW, et al. 2015. Real-time resolution of point mutations that cause phenovariance in mice. Proc Natl Acad Sci 112: E440-E449. doi:10.1073/pnas .1423216112

Wang H, La Russa M, Qi LS. 2016a. CRISPR/Cas9 in genome editing and beyond. Annu Rev Biochem 85: 227-264. doi:10 .1146/annurev-biochem-060815-014607

Wang W, Kutny PM, Byers SL, Longstaff CJ, DaCosta MJ, Pang C, Zhang Y, Taft RA, Buaas FW, Wang H. 2016b. Delivery of Cas9 protein into mouse zygotes through a series of electroporation dramatically increases the efficiency of model creation. J Genet Genomics 43: 319-327. doi:10.1016/j.jgg.2016 .02 .004

Wang T, Bu CH, Hildebrand S, Jia G, Siggs OM, Lyon S, Pratt D, Scott L, Russell J, Ludwig S, et al. 2018. Probability of phenotypically detectable protein damage by ENU-induced mutations in the Mutagenetix database. Nat Commun 9: 441. doi:10.1038/s41467-017-02806-4

Wang D, Zhang F, Gao G. 2020a. CRISPR-based therapeutic genome editing: strategies and in vivo delivery by AAV vectors. Cell 181: 136-150. doi:10.1016/j.cell.2020.03.023

Wang X, Ding C, Yu W, Wang Y, He S, Yang B, Xiong YC, Wei J, Li J, Liang J, et al. 2020b. Cas12a base editors induce efficient and specific editing with low DNA damage response. Cell Rep 31: 107723. doi:10.1016/j.celrep.2020.107723

Wang X, Liu Z, Li G, Dang L, Huang S, He L, Ma Y, Li C, Liu M, Yang $G$, et al. 2020c. Efficient gene silencing by adenine base editor-mediated start codon mutation. Mol Ther 28: 431-440. doi:10.1016/j.ymthe.2019.11.022

Wang Z, Wang Y, Wang S, Gorzalski AJ, McSwiggin H, Yu T, Castaneda-Garcia K, Prince B, Wang H, Zheng H, et al. 2020d. Efficient genome editing by CRISPR-Mb3Cas12a in mice. J Cell Sci 133: jcs240705. doi: $10.1242 /$ jcs. 240705

Weismann A. 1889. Essays upon heredity and kindred biological problems. Clarendon Press, Oxford.

Wernig M, Meissner A, Foreman R, Brambrink T, Ku M, Hochedlinger K, Bernstein BE, Jaenisch R. 2007. In vitro reprogramming of fibroblasts into a pluripotent ES-cell-like state. Nature 448: 318-324. doi:10.1038/nature05944

Wheeler VC, Auerbach W, White JK, Srinidhi J, Auerbach A, Ryan A, Duyao MP, Vrbanac V, Weaver M, Gusella JF, et al. 1999. 
Length-dependent gametic CAG repeat instability in the Huntington's disease knock-in mouse. Hum Mol Genet 8: 115122. doi: $10.1093 / \mathrm{hmg} / 8.1 .115$

Woychik RP, Stewart TA, Davis LG, D'Eustachio P, Leder P. 1985. An inherited limb deformity created by insertional mutagenesis in a transgenic mouse. Nature 318: 36-40. doi:10 $.1038 / 318036 \mathrm{a} 0$

Wurst W, Rossant J, Prideaux V, Kownacka M, Joyner A, Hill DP, Guillemot F, Gasca S, Cado D, Auerbach A, et al. 1995. A large-scale gene-trap screen for insertional mutations in developmentally regulated genes in mice. Genetics 139: 889-899.

Würtele H, Little KC, Chartrand P. 2003. Illegitimate DNA integration in mammalian cells. Gene Ther 10: 1791-1799. doi:10 .1038/sj.gt.3302074

Yagi T, Ikawa Y, Yoshida K, Shigetani Y, Takeda N, Mabuchi I, Yamamoto T, Aizawa S. 1990. Homologous recombination at c-fyn locus of mouse embryonic stem cells with use of diphtheria toxin A-fragment gene in negative selection. Proc Natl Acad Sci 87: 9918-9922. doi:10.1073/pnas.87.24.9918

Yamagata Y, Kobayashi S, Umeda T, Inoue A, Sakagami H, Fukaya $M$, Watanabe $M$, Hatanaka $N$, Totsuka $M$, Yagi $T$, et al. 2009. Kinase-dead knock-in mouse reveals an essential role of kinase activity of $\mathrm{Ca} 2+/$ calmodulin-dependent protein kinase IIa in dendritic spine enlargement, long-term potentiation, and learning. Journal of Neuroscience 29: 7607-7618. doi:10.1523/JNEUROSCI.0707-09.2009

Yamauchi Y, Doe B, Ajduk A, Ward MA. 2007. Genomic DNA damage in mouse transgenesis. Biol Reprod 77: 803-812. doi:10.1095/biolreprod.107.063040

Yang H, Wang H, Shivalila CS, Cheng AW, Shi L, Jaenisch R. 2013. One-step generation of mice carrying reporter and conditional alleles by CRISPR/Cas-mediated genome engineering. Cell 154: 1370-1379. doi:10.1016/j.cell.2013.08.022

Yang L, Wang L, Huo Y, Chen X, Yin S, Hu Y, Zhang X, Zheng R, Geng H, Han H, et al. 2020. Amelioration of an inherited metabolic liver disease through creation of a de novo start codon by cytidine base editing. Mol Ther 28: P1673-P1683. doi:10 .1016/j.ymthe.2020.05.001

Yao X, Zhang M, Wang X, Ying W, Hu X, Dai P, Meng F, Shi L, Sun Y, Yao N, et al. 2018. Tild-CRISPR allows for efficient and precise gene knockin in mouse and human cells. Dev Cell 45: 526-536.e5. doi:10.1016/j.devcel.2018.04.021

Yates AD, Achuthan P, Akanni W, Allen J, Allen J, Alvarez-Jarreta J, Amode MR, Armean IM, Azov AG, Bennett R, et al. 2020. Ensembl 2020. Nucleic Acids Res 48: D682-D688. doi:10 $.1093 /$ nar/gkz966

Ye Z, Sun L, Li R, Han M, Zhuang Y, Wu X, Xu T. 2016. Generation of a mouse full-length balancer with versatile cassetteshuttling selection strategy. Int I Biol Sci 12: 911-916. doi:10.7150/ijbs. 15172

Yeh WH, Shubina-Oleinik O, Levy JM, Pan B, Newby GA, Wornow M, Burt R, Chen JC, Holt JR, Liu DR. 2020. In vivo base editing restores sensory transduction and transiently improves auditory function in a mouse model of recessive deafness. Sci Transl Med 12: eaay9101. doi:10.1126/scitranslmed .aay9101

Yen ST, Zhang M, Deng JM, Usman SJ, Smith CN, Parker-Thornburg J, Swinton PG, Martin JF, Behringer RR. 2014. Somatic mosaicism and allele complexity induced by CRISPR/Cas9 RNA injections in mouse zygotes. Dev Biol 393: 3-9. doi:10 .1016/j.ydbio.2014.06.017

Yuan J, Ma Y, Huang T, Chen Y, Peng Y, Li B, Li J, Zhang Y, Song B, Sun $X$, et al. 2018. Genetic modulation of RNA splicing with a CRISPR-guided cytidine deaminase. Mol Cell 72: 380-394.e7. doi:10.1016/j.molcel.2018.09.002

Zambrowicz BP, Imamoto A, Fiering S, Herzenberg LA, Kerr WG, Soriano P. 1997. Disruption of overlapping transcripts in the ROSA $\beta$ geo 26 gene trap strain leads to widespread expression of $\beta$-galactosidase in mouse embryos and hematopoietic cells. Proc Natl Acad Sci 94:3789-3794. doi:10.1073/pnas.94.8.3789

Zambrowicz BP, Friedrich GA, Buxton EC, Lilleberg SL, Person C, Sands AT. 1998. Disruption and sequence identification of 2,000 genes in mouse embryonic stem cells. Nature 392: 608-611. doi:10.1038/33423

Zeiher BG, Eichwald E, Zabner J, Smith JJ, Puga AP, McCray PB Jr, Capecchi MR, Welsh MJ, Thomas KR. 1995. A mouse model for the $\Delta$ F508 allele of cystic fibrosis. J Clin Invest 96: 2051 2064. doi:10.1172/JCI1 18253

Zetsche B, Gootenberg JS, Abudayyeh OO, Slaymaker IM, Makarova KS, Essletzbichler P, Volz SE, Joung J, van der Oost J, Regev A, et al. 2015. Cpf1 is a single RNA-guided endonuclease of a class 2 CRISPR-Cas system. Cell 163: 759-771. doi:10 $.1016 /$ j.cell.2015.09.038

Zhang L, Jia R, Palange NJ, Satheka AC, Togo J, An Y, Humphrey M, Ban L, Ji Y, Jin H, et al. 2015. Large genomic fragment deletions and insertions in mouse using CRISPR/Cas9. PLOS One 10: e0120396. doi:10.1371/journal.pone.0120396

Zhang X, Liang P, Ding C, Zhang Z, Zhou J, Xie X, Huang R, Sun Y, Sun H, Zhang J, et al. 2016. Efficient production of genemodified mice using Staphylococcus aureus Cas9. Sci Rep 6: 32565. doi:10.1038/srep32565

Zhang X, Chen L, Zhu B, Wang L, Chen C, Hong M, Huang Y, Li $\mathrm{H}, \mathrm{Han} \mathrm{H}, \mathrm{Cai} \mathrm{B}$, et al. 2020a. Increasing the efficiency and targeting range of cytidine base editors through fusion of a singlestranded DNA-binding protein domain. Nat Cell Biol 22: 740 750. doi:10.1038/s41556-020-0518-8

Zhang X, Zhu B, Chen L, Xie L, Yu W, Wang Y, Li L, Yin S, Yang L, $\mathrm{Hu} \mathrm{H}$, et al. 2020b. Dual base editor catalyzes both cytosine and adenine base conversions in human cells. Nat Biotechnol 38: 856-860. doi:10.1038/s41587-020-0527-y

Zhang Y, Li H, Min YL, Sanchez-Ortiz E, Huang J, Mireault AA, Shelton JM, Kim J, Mammen PPA, Bassel-Duby R, et al. 2020c. Enhanced CRISPR-Cas9 correction of Duchenne muscular dystrophy in mice by a self-complementary AAV delivery system. Sci $A d v$ 6: eaay6812. doi:10.1126/sciadv .aay6812

Zhao J, Sun W, Liang J, Jiang J, Wu Z. 2016. A one-step system for convenient and flexible assembly of transcription activatorlike effector nucleases (TALENs). Mol Cells 39: 687-691. doi:10.14348/molcells.2016.0140

Zheng B, Sage M, Cai WW, Thompson DM, Tavsanli BC, Cheah YC, Bradley A. 1999. Engineering a mouse balancer chromosome. Nat Genet 22: 375-378. doi:10.1038/11949

Zheng B, Sage M, Sheppeard EA, Jurecic V, Bradley A. 2000. Engineering mouse chromosomes with Cre-loxP: range, efficiency, and somatic applications. Mol Cell Biol 20: 648-655. doi:10 .1128/MCB.20.2.648-655.2000

Zheng Q, Cai X, Tan MH, Schaffert S, Arnold CP, Gong X, Chen CZ, Huang S. 2014. Precise gene deletion and replacement using the CRISPR/Cas9 system in human cells. BioTechniques 57: 115-124. doi:10.2144/000114196

Zimmer A, Gruss P. 1989. Production of chimaeric mice containing embryonic stem (ES) cells carrying a homoeobox Hox 1.1 allele mutated by homologous recombination. Nature 338: 150-153. doi:10.1038/338150a0

Zong H, Espinosa JS, Su HH, Muzumdar MD, Luo L. 2005. Mosaic analysis with double markers in mice. Cell 121: 479-492. doi:10.1016/j.cell.2005.02.012 
Clark et al.

Zuo E, Sun Y, Yuan T, He B, Zhou C, Ying W, Liu J, Wei W, Zeng $\mathrm{R}, \mathrm{Li} \mathrm{Y}$, et al. 2020. A rationally engineered cytosine base editor retains high on-target activity while reducing both DNA and RNA off-target effects. Nat Methods 17: 600-604. doi:10 .1038/s41592-020-0832-x
Zuris JA, Thompson DB, Shu Y, Guilinger JP, Bessen JL, Hu JH, Maeder ML, Joung JK, Chen ZY, Liu DR. 2015. Cationic lipid-mediated delivery of proteins enables efficient proteinbased genome editing in vitro and in vivo. Nat Biotechnol 33: 73-80. doi:10.1038/nbt.3081 


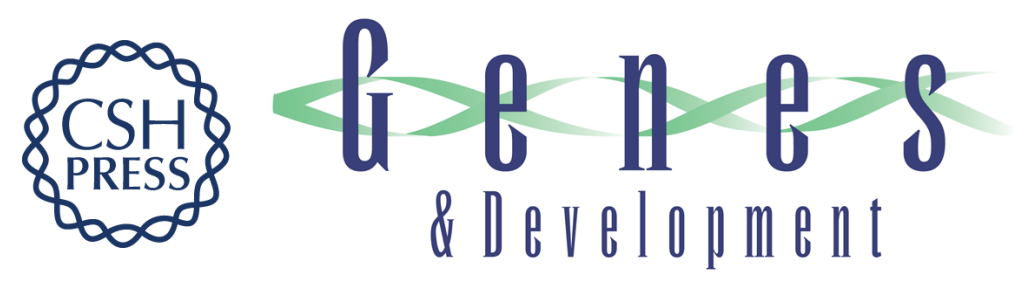

\section{A most formidable arsenal: genetic technologies for building a better mouse}

James F. Clark, Colin J. Dinsmore and Philippe Soriano

Genes Dev. 2020, 34:

Access the most recent version at doi:10.1101/gad.342089.120

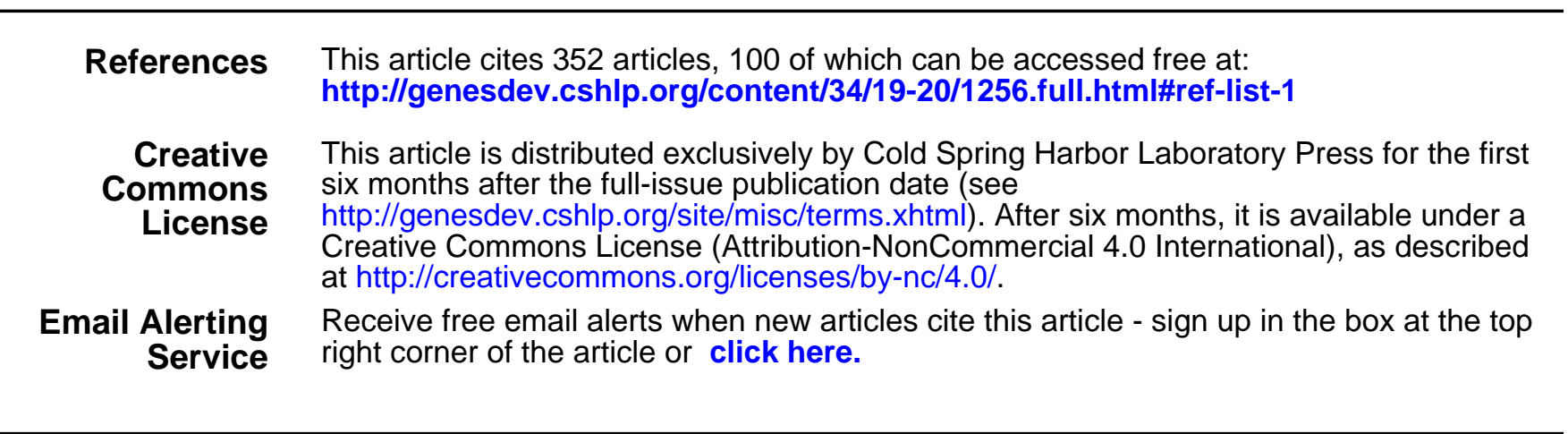

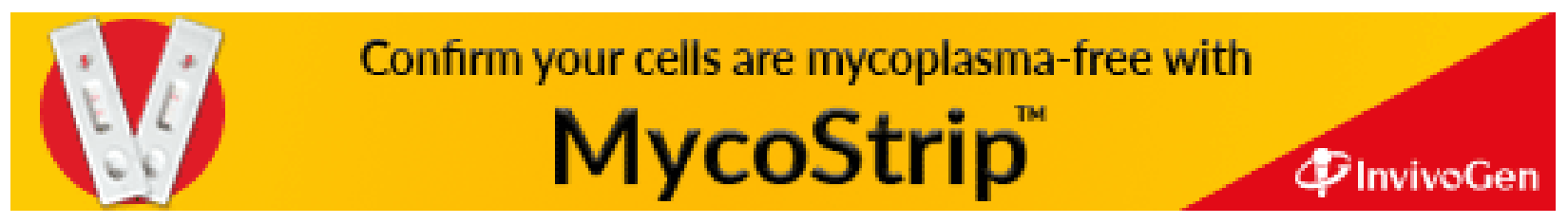

